\title{
WestVirginiaUniversity
}

THE RESEARCH REPOSITORY @ WVU

Graduate Theses, Dissertations, and Problem Reports

2021

\section{Three Essays on Energy and Agricultural Price Analysis}

Sara Farhangdoost
sf0041@mix.wvu.edu

Follow this and additional works at: https://researchrepository.wvu.edu/etd

Part of the Agricultural and Resource Economics Commons

\section{Recommended Citation}

Farhangdoost, Sara, "Three Essays on Energy and Agricultural Price Analysis" (2021). Graduate Theses, Dissertations, and Problem Reports. 10328.

https://researchrepository.wvu.edu/etd/10328

This Dissertation is protected by copyright and/or related rights. It has been brought to you by the The Research Repository @ WVU with permission from the rights-holder(s). You are free to use this Dissertation in any way that is permitted by the copyright and related rights legislation that applies to your use. For other uses you must obtain permission from the rights-holder(s) directly, unless additional rights are indicated by a Creative Commons license in the record and/ or on the work itself. This Dissertation has been accepted for inclusion in WVU Graduate Theses, Dissertations, and Problem Reports collection by an authorized administrator of The Research Repository @ WVU.

For more information, please contact researchrepository@mail.wvu.edu. 


\title{
Three Essays on Energy and Agricultural Price Analysis
}

\author{
Sara Farhangdoost \\ Dissertation submitted \\ to the Davis College of Agriculture, Natural Resources, and Design \\ at West Virginia University
}

In partial fulfillment of the requirements for the degree of

Doctor of Philosophy

in

Natural Resource Economics

Xiaoli Etienne, Ph.D., Chair

Alan Collins, Ph.D.

Ana Claudia Sant'Anna, Ph.D.

Alexander Kurov, Ph.D.

Division of Resource Economics and Management

Morgantown, West Virginia

2021

Keywords: Natural Gas, Price Forecast, Forecast Evaluation, Corn, Announcement Effect, EIA inventory report

Copyright 2021 Sara Farhangdoost 


\section{Abstract \\ Three Essays on Energy and Agricultural Price Analysis}

\section{Sara Farhangdoost}

This dissertation consists of three essays on energy and agricultural commodity price analysis: 1) Natural Gas Price Forecasting in a Changing World; 2) The Effect of EIA Storage Announcement on Natural Gas Returns: A Comprehensive Analysis; and 3) Forecasting the U.S. Season-Average Farm Price of Corn: Derivation of an Alternative Futures based Forecasting Model.

The first essay evaluates the performances of various individual and composite forecasting models when predicting natural gas prices in the United States. The empirical results show that forecast generated by the Energy Information Administration Short-Term Energy Outlook provides a more accurate price prediction at longer forecasting horizons (6- and 12-month ahead) while futuresbased forecasts perform better in the short-run (1- and 3-month ahead). Projections based on timeseries models perform well at longer forecast horizons when price volatility is relatively low. Further, the Hotelling model performs well for 1- and 3-month ahead forecast horizons. Our findings further support the additional benefit of composite forecasts based on individual methods for more accurate predictions; however, the performance is not uniform at different forecasting horizons.

The second essay examines how natural gas prices react to inventory surprises contained in Energy Information Administration's weekly inventory report. Results indicate that natural gas prices are more responsive to 1) negative (more-than-expected) surprise storage news as compared to positive (less-than-expected) surprises, 2) news released during the injection season as compared to the withdrawal season, and 3) inventory surprises occurring in periods of tight supply in withdrawal season compared to when the market has an abundant supply. Finally, we find that EIA's inventory report has exerted a smaller impact on natural gas prices over time. Possible contributing factors to this declining impact include the increasing availability of alternative information providers in the market, the relatively over-supply of natural gas during the period of analysis since the rise of unconventional production, and a more integrated regional market that can transport natural gas from production to consumption regions more efficiently.

The third essay investigates an alternative futures-based procedure to forecast the season-average farm price (SAFP) for U.S. corn, an under-researched price forecast. With the exceptionally volatile conditions experienced in the corn market since 2006, the need for price forecasting has become more critical. The new model developed in this essay performs better than two widely watched season-average price forecasts (World Agricultural Supply and Demand Estimates and the Hoffman futures-based forecasts) at the beginning of the post-harvest season, and just as well as those forecasts at the beginning of the forecast cycle and in the later post-harvest season. We attribute the performance of the proposed model's forecasts to its assignment of heterogeneous weights to both futures and cash prices depending on the underlying market conditions. Improved performance of the proposed model's forecasts is especially noticeable when the market is more volatile. 


\section{Acknowledgments}

I would like to express my thanks to all the people who helped and supported me while I was working on my Ph.D. at West Virginia University.

First of all, I would like to thank my Ph.D. advisor, Dr. Xiaoli Etienne, for her support, encouragement, and kindness during my Ph.D. study at WVU. Without her guidance and constant feedback, this Ph.D. would not have been achievable.

Additionally, I am thankful to my committee members Dr. Alan Collins, Dr. Alexander Kurov, and Dr. Ana Claudia Sant'Anna, for their time, efforts, encouragement, and valuable inputs on my dissertation.

My sincere thanks also go to the RRI team at WVU, especially Dr. Randall Jackson, Peter Jarosi, Gi-Eu Lee, Doris, and Caigan, for offering me a GA position in their group. I had the opportunity to work on many exciting projects while there. I also thank the funding support from the WVU Division of Resource Economics and Management, as well as the U.S. Department of Agricultural Economics Research Service, which has made my Ph.D. journey at WVU possible.

I acknowledge and thank my WVU friends: Ritika, Anica, Pinky, Alex, Douglas, Fahad, Kuan-Ming, and many more. There are many good memories that we have made together.

In addition, I would like to thank my parents, Hadi and Pouran, as well as my little sister, Negar. Because of you, I am who I am today, and I will be forever grateful for all of your love and support while I underwent the task of completing this degree.

Finally, I have no words to thank my husband, Navid, for all his support, love, encouragement, understanding, and intellectual inputs during this period. None of this would be possible without you! 


\section{Contents}

Acknowledgments ....................................................................................................................................................

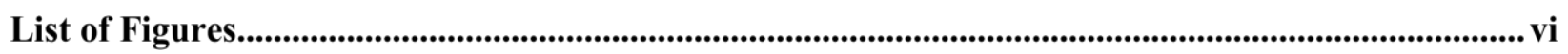

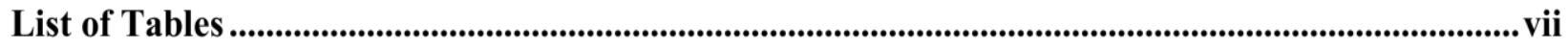

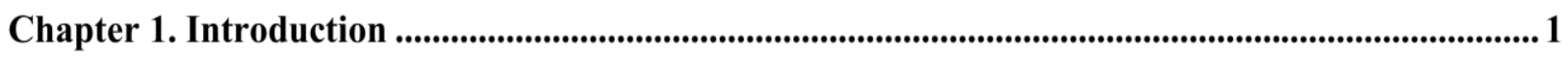

Chapter 2. Natural Gas Price Forecasting in a Changing World ..........................................................6

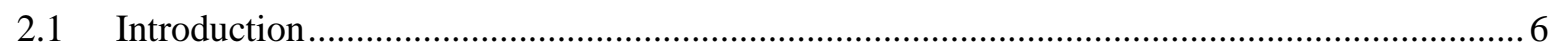

2.2 Forecasting Models and Forecast Evaluation Methods .................................................... 8

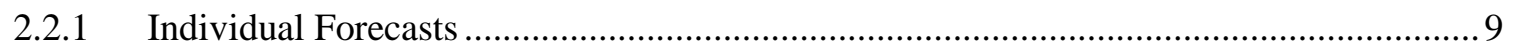

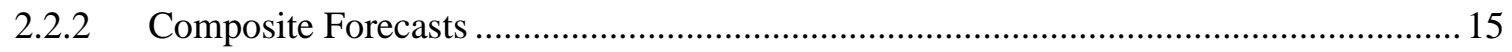

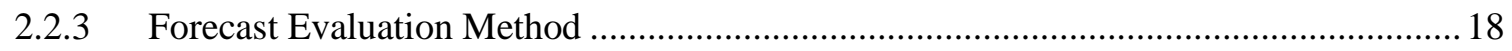

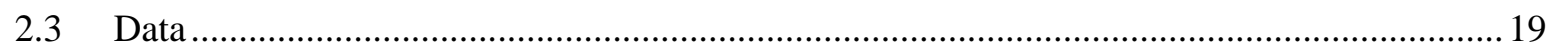

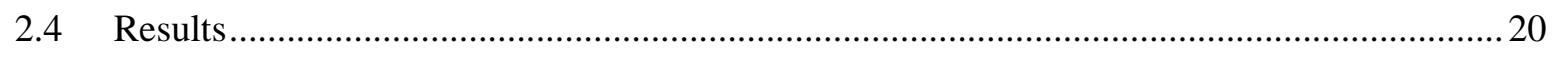

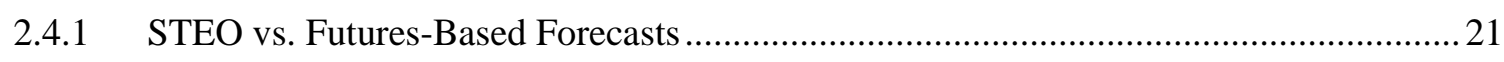

2.4.2 Performance of Other Individual Forecasts Relative to STEO and Futures Forecasts ...22

2.4.3 Can Composite Forecast Outperform Individual Forecasts? .......................................25

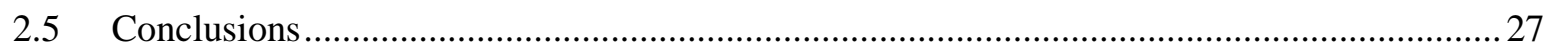

Chapter 3. The Effect of EIA Storage Announcement on Natural Gas Returns: A Comprehensive

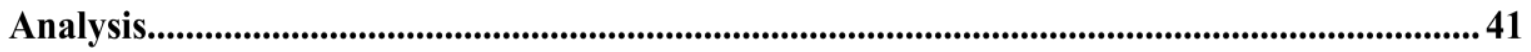

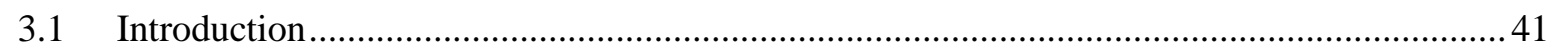

3.2 Literature Review and Hypotheses ........................................................................... 44

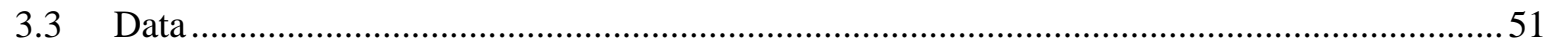

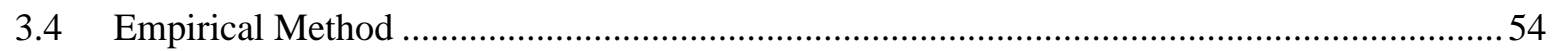

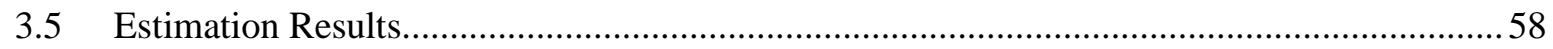

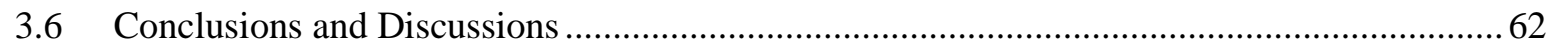

Chapter 4. Forecasting the U.S. Season-Average Farm Price of Corn: Derivation of an Alternative

Futures based Forecasting Model .......................................................................................................... 74 


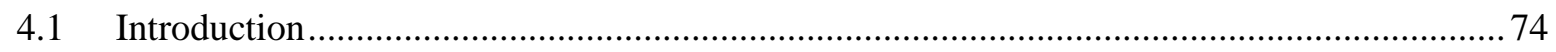

4.2 Season Average Price Forecasts and Proposed Forecasting Model ..................................... 77

4.3 WASDE Season-Average Price Forecasts For Corn....................................................... 78

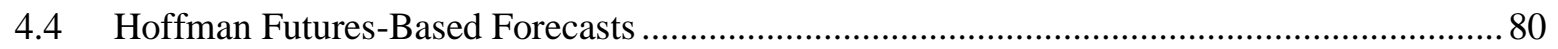

4.5 An Alternative Futures-Based Forecasting Model ........................................................... 81

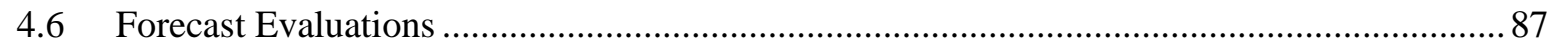

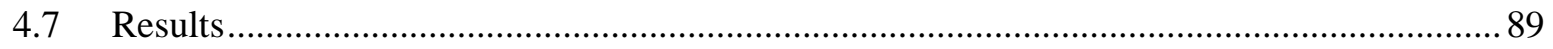

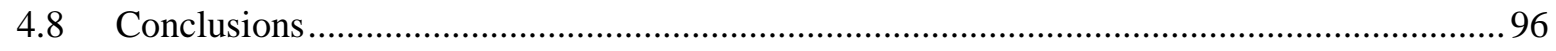

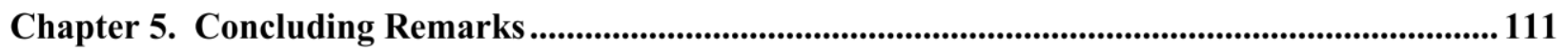

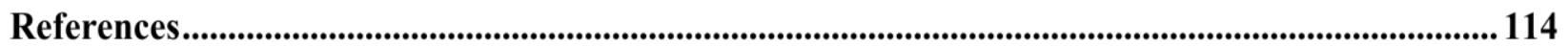




\section{List of Figures}

Figure 2-1. Monthly natural gas cash price at Henry Hub, Sep. 2005-Dec. 2020 ................................... 34

Figure 2-2. Futures-based, STEO projections, and no-change forecasts, Sep. 2005-Dec. 2020................. 35

Figure 2-3. Alternative individual forecasts, Sep. 2005-Dec. 2020 ...................................................... 36

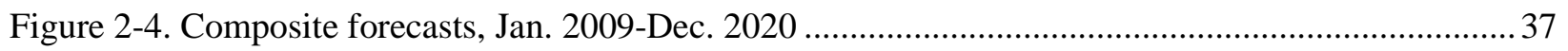

Figure 2-5. Differences in recursive MAPE between combination forecasts and STEO forecast.............. 38

Figure 2-6. Differences in recursive MAPE between combination forecasts and no-change forecast........ 39

Figure 3-1. Supply and demand shift during withdrawal and injection season ....................................... 68

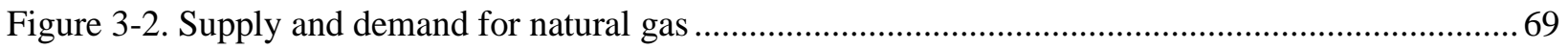

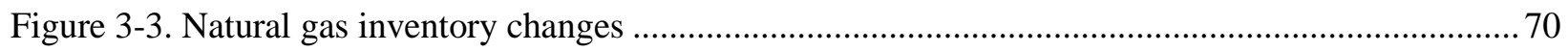

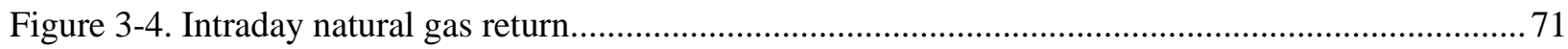

Figure 3-5. Time-varying parameters for withdrawal season ............................................................ 72

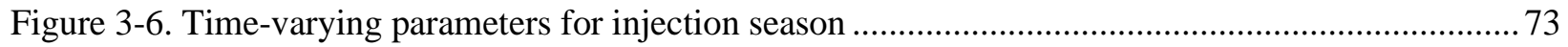

Figure 4-1. Forecasted prices (\$/bushel) in selected forecast months, 1990/91-2019/20 marketing years

Figure 4-2. Differences in MAEs (\$/bushel) and MAPEs (\%) between futures-based/new forecasts and

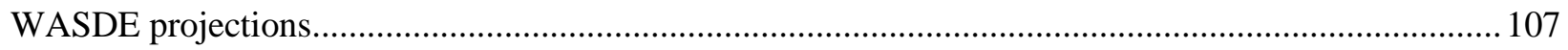

Figure 4-3. P-values of MDM test throughout the forecast cycle (red line represents $10 \%$ significance level) 108

Figure 4-4. P-values of encompassing test throughout the forecast cycle (red line represents $10 \%$ significance level).

Figure 4-5. Regression coefficients for nearby futures prices and previous period cash prices in equation (4-1) based on 15-year rolling window analysis 110 


\section{List of Tables}

Table 2-1. Mean Absolute Prediction Error (MAPE) for each individual forecasting model .29

Table 2-2. Differences in MAPE between alternative, STEO, and no-change forecasts, Sep. 2005 to Dec. 2020 (full sample)

Table 2-3. Differences in MAPE between alternative, STEO, and no-change forecasts, Sep. 2005-Dec. 2008

(high volatility)

Table 2-4. Differences in MAPE between alternative, STEO, and no-change forecasts, Jan. 2009-Dec. 2020

(low volatility) 32

Table 2-5. Performances of composite forecasts, Jan 2009-Dec 2020 .33

Table 2-6. Changes in MAPE of "Leave-One-Out" forecast combinations relative to original combination 40

Table 3-1 Summary statistics of inventory surprise and futures return .64

Table 3-2. Impacts of EIA inventory reports on natural gas return using OLS model ... 65

Table 3-3. Impacts of EIA inventory reports on natural gas volatility using threshold model 66

Table 3-4. Time-varying impact of EIA inventory reports on natural gas futures market (dependent variable: Returns)

Table 4-1. Forecasting cycle for corn season-average farm price, including marketing year and crop season

Table 4-2. Examples of price forecasts (\$/bushel) using the proposed procedure for marketing year 2010/11 100

Table 4-3. Data used in the analysis and sources of data 101

Table 4-4. Mean absolute error (MAE) for each forecasting method in \$/bushel, 1990/91-2019/20 marketing years (full sample)

Table 4-5. Mean absolute error (MAE) for each forecasting method in \$/bushel, 1990/91-2004/05 marketing years 103

Table 4-6. Mean absolute error (MAE) for each forecasting method in \$/bushel, 2005/06-2019/20 marketing years 104

Table 4-7. Effect of price volatility on the relative performance of the proposed forecast against WASDE price projections. 105 


\section{Chapter 1. Introduction}

Accurate price forecasting and understanding the factors that contribute to price volatility are some of the most challenging and important tasks of economists. Although many efforts have been made to model commodity prices over the past several decades, economists have yet to reach a consensus on the best practices to follow when generating price forecasts. This dissertation presents three essays analyzing energy and agricultural commodity prices. The first two essays evaluate various price forecasting models and analyze price volatility in the natural gas market in the United States (U.S.). The last essay develops a new model to forecast the U.S. season-average farm price of corn.

In the energy sector, natural gas (after oil) is the second most actively traded energy commodity globally. Over the past two decades, natural gas consumption and production have skyrocketed due to the widespread exploitation of shale gas and improvements in global transportation infrastructure. In 2020, natural gas production in the U.S. reached 40 million cubic feet, a 40\% increase compared to the amount produced in 2000 (EIA, 2020). On the usage side, natural gas accounted for $34 \%$ of the U.S. primary energy consumption in 2020 , second to the $35 \%$ share of petroleum products (EIA, 2020). The importance of the natural gas market is further elevated as more and more institutional investors flourish into natural gas derivatives trading (Trolle and Schwartz, 2010).

Given the tremendous changes to the natural gas market during the past two decades, natural gas prices have experienced high volatility. Before 2005, natural gas prices were relatively stable, rising gradually with occasional spikes due to external events such as hurricanes and colderthan-expected winters. In October 2005, natural gas prices at Henry Hub broke above \$13/MMBtu following Hurricane Katrina. However, natural gas prices suffered a rapid decline in subsequent 
months, settling between $\$ 5$ and \$9/MMBtu between late 2006 and early 2008. In mid-2008-2009, natural gas prices experienced another round of boom-and-bust cycles, with prices approaching $\$ 13 /$ MMBtu in summer 2008 but dropped rapidly to below $\$ 3 /$ MMBtu by 2009. Since 2010, natural gas prices have mostly fluctuated between $\$ 1.5$ and $\$ 6 / \mathrm{MMBtu}$, although the volatility remains high (EIA, 2020). These price fluctuations significantly increase the business and management risks of natural gas market participants, highlighting the importance of accurate price predictions, as well as understanding the drivers of price volatility. Knowledge of this information can help firms and investors establish more informed trading and investment strategies and provide essential information to policymakers to design more effective energy policies conducive to longterm economic growth.

Chapter 2 of this dissertation evaluates the performances of various individual and composite forecasting models when predicting Henry Hub natural gas prices in the U.S. Specifically, we compare the forecast performance of Short-Term Energy Outlook released by the Energy Information Administration (EIA) and futures-based forecasts, as well as several alternative individual forecasting models and three composite forecasts, from September 2005December 2020. The results indicate that the forecast generated by the Energy Information Administration Short-Term Energy Outlook provides a more accurate price prediction at longer forecasting horizons while futures-based forecasts perform better in the short run. Projections based on time-series models perform well at longer forecast horizons when price volatility is relatively low. Further, the Hotelling model performs well for 1- and 3-month ahead forecast horizons. Findings further support the additional benefit of composite forecasts based on individual methods for more accurate predictions; however, the performance is not uniform at different forecasting horizons. 
According to the theory of storage (Working, 1927), changes in the inventory level of storable commodities significantly affect commodity price movements. Chapter 3 comprehensively examines how natural gas prices react to inventory surprises contained in EIA's weekly inventory report. To this end, four hypotheses based upon previous literature and theoretical frameworks are proposed and tested. The first hypothesis focuses on the difference between the price responses to positive surprises (less-than-expected inventory level) and negative surprises (more-than-expected inventory level). The second hypothesis concerns whether the impact of inventory surprises varies during injection versus withdrawal seasons. In the third hypothesis, we explore whether the effect of inventory surprises differs depending on the underlying market condition. Finally, the fourth hypothesis focuses on natural gas price reaction to the EIA's inventory report over the years. Results indicate that larger impacts on natural gas prices occur for: a negative surprise (more-than-expected) compared to a positive surprise (lessthan-expected), surprises occurred during the injection season rather than the withdrawal season, and inventory news in periods of tight supply compared to abundant storage in withdrawal season. Finally, we find that EIA's inventory report has exerted a smaller impact on natural gas prices over time. Possible contributing factors to this declining impact include the increasing availability of alternative information providers in the market, the relatively over-supply of natural gas since the rise of unconventional production, and a more integrated regional market that can transport natural gas from production to consumption regions more efficiently.

The last essay of the dissertation shifts away from natural gas markets and examines corn prices in the United States. Corn is the most widely produced feed grain in the U.S., accounting for over 95 percent of total production and use (ERS, 2018). Corn is used as an input for ethanol production, animal feed, industrial use, and many related industries. U.S. corn prices have 
experienced high volatility since 2006 . These large price swings have generated much concern about market participants' ability to manage adverse price movements, as the risk associated with grain merchandising and the cost of hedging at commodity futures exchanges has dramatically increased (McPhail et al., 2012).

Chapter 4 explores an alternative model to forecast the season-average farm price (SAFP) for U.S. corn producers, a relatively under-researched price forecast that plays a crucial role in many crop programs in the U.S. We propose a forecasting model for the SAFP of corn that weights the monthly cash price forecasts generated through nearby futures and previous-period cash prices, using monthly marketing weights for a given marketing year. This proposed forecasting model is compared to two widely watched season-average price forecasts: the WASDE (World Agricultural Supply and Demand Estimates) and the Hoffman futures-based forecasts. Results show that this new model performs better than the two alternative forecasts at the beginning of the post-harvest season, and just as well as those forecasts at the beginning of the forecast cycle and in the later months of the post-harvest season. We attribute the performance of this model's forecasts to its assignment of heterogeneous weights to futures and cash prices depending on the underlying market conditions. Improved performance of this model's forecasts is especially noticeable when the market is more volatile. Overall, this model complements and provides incremental information to the existing SAFP forecasts for corn.

A revised version of the Chapter 2 essay co-authored with Dr. Xiaoli Etienne was submitted to Energy Economics and is currently under review. The Chapter 3 essay with co-authors Dr. Xiaoli Etienne and Dr. Alexander Kurov is being prepared for journal submission. Finally, a revised version of the Chapter 4 essay with co-authors Dr. Xiaoli Etienne, Dr. Linwood Hoffman 
(USDA-ERS), and Dr. Brian Adam (USDA-ERS) was submitted to Journal of Commodity Markets and is currently in preparation for a second-round review. 


\section{Chapter 2. \\ Natural Gas Price Forecasting in a Changing World}

\subsection{Introduction}

In a capital-intensive industry such as natural gas exploration and production, there is an acute need for accurate and up-to-date price predictive capability. Strategic business decisions regarding expansion or contraction of operations and commitment to geographic areas rely primarily on their expected profitability, an indicator that heavily depends on predicted prices in the future. The ability to accurately forecast future natural gas prices enables operators to make long- and short-term decisions that have implications for industry partnerships, investment in new technologies, and expansion into new production and consumption areas. Inaccurate price predictions may also lead to disastrous losses for investors in the financial sector. Amaranth Hedge Fund, for instance, suffered a $\$ 9,668$ billion loss in September 2006 as a result of natural gas prices moving in the opposite direction than forecasted (Rogel-Salazar and Sapsford, 2014).

Price forecasting is also essential for policymakers as many policy decisions, such as regulatory actions on technologies (i.e., appliance efficiency standards), use of public lands (i.e., mineral exploration), foreign policy, state tax revenue, and environmental management, may all be influenced by changing expectations about future natural gas prices (Wong-Parodi et al., 2006). For instance, many natural gas-producing states (e.g., West Virginia and Texas) impose severance taxes on the oil and gas industry based on the gross value of energy, with prices being a key input in the calculation. An accurate price forecast is thus needed for state budget planning.

Currently, market participants obtain natural gas price forecasts primarily from two sources: the Short-Term Energy Outlook (STEO) forecasts released by the U.S. Energy Information Administration (EIA) and the prices of natural gas futures contracts traded at the New 
York Mercantile Exchange (NYMEX). Wong-Parodi et al. (2006) examine the predictive capability of STEO and futures-based forecasts between 1998 and 2004. They show that, on average, the futures-based forecast performed slightly better than the STEO prediction-the futures-based forecast had an average forecast error of $-\$ 0.52 / \mathrm{Mcf}$, while the STEO had an average forecast error of $-\$ 0.83 / \mathrm{Mcf}$. However, the sample period examined in the study predates the shale boom. Over the past two decades, the widespread exploitation of shale gas through the combined use of horizontal drilling and hydraulic fracturing has dramatically increased natural gas production and lowered prices throughout the US. Nevertheless, figure (2-1) shows that natural gas price volatility remained high after the period examined in Wang-Parodi et al. (2006), in particular between 2005 and 2009. Although natural gas prices have settled at a relatively low level in recent years, the magnitude of price fluctuations is still substantial, with the coefficient of variation (standard deviation over mean) reaching 26.6\% between 2012 and 2020.

Given the tremendous changes to the natural gas market and the increasing importance of natural gas in the U.S. energy mix, there is a clear need to re-assess the performance of these two forecasts and explore alternative procedures that may offer more accurate forecasts. The purpose of this paper is thus to determine the performances of various price forecasting models for US natural gas. Specifically, we aim to a) evaluate how well the STEO and NYMEX futures-based forecasts are able to predict natural gas spot prices; $b$ ) assess the performance of several alternative forecasting models against the STEO and futures-based forecasts; c) explore whether composite forecasts based on individual models can outperform the existing forecasts. The sample period examined runs from September 2005 to December 2020, when the monthly STEO forecasts are available. Since natural gas prices had experienced more volatility from 2005 to 2009, we also compare the performances of forecasting models during two sub-periods: September 2005 to 
December 2008 and January 2009 to December 2020. Following Alquist and Kilian (2010) and Baumeister and Kilian (2015), the no-change forecast based on the previous period price is used as the benchmark for forecast comparisons.

Overall, we find that the STEO forecast performs well at longer forecasting horizons (6and 12-month ahead forecasts) while futures-based forecasts give a more accurate prediction in the near term (1- and 3-month ahead forecasts). Compared with alternative forecasting models, although futures-based and STEO forecasts have lower forecasting errors than time-series models, the latter provides more accurate predictions at longer forecasting horizons when natural gas prices experience relatively low volatility. The Hotelling model forecasts, constructed based on current period spot prices and interest rates, outperform many forecasting models at various forecast horizons. Further, we find composite forecasting models constructed based on individual forecasts help improve natural gas price forecasting, in particular when compared to STEO forecasts.

The remainder of the paper proceeds as follows. In the next session, we discuss the individual and composite forecasting models considered in this paper. Sections three and four discuss the data and results, respectively. The last section concludes the paper.

\subsection{Forecasting Models and Forecast Evaluation Methods}

In this section, we briefly review the STEO and futures-based forecasts, as well as several alternative individual forecasting models and three composite forecasts used in this study. We focus on 1-, 3-, 6-, and 12-month ahead forecasts, which are the months-ahead forecasts included in STEO. Forecasting models are evaluated for spot prices at Henry Hub in Louisiana, the official delivery location for NYMEX natural gas futures contracts and the nation's largest natural gas spot market. We also discuss metrics to assess the accuracy of various forecasting methods. 


\subsubsection{Individual Forecasts}

We consider six types of individual forecasts: the STEO report, NYMEX futures-based forecasts, the no-change forecast, the Hotelling model forecast, forecasts based on autoregressive moving average (ARMA) models, and vector autoregression (VAR) forecasts. The latter two forecasts are generated using both rolling and recursive analysis.

\subsubsection{STEO Forecast}

Each month, typically on the first Tuesday following the first Thursday of the month, the EIA publishes the STEO, which contains 1 to 24 -month ahead natural gas price forecasts. The release time is usually between $12: 00 \mathrm{pm}$ and 12:15 pm eastern time. Generally, the EIA uses what might be called a "mixed" modeling procedure — combining structural econometric equations and time-series methods - to generate initial quantity and price forecasts within a system framework (Gamson, 2008). The estimated prices are then used as guidance to construct the STEO forecasts in a process mainly determined by analyst judgment (EIA, 2018). Baumeister and Kilian (2015) note that the STEO forecasts are hard to replicate and justify due to their largely judgmental nature. However, the forecasts remain highly anticipated by numerous business sectors that are sensitive to energy price changes and are used for other macroeconomic projections (Sanders et al., 2009). For instance, price forecasts in the EIA annual energy outlook (AEO), the primary source of projections used in federal energy policymaking since the early, are calibrated on the STEO report (Wong-Parodi et al., 2006).

Given the importance of the STEO report, it is somewhat surprising that the academic literature so far has paid little attention to the performance of this vital source of price forecasts for natural gas. Wong-Parodi et al. (2006) note that in 1998-2004 the futures-based forecast 
performed slightly better than the STEO prediction. Sanders et al. (2009) find that although STEO forecasts were biased at certain horizons in 1997-2007, they provided unique information in addition to those included in the no-change forecasts.

\subsubsection{Futures-Based Price Forecasts}

The prices of futures contracts reflect investors' expectations regarding the value of the specific commodity on a future date and have been used as a primary source of price forecasts by many practitioners. A large amount of literature has evaluated the performance of futures-based forecasts. There are two competing views about the forecast performance of futures prices. Several papers find that futures are unbiased and accurate predictors of future spot prices. For example, Chinn et al. (2005) indicate that futures prices are unbiased predictors of crude oil, gasoline, and heating oil prices, but not of natural gas prices at the 3-month horizon. Reeve and Vigfusson (2011) analyze the empirical forecasting performance of futures prices for energy, metals, and agricultural commodities and suggest that futures prices have generally outperformed a random walk forecast and can be used as a reasonable guide for forecasting commodity prices. Chinn and Coibion (2014) investigate the predictive content of futures prices for different markets, finding futures prices forecasts for energy commodities perform substantially better than for precious metals.

On the other hand, various studies report that futures prices are biased forecasts of future spot prices. Several theories are offered to explain such mispricing. The risk premium hypothesis

pioneered by Keynes (1930) notes that hedgers are willing to pay a premium to speculators for taking on price risks, so that futures prices reflect the expected future spot price plus a risk premium. The behavioral finance literature (e.g., (Barberis and Thaler, 2003) argues that mispricing can occur due to traders' psychology and irrational trading, such as herding, 
overreaction, overconfidence, etc. Herbert (1993) finds natural gas futures forecasts to be often higher than realized spot prices, which they attributed to the significant price risk in this market. Similarly, Modjtahedi and Movassagh (2005) show natural gas futures contracts to be biased predictors of the future spot prices for contracts ranging from 3 to 12 months. Wei and Zhu (2006) find that futures contracts are biased predictors of future spot prices due to the existence of a timevarying risk premium.

Denote $F_{t}^{t+h}$ the close price for natural gas futures contract with a delivery month $t+h$ at month $t$, the futures price forecast can be written as:

$$
\hat{P}_{t+h \mid t}=F_{t}^{t+h}, \quad h=1,3,6,12
$$

where $h$ is the 1-, 3, 6, and 12-month ahead forecast horizon and $\hat{P}_{t+h \mid t}$ is the forecast price for $t+h$ made at $t$. To ensure that the futures-based forecast does not contain information from the STEO report, we compute $F_{t}^{t+h}$ as the average settlement price for a given contract from the first trading day of the month to the day before the STEO release. For robustness, we also compute the second futures-based forecast, with $F_{t}^{t+h}$ being the futures price at closing on the day prior to the STEO release.

An alternative way to forecast the spot price is to use the spread between futures and cash prices. If the futures price is the expected spot price in a future period, then the futures and cash price spread should be indicative of the expected change in cash prices. Define the price spread as $\ln \left(F_{t}^{t+h} / P_{t}\right)$, following previous studies (e.g., Gramlich, 2004; Alquist and Kilian, 2010; McCallum and $\mathrm{Wu}, 2005)$, the price forecast can be written as:

$$
\hat{P}_{t+h \mid t}=P_{t}\left(1+\ln \left(\frac{F_{t}^{t+h}}{P_{t}}\right)\right) \quad h=1,3,6,12
$$




\subsubsection{Hotelling's Model}

Hotelling (1931) argues that the net price of non-renewable natural resources will increase by the interest rate when the resource is optimally extracted. In other words, the opportunity cost of storing non-renewable resources is the foregone interest. The forecast generated based on the Hotelling model can be written as:

$$
\hat{P}_{t+h \mid t}=P_{t}\left(1+r_{t, h}\right) \quad h=1,3,6,12
$$

where $r_{t, h}$ is the interest rate at the relevant maturity h. Previous research often finds the Hotelling model to outperform many alternative forecasting models, in particular for short-term forecasts. For instance, McCallum and $\mathrm{Wu}$ (2005) show that the Hotelling forecasts are the second-best performer (after the futures-spot spread model) when forecasting oil prices in 1985-2005. Alquist and Kilian (2010) note that the Hotelling forecasts for oil prices are systematically less biased than no-change forecasts at all forecast horizons. Lin and Wagner (2007) and Atewamba and Nkuiya (2017) find prices generated by the extended Hotelling model, which include technological progress and storage effects, to closely mimic the actual behavior of most of the mineral resources.

\subsubsection{Univariate Time-Series Forecasting Model (ARMA Model)}

The Autoregressive and Moving average (ARMA) model is one of the classical time series methods commonly used in price forecasting. Forecasts based on ARMA models can be written as:

$$
\hat{P}_{t+h \mid t}=\alpha_{0}+\sum_{i=i}^{b}\left(\alpha_{i} P_{t-i}\right)-\sum_{i=1}^{q}\left(\theta_{i} \varepsilon_{t-i}\right)+\varepsilon_{t}
$$

where $\varepsilon_{t}$ is the error term, $\sum_{\mathrm{i}=0}^{\mathrm{b}} \alpha_{\mathrm{i}} P_{t-\mathrm{i}}$ is the AR term (lagged value of $\left.P_{t}\right), \sum_{\mathrm{i}=1}^{\mathrm{q}}\left(\theta_{t-\mathrm{i}} \varepsilon_{t-\mathrm{i}}\right)$ is the MA term (lagged errors), and $\alpha_{\mathrm{i}}$ and $\theta_{\mathrm{i}}$ are the coefficients to be estimated. 
Several recent studies have applied the ARMA method to forecast energy prices. Fernandez (2006) finds that ARMA tends to outperform artificial neural networks (ANN) and support vector machines (SVM) models for oil and natural gas forecasts made in the near term. Erdogdu (2010) uses ARMA models to obtain short- and long-run estimates of price and income elasticities, as well as forecasts of natural gas demand in Turkey. Jin and Kim (2015) use combination wavelet decomposition with ARMA and other models to predict natural gas prices and show that including ARMA models in composite forecasts improves forecasting performance.

\subsubsection{Multivariate Time-Series Forecasting Model (VAR Model)}

Models described above are based on past natural gas or futures contract prices, without considering demand or supply shifters that could affect the equilibrium market price. We next consider a reduced-form vector autoregression (VAR) model that allows for the dynamic linkages between prices and supply/demand variables. In constructing the VAR model, we focus on the demand and supply variables identified in the previous studies (Hulshof et al., 2016; Huang and Etienne, 2021; Nick and Thoenes, 2014; and Wiggins and Etienne, 2017). Equation (2-5) shows a VAR model with p lags:

$$
y_{t}=B_{1, t} y_{t-1}+\cdots+B_{p, t} y_{t-p}+u_{t},
$$

where $y_{t}$ is a vector of endogenous variables including the U.S. natural gas marketed production, aggregate real economics activities, the U.S. natural gas inventory, and the price of natural gas, $B_{1, t}, \ldots, B_{p, t}$ are the coefficients on the lags of the endogenous variables, and $u_{t}$ is a vector of error terms. We also include monthly dummies in the VAR model to capture the seasonal-demand pattern due to weather-related events. Based on the estimated coefficients, we further generate natural gas price predictions at various forecasting horizons. 
Various studies have used VAR models to forecast commodity prices. Baumeister and Kilian (2012 find that recursive VAR forecasts based on global oil market variables have lower prediction errors and higher directional accuracy than various competing models at certain horizons. On the other hand, Mirmirani and Li (2004) compare VAR models with neural networks in forecasting oil prices, finding the latter to outperform the VAR model.

\subsubsection{No-change Forecast}

The efficient market hypothesis states that asset prices change randomly, and it would be difficult to predict these price changes (Fama, 1965). In other words, asset prices in a wellfunctioning financial market behave very much like a random walk. Although much theoretical and empirical work has challenged the efficient market hypothesis (e.g., Shiller, 2015; and Malkiel, 2003), a consensus in the literature is that commodity market is likely to be efficient (e.g., Schwert, 2003; and Ball, 2009), at least in its weak form where all past information is reflected in prices and current prices are the best approximation of future prices. Following Alquist and Kilian (2010), we denote the no-change forecast as:

$$
\hat{P}_{t+h \mid t}=P_{t} \quad h=1,3,6,12
$$

The forecast is essentially based on a random-walk model without intercept. Due to its simplicity, the no-change forecast is often considered a good benchmark for comparing the performances of various forecasting models. Alquist and Kilian (2010) find that the no-change forecast possesses higher accuracy than those based on econometric or survey models when predicting oil prices. They attribute the superior performance of the no-change forecast to the complex mechanism of how some important factors (e.g., macroeconomic fundamentals) affect the market and the inability of econometric procedures to accurately reflect these relationships. 


\subsubsection{Composite Forecasts}

In practice, it is hard to find an individual forecasting model that consistently demonstrates superior performances at all horizons and under all circumstances (Baumeister and Kilian, 2015; Baumeister et al., 2014; and Bernard et al., 2018). Existing evidence shows that composite forecasts, using various models and weights, may improve the forecast accuracy as compared to when using only a single forecast as long as the errors from candidate models are not perfectly correlated (Bates and Granger, 1969; Granger, 1989; Newbold and Harvey, 2002; Baumeister and Kilian, 2015; Nowotarski et al., 2014; and Clements and Doolan, 2020). The question of forecast combination then boils down to finding the optimal weight for each individual forecast that would generate the lowest composite forecast error.

Several existing papers explored the use of composite forecasts in the energy market. Baumeister and Kilian (2015) show that combining forecasts from VAR and futures-based models, as well as from models based on product spreads, derive more accurate forecasts than no-change forecasts in the oil market. Bernard et al. (2018) show that composite forecasts perform well at the 7- and 10-year forecasting horizons in the oil market. Nowotarski et al. (2014) indicate that the equal-weighted composite forecasts perform well for day-ahead electricity prices. Wang et al. (2020) find that composite forecasting models present higher prediction accuracy when compared with individual models. Despite the increasing literature on the benefits of using composite forecasts, to our best knowledge, except for Wang et al. (2020), no other studies have examined the performances of composite forecasts in the natural gas market. In the following section, we briefly discuss the four composite forecasting methods used in the present study. 


\subsubsection{Simple Average (SA) Forecast Combination (Equal Weights)}

The simple average model, which assigns equal weight to each individual forecast to generate the composite forecast, has established itself as an excellent forecasting model due to its simplicity and satisfactory performance. Previous studies (Clemen, 1989; Stock and Watson, 2004; Colino et al., 2008; Genre et al., 2013; Smith and Wallis, 2009) show that using the simple average of all individual forecasts performs well relative to other approaches that rely on estimated weights. Smith and Wallis (2009) and Claeskens et al. (2016) argue that if the weight for each individual forecast is random (as in the estimated forecast combination case) rather than fixed (as in the simple average forecast), then the composite forecast will be biased, with the variance greater than that in the fixed-weight case. Specifically, the simple average forecast can be written as:

$$
\hat{P}_{t+h \mid t}^{c}=1 / N \sum_{i=1}^{N} \hat{P}_{t+h \mid t}^{i}, h=1,3,6,12
$$

where $\hat{P}_{t+h}^{i}$ is the forecast generated by individual model $i$ at time $t$ for $h$-period ahead price, and $\hat{P}_{t+h}^{c}$ is the corresponding composite forecast at time $t$ using $N$ individual models.

\subsubsection{Inverse Mean Squared Prediction Error (IMSPE) Forecast Combination:}

Bates and Granger (1969) propose using the historical inverse mean squared prediction error (IMSPE) of each individual forecast as the weight to construct composite forecasts. In other words, the individual forecast with a smaller MSPE at $t$ receives a higher weight in the composite forecast. The IMSPE-forecasts are built upon the portfolio diversification theory that combines various assets to reduce the overall risk of an investment portfolio, while lowering the volatility by holding non-correlated assets (Weiss et al., 2018).

Specifically, the IMSPE composite forecast is computed as: 


$$
\hat{P}_{t+h \mid t}^{c}=\sum_{i=1}^{N} \omega_{i t} \hat{P}_{t+h \mid t}^{i}, \quad \omega_{i t}=\frac{m_{i t}^{-1}}{\sum_{i=1}^{N} m_{i t}^{-1}}, \sum_{i=1}^{N} \omega_{i t}=1
$$

where $m_{i t}^{-1}$ denotes the MSPE of model $i$ at time $t$ computed recursively using historical data. Manescu and Van Robays (2014), Baumeister and Kilian (2015), and Bernard et al. (2018) use the recursive IMSPE model to generate weights for individual models, noting that the recursive approach allows the resulting composite forecast to adjust composite ratios based on the recent performance of each model.

\subsubsection{Ordinary Least Squares (OLS) regression Forecast Combination:}

The Ordinary Least Squares averaging method was first introduced by Crane and Crotty (1967), and subsequently driven to the forefront by Granger and Ramanathan (1984). The weights in this model $\left(\omega_{i}\right)$ are estimated using a regression model, where the actual price $\left(P_{t+h}\right)$ is regressed against each individual forecast using the historical data, as in equation (2-9):

$$
P_{t+h}=\beta+\sum_{i=1}^{N} \omega_{i} \hat{P}_{t+h \mid t}^{i}
$$

where $\beta$ is the constant term. As noted by Nowotarski et al. (2014), the OLS-based composite forecast has the advantage of generating unbiased forecasts due to the inclusion of intercept in the regression, even if one of the individual forecasts is biased. Poncela et al. (2011) find that the OLSbased composite forecasts present similar or better performance than the equal-weight composite forecast. However, a disadvantage of equation (2-9) is that it may lead to negative weights, or the weights may not add up to one, which complicates the interpretation (Weiss et al., 2018). Nowotarski et al. (2014) and Mirakyan et al. (2017) provide empirical evidence that some other popular forecast averaging methods, such as the simple averaging and constrained least squares regression (CLS), sometimes perform better than OLS-based forecasts. 


\subsubsection{Constrained Least Squares (CLS) Regression Forecast Combination:}

As discussed earlier, composite forecasts based on the unconstrained OLS regressions may be difficult to interpret. To address this issue, we follow Gunter and Aksu (1989) and restrict the estimated weights to be positive and also sum up to one in the OLS regression:

$$
P_{t+h}=\beta+\sum_{i=1}^{N} \omega_{i} \hat{P}_{t+h \mid t}^{i} \quad \omega_{i} \geq 0 \quad \forall_{i} \quad \text { and } \quad \sum_{i=1}^{6} \omega_{i}=1
$$

The estimated coefficients can be viewed as the relative importance of each forecast compared to all other candidate models. Mirakyan et al. (2017) and Yang and Dong (2018) find that CLS performs better than SA and OLS in predicting the next-day electricity prices. They attribute the superior performance of the CLS model to its ability to generate convex weights by adding two constraints, especially when forecasts generated by individual models are correlated.

\subsubsection{Forecast Evaluation Method}

We use mean absolute prediction errors (MAPEs) to compare the performance of each forecasting model, as in equation (2-11):

$$
M A P E=\frac{1}{N} \sum_{i-1}^{N}\left|P_{t+h}-\hat{P}_{t+h \mid t}\right|
$$

where $P_{t+h}$ and $\hat{P}_{t+h \mid t}$ are the actual and forecasted prices for month $t+h$, respectively. The smaller the magnitude of the forecast error, the lower the MAPE, and hence the better the forecast. Compared to the mean prediction error, the MAPE avoids the cancellation of positive and negative prediction errors when evaluating the performances of each model.

Following previous studies (e.g., Colino et al., 2008; Colino et al., 2012; and Alquist and Kilian, 2010), we use the modified Diebold Mariano (MDM) test developed by Harvey et al. 
(1997) to test the statistical significance of the difference between the MAPEs of two competing forecasts. ${ }^{1}$ The null hypothesis of this test is that the difference between the absolute forecast error equals zero. Rejection of the null hypothesis indicates that the forecast with smaller prediction errors has statistically superior performance.

The MDM statistic is calculated using equation (2-12):

$$
\begin{array}{r}
M D M_{t}=\left[\frac{T+1-2 h+h(h-1) / T}{T}\right]^{\frac{1}{2}}\left[V\left(\bar{d}_{t}\right)\right]^{-\frac{1}{2}}\left[\bar{d}_{t}\right], \\
V\left(\bar{d}_{t}\right)=\left[T^{-1}\left(\gamma_{0}+2 \sum_{s=1}^{t-1} \gamma_{s}\right)\right],
\end{array}
$$

where $\bar{d}_{t}$ is the sample mean of the differences in absolute errors of two competing forecasts, $\gamma_{0}$ and $\gamma_{s}$ are the variance and $s^{\text {th }}$-order auto-covariance, respectively. Similar tests can be carried out for other loss functions, including the absolute percentage errors and quartic errors.

\subsection{Data}

Monthly natural gas spot prices at Henry Hub are obtained from the EIA. Henry Hub is the official delivery location for futures contracts traded on NYMEX, and its prices are more widely accessible and have been reported over a longer time period than other spot markets in the U.S. The STEO forecasts, available for prices up to 24 months ahead, are also obtained from the EIA. Futures price data for natural gas contracts traded on NYMEX, obtained from Bloomberg, are used to compute various futures-based forecasts.

For Hotelling's model, we use the U.S. Treasury bill rates from the U.S. Federal Reserve Bank as a proxy for the risk-free rate. For the VAR model, following Arora and Lieskovsky (2014)

\footnotetext{
${ }^{1}$ We also use the Clark and West (2006) test to evaluate the equal forecasting accuracy of two nested models. In the current paper, the no-change forecast is nested within the futures-spot spread, ARMA, VAR and Hotelling and composite forecasting models. Results are consistent with those from the MDM test.
} 
and Wiggins and Etienne (2017), aggregate demand for natural gas is represented by an index of industrial production and capacity utilization constructed by the Federal Reserve Bank. Natural gas inventory data is obtained from EIA and used to measure the precautionary inventory demand in anticipation of changes in future supply-and-demand conditions.

The period considered for forecast evaluation is September 2005 to December 2020. Prior to September 2005, only quarterly STEO forecasts are publicly available. We use the data from January 1997 to August 2005 to generate the initial parameters for VAR and ARMA models. We evaluate the forecast performances for each forecasting model during two sub-periods: September 2005-December 2008 (high volatility) and January 2009-December 2020 (low volatility). For the composite forecasts, data from September 2005 to December 2008 are used to estimate the initial weights, and the evaluation for the composite forecasts is performed for January 2009-December 2020.

\subsection{Results}

In total, we examine the accuracy of six different types of individual forecasting models (no-change, futures-based, Hotelling model, ARMA, VAR, and STEO forecasts) and four composite forecasts. Following Alquist and Kilian (2010) and Baumeister and Kilian (2015), the no-change forecast is used as a benchmark for forecast comparison. Since one important objective of the paper is to evaluate the performance of STEO forecasts, we also compare the performances of competing forecasts against the STEO projections.

We report the results for 1-, 3-, 6-, and 12-month ahead forecasts using MAPE. Since the STEO report is typically released early in the month, its one-month ahead is, in fact, the forecast for the current month. To match the forecasting timeline of other models, we consider the forecast 
for the month following the current month as the 1-month forecast (i.e., the 2-month ahead forecast in the STEO report is, in fact, the 1-month ahead forecast considered in the paper). Since all forecasts are generated using the information available up to the forecast date, the evaluation can be considered, in a sense, out-of-sample. In the following sections, we first discuss the results from individual forecasts, and then discuss the performances of composite forecasts.

\subsubsection{STEO vs. Futures-Based Forecasts}

Figure (2-2) plots the STEO projections, the three futures-based forecasts (prior day futures price, average futures price, and futures-spot spread forecasts), the no-change forecast, and the actual natural gas prices at various forecast horizons during the full sample period. It is apparent from the figure that all forecasts are highly correlated and follow a similar trend except the futuresspot spread model which shows relatively large deviations from actual prices. However, the futures-spot spread forecasts become more accurate at more distant forecasting horizons.

The MAPEs of individual forecasting models during the full sample, high-volatility (20052008), and low-volatility (2009-2020) periods at 1, 3, 6, and 12-month ahead horizons are presented in table (2-1) panels A, B, and C, respectively. The prior day futures price forecast and average futures price forecast have lower MAPEs than STEO at 1- and 3-month horizons in all three sample periods. However, STEO forecasts perform better than futures-based forecasts at 6and 12-month horizons. Compared with the benchmark no-change forecast, we find that the STEO forecast has lower MAPEs at longer forecasting horizons (6- and 12-month ahead) in all three sample periods. Further, the prior day futures price forecast outperforms the no-change forecast at the 1-month horizon in the full sample and 1- and 3-month horizons in the low-volatility period. 
We next evaluate whether the forecast performances between competing models are statistically significant by using the MDM test in equation (2-13). Tables (2-2) to (2-4) show the differences in MAPEs and $p$-values of the MDM test. For each forecast, we compare its performance with either STEO or no-change forecasts. As can be seen, the futures-based and nochange forecasts perform statistically better than STEO projections at 1-month ahead forecasting horizon, while the differences in MAPEs between STEO, the futures-based, and no-change forecasts are not statistically significant at the 3-month forecasting horizon. The STEO forecasts present statistically significantly lower MAPEs than the futures-based forecast at 6- and 12- month horizons during the full sample and high-volatility periods. Comparing the futures-based and nochange forecasts (panel B of tables (2-2) to (2-4)), the prior day futures-based forecast performs statistically better than no-change only at 1-month ahead forecasting horizon in the full and lowvolatile sample period.

\subsubsection{Performance of Other Individual Forecasts Relative to STEO and Futures Forecasts}

We next evaluate whether other individual forecasts, including ARMA, VAR, and Hotelling models can outperform STEO and futures-based forecasts. We consider both recursive (with January 1997 and August 2005 as the initial window) and rolling window (with 104 months as the fixed window size) analyses for ARMA and VAR forecasts. The number of lags used in the ARMA and VAR models is selected based on the Schwartz Information Criteria.

Figure (2-3) plots the VAR, ARMA, and Hotelling model forecasts, as well as the actual natural gas price during the sample period. Overall, all forecasts closely follow the actual price movement. However, the VAR model appears to have low predictive power at the beginning of the sample when natural gas actual prices were subject to large fluctuations. The large forecast 
errors associated with the VAR model in certain months may reflect the uncertainty introduced when predicting other endogenous variables that are necessary to produce a price forecast.

Comparing all forecasting models in the full sample period (panel A of table (2-1)), we find that neither the time-series nor Hotelling forecasts generate the most accurate prediction. Prior day futures price forecast has the smallest error at 1-month ahead horizon, while the no-change model is the most accurate forecast at the 3-month horizon. At 6- and 12-month forecasting horizons, the STEO forecast has the lowest MAPEs. Hotelling forecasts perform similarly to the no-change forecasts due to the low interest rates during the sample period.

Relative performances across individual forecasts vary during the two sub-periods. For sub-period I when natural gas prices were more volatile (table (2-1) panel B), the no-change forecast has the lowest MAPE at 1- and 3-month ahead horizons, while STEO forecast achieves the highest accuracy among all predictions at 3- and 6-month ahead horizons. During the second sub-period (table (2-1) panel C), the prior day futures price forecast has the most accurate prediction among all models at 1- and 3-month ahead horizons. Interestingly, while VAR forecasts have the highest MAPE in sub-period 1, their forecast performance significantly improved in subperiod II-VAR models with recursive analysis present the lowest MAPE among all forecasts at 6- and 12-month horizons. Results suggest that the VAR model may potentially be useful in longer-term business planning when the volatility of prices is low. Further, the Hotelling model presents higher forecast accuracy than the STEO forecasts at 1- and 3-month ahead horizons, and futures-based forecasts in certain cases.

The MDM test results (tables (2-3) to (2-5)) show that at the 1-month ahead horizon, STEO forecasts perform statistically better than the VAR model with rolling window analysis in the full and low-volatility periods. However, the Hotelling forecasts have a significantly lower MAPE than 
STEO at the 1-month horizon. Except for VAR-rolling in the full sample, these statistical significances disappear at the 3-month horizon. At the 6-month horizon, STEO performs statistically better than the majority of forecasting models in both full and high-volatility sample periods. In the low-volatility period, the STEO forecasts present a statistically lower MAPE than the ARMA model at the 6-month horizon. At the 12-month horizon, the STEO forecast statistically outperforms futures-based and ARMA rolling-window forecasts in the full sample period. However, the VAR recursive-window forecasts show significantly lower MAPEs than STEO in the high-volatility period at the same horizon.

In panel B of tables (2-3) to (2-5), we show the differences in MAPE between alternative and no-change forecasts. The VAR model performs statistically inferior to no-change forecasts at almost all horizons in the full and high-volatility periods. However, the VAR recursive-window forecasts present statistically lower MAPE in the low-volatility period at 3-,6- and 12-month horizons. Additionally, in all sample periods the no-change forecasts performance significantly better than ARMA at short-term forecasting horizons. Except for the 12-month ahead forecast, no significant differences are found between the Hotelling and no-change forecasts.

Overall, our results suggest that prior day futures forecast, simple no-change forecasts, and STEO projections tend to have lower MAPEs than the alternative forecasting models in most cases. The favorable forecasting performance of the no-change forecast is consistent with the findings of Alquist and Kilian (2010). Alquist and Kilian (2010) note that given the complexity of the market, particularly when the market is volatile, complicated forecasting methods may fail to outperform the simple no-change forecast due to their inability to accurately reflect the underlying fundamental factors. The superior forecasting accuracy of no-change forecasts in the short-term may also indicate that futures markets are weakly efficient, with prices reflecting all publicly 
available information. Since the EIA analysts involved in the STEO report may have access to information not known to the public, STEO forecast may outperform other forecasting models, especially at longer horizons. However, the favorable performance of STEO, no-change, and futures forecasts does not rule out the predictive power of alternative models. In particular, VAR models perform better than no-change at longer forecasting horizons. Our results corroborate the findings of Baumeister and Kilian (2012) that VAR models tend to perform the best during times of less unpredictable fluctuations in economic fundamentals, and that the Hotelling forecasts perform well and show statistically lower MAPEs than STEO at certain forecasting horizons.

\subsubsection{Can Composite Forecast Outperform Individual Forecasts?}

Based on the individual forecasts, we generate four composite forecasts (SA, IMSPE, OLS, and CLS) using the procedures described in section 2.2. Individual forecasts from September 2005 to December 2008, including futures previous day, futures-spot, ARMA, VAR, Hotelling, nochange, and STEO forecasts, are used to estimate the initial weights. Composite forecasts are recursively generated for January 2009-December 2020, where model parameters are updated ahead of a given forecast. Figure (2-4) plots the composite forecasts and actual natural gas prices in 2009-2020. Same as the individual models, the four combination forecasts follow a similar trend and are highly correlated with each other. Forecast performances tend to worsen as we move to longer forecast horizons.

Table (2-5) panel A shows the MAPEs of the four composite forecasts. The OLS model achieves the best forecasting performances at 1- and 12- month horizons and the simple averaging (SA) approach at 3- and 6-month horizons. Compared to individual forecasting models, again OLS regression and SA composite forecasts yield considerably higher forecast accuracy during the 
evaluation period. Additionally, IMSPE forecasts outperform other individual forecasting models at 3- and 6- month ahead horizons. CLS also provides smaller MAPEs than the no-change and STEO forecasts at 3- and 12-month ahead forecasting horizons. Overall, our results indicate that combining forecasts from individual models clearly outperforms most of the individual forecasts.

Further analysis using the MDM tests suggests that the IMSPE and SA forecasts perform statistically better than STEO forecasts at almost all horizons (panel B of table (2-5)). The CLS forecasts perform statistically better than STEO at the 1-month horizon, while the OLS forecasts show statistically superior performance than STEO at both the 1- and 12-month horizons. Compared to the no-change forecasts, table (2-5) panel $\mathrm{C}$ shows that all composite forecasts perform statistically better at the 12-month horizon. However, at the one-month horizon, only OLS composite forecasts statistically outperform no-change forecasts.

We also conduct sensitivity analysis by eliminating one of the seven individual models from each of the forecast combinations (the "leave-one-out" forecasts) and examine the forecast accuracy of the combination models. Appendix 1 shows the differences in MAPEs and $p$-values of the MDM test between leave-one-out and original composite forecasts. A positive (negative) value indicates that leaving the model out would have improved (lowered) the accuracy of composite forecasts. A statistically significant improvement can be achieved by excluding the futures-spot spread model in OLS and IMSPE models at near-term horizons. Leaving out the ARMA model statistically decreases the MAPE of the IMSPE, CLS and SA models at various forecasting horizons. Eliminating the VAR model improves the accuracy of the OLS and SA forecasts at 1-month ahead horizon; however, it significantly worsens the accuracy of the IMSPE model at all forecasting horizons. 
Finally, to better understand the performance of composite forecasts, we calculate the recursive MAPE of each composite forecast and compare it with the no-change and STEO forecasts. Figures (2-5) and (2-6) plot the difference in recursive MAPEs between composite, STEO, and no-change forecasts. A value below zero indicates an improvement in combination forecasts relative to the STEO forecast (figure (2-5)) and no-change forecast (figure (2-6)). As shown in figure (2-5), at 1 and 12-month horizons, the OLS composite forecast shows consistently higher accuracy than the STEO forecast throughout the entire evaluation period. Similar results are obtained for IMSPE and SA at 1-, 3- and 6-month horizons and CLS at the 12-month horizon. However, at the 3-month horizon STEO performs better than the OLS composite forecasts during the entire sample. We also note that the STEO forecasts have been slightly more accurate than CLS (at 1- and 3-month ahead horizons), OLS (at the 6-month horizon), IMSPE and SA forecast (at 12-month ahead horizon) early in the sample period. Similarly, figure (2-6) confirms the superior performance of the OLS model at the 1-month ahead forecasting horizon and all composite models at the 12-month horizon than the no-change forecast during the entire forecasting sample.

\subsection{Conclusions}

In this paper, we evaluate the performance of various individual and composite forecasting models in predicting natural gas prices in the U.S. from 2005 to 2020 . An accurate prediction of natural gas prices is imperative to market participants and policymakers involved in the natural gas exploration, production, transportation, trading, and regulatory actions as well as consumers involved in the utilization of the natural gas (Mishra, 2012). We find that overall, futures-based forecasts give a more accurate prediction of natural gas prices at 1 - and 3-month ahead horizons, 
while the STEO forecast performed well at 6-month and 12-month ahead horizons. Additionally, the relative forecast performances of the VAR models improved significantly when natural gas prices had experienced less volatility (January 2009 to December 2020). The Hotelling forecasts appear to perform well at the 1- and 3-month ahead horizons. Furthermore, our findings support the additional benefits of combining forecasts for deriving more accurate price forecasts in the natural gas market. In particular, the simple average forecasts perform consistently well against STEO forecasts.

This research provides some much-needed information on natural gas price forecasts that are important to market participants and policymakers. Natural gas prices have experienced high volatility due to changes of different endogenous and exogenous factors over the past two decades, posing significant business and management risks to both market participants and policymakers and highlighting the importance of accurate price predictions. From the practitioner's perspective, if following individual models is the preferred approach, then futures-based forecasts, or simple no-change forecasts should be used for short-term price prediction, while at longer horizons, STEO forecasts should be used due to their superior performances. However, using composite forecasts may prove to be preferable, especially at the 12-month ahead forecast horizons. For simplicity, the simple average weight composite forecasts may be used, which outperforms the STEO and nochange forecasts at almost all forecast horizons. 
Tables and Figures

Table 2-1. Mean Absolute Prediction Error (MAPE) for each individual forecasting model

\begin{tabular}{l|ccc|cc|cc|c|c|c}
\hline $\begin{array}{l}\text { Forecasting } \\
\text { horizons }\end{array}$ & $\begin{array}{c}\text { Fut- } \\
\text { previous }\end{array}$ & $\begin{array}{c}\text { Fut- } \\
\text { average }\end{array}$ & Fut-spot & $\begin{array}{c}\text { ARMA- } \\
\text { recursive }\end{array}$ & $\begin{array}{c}\text { ARMA- } \\
\text { rolling }\end{array}$ & $\begin{array}{c}\text { VAR- } \\
\text { recursive }\end{array}$ & $\begin{array}{c}\text { VAR- } \\
\text { rolling }\end{array}$ & $\begin{array}{c}\text { Hotelling } \\
\text { No }\end{array}$ & STEO \\
\hline \\
\hline Panel A. MAPE of Each Individual Forecasting Method Between Sep. 2005 to Dec. 2020 (Full Sample Period) \\
\hline 1 month-ahead & 0.4305 & 0.5537 & 1.3438 & 0.6700 & 0.6454 & 0.6493 & 0.7155 & 0.4623 & 0.4616 & 0.6198 \\
3 month-ahead & 0.8157 & 0.8410 & 1.4036 & 0.9196 & 0.9160 & 0.9003 & 1.0159 & 0.7952 & 0.7941 & 0.8605 \\
6 month-ahead & 1.1560 & 1.1565 & 1.4604 & 1.1547 & 1.1545 & 1.1585 & 1.3342 & 1.1244 & 1.1133 & 1.0008 \\
12 month-ahead & 1.4089 & 1.4128 & 1.5092 & 1.3668 & 1.4040 & 1.4277 & 1.6229 & 1.3801 & 1.3157 & 1.2381 \\
\hline
\end{tabular}

Panel B. MAPE of Each Individual Forecasting Method Between Sep. 2005 to Dec. 2008 (High-Volatility Sample Period)

\begin{tabular}{l|lll|ll|l|l|l|l|l}
\hline 1 month-ahead & 1.1546 & 1.3053 & 2.0766 & 1.5033 & 1.3313 & 1.5392 & 1.6203 & 1.0439 & 1.0418 & 1.3810 \\
3 month-ahead & 1.8776 & 1.9757 & 2.1608 & 1.9291 & 1.8493 & 2.2333 & 2.4408 & 1.7005 & 1.6989 & 1.9565 \\
6 month-ahead & 2.5380 & 2.5296 & 2.1956 & 2.1596 & 2.0615 & 3.0017 & 3.4295 & 2.4168 & 2.3817 & 1.8613 \\
12 month-ahead & 2.2355 & 2.2569 & 2.1878 & 2.5033 & 2.3195 & 3.7709 & 4.5574 & 2.0929 & 1.5195 & 1.3972 \\
\hline
\end{tabular}

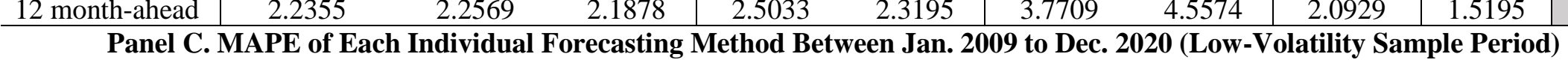

\begin{tabular}{l|lll|ll|l|l|l|l|l}
\hline 1 month-ahead & 0.2294 & 0.3519 & 1.1563 & 0.4385 & 0.4549 & 0.4021 & 0.4641 & 0.3007 & 0.3004 & 0.4084 \\
3 month-ahead & 0.5361 & 0.5423 & 1.2138 & 0.6532 & 0.6697 & 0.5485 & 0.6399 & 0.5564 & 0.5553 & 0.5712 \\
6 month-ahead & 0.8226 & 0.8245 & 1.2846 & 0.9104 & 0.9341 & 0.7105 & 0.8249 & 0.8103 & 0.8051 & 0.7917 \\
12 month-ahead & 1.2470 & 1.2475 & 1.3905 & 1.1379 & 1.2197 & 0.9558 & 1.0319 & 1.1749 & 1.1530 & 1.1302 \\
\hline
\end{tabular}

Notes: Shaded area represents the forecast that has the lowest error compared with other forecasting models. Mean absolute prediction error (MAPE) are in \$/MMBtu. "fut-previous," "fut-average," and "fut-spot" represent prior day futures price forecast, average future-based forecast, and futures-spot spread,

respectively. "ARIMA-recursive," "ARIMA-rolling," "VAR-recursive," and "VAR-rolling" are the ARIMA and VAR forecasts with recursive estimation and rolling-window estimation, respectively. 
Table 2-2. Differences in MAPE between alternative, STEO, and no-change forecasts, Sep. 2005 to Dec. 2020 (full sample)

\begin{tabular}{|c|c|c|c|c|c|c|c|c|c|}
\hline $\begin{array}{l}\text { Forecasting } \\
\text { horizons }\end{array}$ & $\begin{array}{c}\text { Fut- } \\
\text { previous }\end{array}$ & $\begin{array}{c}\text { Fut- } \\
\text { average }\end{array}$ & Fut-spot & $\begin{array}{l}\text { ARMA- } \\
\text { recursive }\end{array}$ & ARMA-rolling & $\begin{array}{l}\text { VAR- } \\
\text { recursive }\end{array}$ & $\begin{array}{l}\text { VAR- } \\
\text { rolling }\end{array}$ & Hotelling & $\begin{array}{c}\text { No } \\
\text { change }\end{array}$ \\
\hline
\end{tabular}

Panel A. Differences in MAPE between forecasting models and STEO projection

\begin{tabular}{lccccccccc} 
& $-0.1893 * * *$ & $-0.0661 * *$ & $0.724 * * *$ & 0.0502 & 0.0256 & 0.0295 & $0.0957 * *$ & $-0.157 * * *$ & $-0.158 * * *$ \\
1 month-ahead & $(0.001)$ & $(0.031)$ & $(0.00)$ & $(0.357)$ & $(0.703)$ & $(0.401)$ & $(0.034)$ & $(0.00)$ & $(0.00)$ \\
& -0.0448 & -0.0195 & 0.5431 & 0.0591 & 0.0555 & 0.0398 & $0.1554 *$ & -0.0653 & -0.0664 \\
3 month-ahead & $(0.283)$ & $(0.60)$ & $(0.283)$ & $(0.688)$ & $(0.641)$ & $(0.576)$ & $(0.064)$ & $(0.132)$ & $(0.127)$ \\
& $0.1552 * * *$ & $0.1557 * * *$ & $0.4596 * * *$ & $0.1539 *$ & $0.1537 *$ & 0.1577 & $0.3334 * *$ & 0.1236 & 0.1125 \\
\multirow{3}{*}{6 month-ahead } & $(0.00)$ & $(0.00)$ & $(0.00)$ & $(0.09)$ & $(0.05)$ & $(0.22)$ & $(0.01)$ & $(0.12)$ & $(0.14)$ \\
& $0.1708 * * *$ & $0.1747 * * *$ & $0.2711 * * *$ & 0.1287 & 0.1659 & 0.1896 & $0.3848 * *$ & 0.142 & 0.0776 \\
12 month-ahead & $(0.00)$ & $(0.00)$ & $(0.00)$ & $(0.53)$ & $(0.11)$ & $(0.22)$ & $(0.03)$ & $(0.21)$ & $(0.22)$ \\
& & & & & &
\end{tabular}

Panel B. Differences in MAPE between forecasting models and no-change forecast

\begin{tabular}{lcccccccccc} 
& $-0.0311 *$ & $0.0921 * * *$ & $0.8822 * * *$ & $0.2084 * *$ & $0.1838 * * *$ & $0.1877 * * *$ & $0.2539 * * *$ & -0.0007 & $0.1582 * * *$ \\
1 month-ahead & $(0.053)$ & $(0.00)$ & $(0.00)$ & $(0.00)$ & $(0.00)$ & $(0.00)$ & $(0.00)$ & $(0.57)$ & $(0.00)$ \\
3 month-ahead & 0.0216 & 0.0469 & 0.6095 & $0.1255^{*}$ & $0.1219 *$ & $0.1062 * * *$ & $0.2218 * *$ & 0.0011 & 0.0664 \\
& $(0.522)$ & $(0.166)$ & $(0.52)$ & $(0.072)$ & $(0.087)$ & $(0.00)$ & $(0.038)$ & $(0.96)$ & $(0.12)$ \\
& 0.0427 & 0.0432 & $0.3471 * * *$ & 0.0414 & 0.0412 & $0.0452 * *$ & 0.2209 & 0.0111 & -0.1125 \\
6 month-ahead & $(0.34)$ & $(0.24)$ & $(0.00)$ & $(0.914)$ & $(0.891)$ & $(0.029)$ & $(0.18)$ & $(0.11)$ & $(0.14)$ \\
& $0.0932 *$ & $0.0971 * *$ & 0.1935 & -0.0511 & 0.0883 & 0.112 & $0.3072 *$ & 0.0644 & -0.0776 \\
\multirow{2}{*}{12 month-ahead } & $(0.07)$ & $(0.033)$ & $(0.161)$ & $(0.555)$ & $(0.845)$ & $(0.371)$ & $(0.06)$ & $(0.61)$ & $(0.22)$ \\
\hline
\end{tabular}

Notes: In panel A, the shaded area indicates that STEO projections have a lower MAPE than the other forecasting models. In panel B, the shaded area shows that nochange forecasts have a lower MAPE relative to the other forecasting models. In parenthesis are $p$-values derived from the modified Diebold-Mariano test. Statistical differences are examined using the MDM test, and $* * * 0.01, * * 0.05$, and $* 0.10$ indicate significance levels. 
Table 2-3. Differences in MAPE between alternative, STEO, and no-change forecasts, Sep. 2005-Dec. 2008 (high volatility)

\begin{tabular}{|c|c|c|c|c|c|c|c|c|c|}
\hline $\begin{array}{l}\text { Forecasting } \\
\text { horizons }\end{array}$ & $\begin{array}{c}\text { Fut- } \\
\text { previous }\end{array}$ & $\begin{array}{c}\text { Fut- } \\
\text { average }\end{array}$ & Fut-spot & $\begin{array}{l}\text { ARMA- } \\
\text { recursive }\end{array}$ & ARMA-rolling & $\begin{array}{c}\text { VAR- } \\
\text { recursive }\end{array}$ & $\begin{array}{l}\text { VAR- } \\
\text { rolling }\end{array}$ & Hotelling & $\begin{array}{c}\text { No } \\
\text { change }\end{array}$ \\
\hline \multicolumn{10}{|c|}{ Panel A. Differences in MAPE between forecasting models and STEO projection } \\
\hline 1 month-ahead & $\begin{array}{c}-0.2264 * \\
(0.0965)\end{array}$ & $\begin{array}{r}-0.0757 \\
(0.517)\end{array}$ & $\begin{array}{c}0.6956^{* * * *} \\
\quad(0.00)\end{array}$ & $\begin{array}{l}0.1223 \\
(0.365)\end{array}$ & $\begin{array}{c}-0.0497 \\
(0.717)\end{array}$ & $\begin{array}{l}0.1582 \\
(0.327)\end{array}$ & $\begin{array}{l}0.2393 \\
(0.153)\end{array}$ & $\begin{array}{c}-0.337 * * \\
(0.039)\end{array}$ & $\begin{array}{c}-0.339 * * \\
(0.038)\end{array}$ \\
\hline 3 month-ahead & $\begin{array}{l}-0.0789 \\
(0.7176)\end{array}$ & $\begin{array}{l}-0.0192 \\
(0.926)\end{array}$ & $\begin{array}{c}0.2043 \\
(0.7176)\end{array}$ & $\begin{array}{l}-0.0276 \\
(0.8789)\end{array}$ & & $\begin{array}{l}0.2768 \\
(0.428)\end{array}$ & $\begin{array}{c}0.4843 \\
(0.1814)\end{array}$ & $\begin{array}{c}-0.256 \\
(0.2168)\end{array}$ & $\begin{array}{l}-0.2576 \\
(0.207)\end{array}$ \\
\hline 6 month-ahead & $\begin{array}{c}0.6767 * * * \\
(0.002)\end{array}$ & $\begin{array}{c}0.6683^{* * * *} \\
(0.002)\end{array}$ & $\begin{array}{c}0.3343 * * * \\
(0.002)\end{array}$ & $\begin{array}{l}0.2983 \\
(0.24)\end{array}$ & $\begin{array}{l}0.2002 \\
(0.397)\end{array}$ & $\begin{array}{l}1.1440^{*} \\
(0.069)\end{array}$ & $\begin{array}{c}1.5682 * * \\
(0.01)\end{array}$ & $\begin{array}{c}0.5555^{*} \\
(0.08)\end{array}$ & $\begin{array}{c}0.5204^{*} \\
(0.08)\end{array}$ \\
\hline 12 month-ahead & $\begin{array}{c}0.8383 * * * \\
(0.005)\end{array}$ & $\begin{array}{c}0.8597 * * * \\
(0.004)\end{array}$ & $\begin{array}{c}0.7906 * * * \\
(0.005)\end{array}$ & $\begin{array}{c}1.1061 * * * \\
(0.009)\end{array}$ & $\begin{array}{c}0.9223 * * \\
(0.0472)\end{array}$ & $\begin{array}{c}2.3737 * \\
(0.059)\end{array}$ & $\begin{array}{c}3.1602 * * \\
(0.011)\end{array}$ & $\begin{array}{l}0.6957 \\
(0.275)\end{array}$ & $\begin{array}{l}0.1223 \\
(0.208)\end{array}$ \\
\hline
\end{tabular}

Panel B. Differences in MAPE between forecasting models and no-change forecast

\begin{tabular}{lcccccccccc} 
& -0.1128 & 0.2635 & $1.0348 * * *$ & $0.4615 * * *$ & $0.2895^{*}$ & $0.4974 * * *$ & $0.5785^{* * *}$ & -0.0021 & $0.3392 * *$ \\
1 month-ahead & $(0.194)$ & $(0.44)$ & $(0.00)$ & $(0.00)$ & $(0.082)$ & $(0.001)$ & $(0.00)$ & $(0.562)$ & $(0.038)$ \\
& 0.1787 & 0.2768 & 0.4619 & 0.2302 & 0.1504 & $0.5344 *$ & $0.7419 * *$ & 0.0016 & 0.2576 \\
3 month-ahead & $(0.1598)$ & $(0.8805)$ & $(0.159)$ & $(0.598)$ & $(0.526)$ & $(0.087)$ & $(0.0303)$ & $(0.902)$ & $(0.207)$ \\
& 0.1563 & $0.1479 * * *$ & -0.1861 & -0.2221 & -0.3202 & 0.62 & $1.0478 * *$ & 0.0351 & $-0.5204 *$ \\
6 month-ahead & $(0.4855)$ & $(0.005)$ & $(0.4855)$ & $(0.914)$ & $(0.221)$ & $(0.174)$ & $(0.0358)$ & $(0.205)$ & $(0.0877)$ \\
& 0.716 & $0.7374 *$ & 0.6683 & 0.9838 & 0.8 & $2.2514 *$ & $3.0379 * *$ & 0.5734 & -0.1223 \\
12 month-ahead & $(0.706)$ & $(0.0802)$ & $(0.161)$ & $(0.706)$ & $(0.571)$ & $(0.0612)$ & $(0.008)$ & $(0.648)$ & $(0.2081)$ \\
\hline
\end{tabular}

Notes: In panel A, the shaded area indicates that STEO projections have a lower MAPE than the other forecasting models. In panel B, the shaded area shows that nochange forecasts have a lower MAPE relative to the other forecasting models. In parenthesis are $p$-values derived from the modified Diebold-Mariano test. Statistical differences are examined using the MDM test, and ${ }^{* * *} 0.01, * * 0.05$, and $* 0.10$ indicate significance levels. 
Table 2-4. Differences in MAPE between alternative, STEO, and no-change forecasts, Jan. 2009-Dec. 2020 (low volatility)

\begin{tabular}{|c|c|c|c|c|c|c|c|c|c|}
\hline $\begin{array}{l}\text { Forecasting } \\
\text { horizons }\end{array}$ & $\begin{array}{c}\text { Fut- } \\
\text { previous }\end{array}$ & $\begin{array}{c}\text { Fut- } \\
\text { average }\end{array}$ & Fut-spot & $\begin{array}{l}\text { ARMA- } \\
\text { recursive }\end{array}$ & ARMA-rolling & $\begin{array}{l}\text { VAR- } \\
\text { recursive }\end{array}$ & $\begin{array}{l}\text { VAR- } \\
\text { rolling }\end{array}$ & Hotelling & $\begin{array}{c}\text { No } \\
\text { change }\end{array}$ \\
\hline \multicolumn{10}{|c|}{ Panel A. Differences in MAPE between forecasting models and STEO projection } \\
\hline 1 month-ahead & $\begin{array}{c}-0.179 * * * \\
(0.000)\end{array}$ & $\begin{array}{c}-0.0565 * * * \\
(0.000)\end{array}$ & $\begin{array}{c}0.7479 * * * \\
(0.000)\end{array}$ & $\begin{array}{c}0.0301 * * * \\
(0.001)\end{array}$ & $\begin{array}{c}-0.0465 * * * \\
(0.000)\end{array}$ & $\begin{array}{c}-0.0063 * * * \\
(0.002)\end{array}$ & $\begin{array}{c}0.0557 * * * \\
(0.000)\end{array}$ & $\begin{array}{c}-0.107 * * * \\
(0.000)\end{array}$ & $\begin{array}{c}-0.108^{* * *} * \\
(0.000)\end{array}$ \\
\hline 3 month-ahead & $\begin{array}{l}-0.0351 \\
(0.205)\end{array}$ & $\begin{array}{l}-0.0289 \\
(0.245)\end{array}$ & $\begin{array}{l}0.6426 \\
(0.205)\end{array}$ & $\begin{array}{l}0.082 * * \\
(0.0131)\end{array}$ & $\begin{array}{c}-0.0985 * * * \\
(0.000)\end{array}$ & $\begin{array}{l}-0.0227 \\
(0.578)\end{array}$ & $\begin{array}{l}0.0687 \\
(0.23)\end{array}$ & $\begin{array}{l}-0.0148 \\
(0.631)\end{array}$ & $\begin{array}{r}-0.0159 \\
(0.611)\end{array}$ \\
\hline 6 month-ahead & $\begin{array}{l}0.0309 \\
(0.351)\end{array}$ & $\begin{array}{l}0.0328 \\
(0.259)\end{array}$ & $\begin{array}{c}0.4929 \\
(0.5492)\end{array}$ & $\begin{array}{c}0.1187 * * * \\
(0.000)\end{array}$ & $\begin{array}{c}0.1424 * * * \\
(0.001)\end{array}$ & $\begin{array}{c}-0.0812 \\
(0.261)\end{array}$ & $\begin{array}{l}0.0332 \\
(0.723)\end{array}$ & $\begin{array}{l}0.0186 \\
(0.755)\end{array}$ & $\begin{array}{l}0.0134 \\
(0.839)\end{array}$ \\
\hline 12 month-ahead & $\begin{array}{l}0.1168 \\
(0.727)\end{array}$ & $\begin{array}{l}0.1173 \\
(0.557)\end{array}$ & $\begin{array}{c}0.260 * * * \\
(0.909)\end{array}$ & $\begin{array}{c}0.0077 * * \\
(0.0193)\end{array}$ & $\begin{array}{c}0.0895 * * * \\
(0.006)\end{array}$ & $\begin{array}{c}-0.1744 * \\
(0.062)\end{array}$ & $\begin{array}{c}-0.0983 * * * \\
(0.000)\end{array}$ & $\begin{array}{c}0.0447 * * * \\
(0.000)\end{array}$ & $\begin{array}{l}0.0228 \\
(0.839)\end{array}$ \\
\hline
\end{tabular}

Panel B. Differences in MAPE between forecasting models and no-change forecast

\begin{tabular}{lcccccccccc} 
& $-0.071 *$ & $0.0515 * * *$ & $0.8559 * * *$ & $0.1381 * * *$ & $0.1545 * * *$ & $0.1017 * * *$ & $0.1637 * * *$ & 0.0003 & $0.108 * * *$ \\
1 month-ahead & $(0.093)$ & $(0.004)$ & $(0.000)$ & $(0.00)$ & $(0.000)$ & $(0.000)$ & $(0.000)$ & $(0.178)$ & $(0.000)$ \\
& -0.0192 & -0.013 & 0.6585 & $0.0979 * * *$ & 0.1144 & $-0.0068^{*}$ & $0.0846 * * *$ & 0.0011 & 0.0159 \\
3 month-ahead & $(0.5309)$ & $(0.3359)$ & $(0.53)$ & $(0.003)$ & $(0.86)$ & $(0.079)$ & $(0.000)$ & $(0.055)$ & $(0.611)$ \\
& 0.0175 & $0.0194 * * *$ & 0.4795 & 0.1053 & 0.129 & -0.0946 & $0.0198 * *$ & 0.0052 & -0.0134 \\
\multirow{2}{*}{6 month-ahead } & $(0.4855)$ & $(0.005)$ & $(0.4855)$ & $(0.914)$ & $(0.221)$ & $(0.174)$ & $(0.0358)$ & $(0.205)$ & $(0.839)$ \\
& 0.094 & 0.0945 & 0.2375 & $-0.0151 * *$ & $0.0667 * * *$ & $-0.1972 *$ & -0.1211 & $0.0219 * * *$ & -0.0228 \\
\multirow{2}{*}{12 month-ahead } & $(0.727)$ & $(0.557)$ & $(0.909)$ & $(0.019)$ & $(0.006)$ & $(0.0625)$ & $(0.743)$ & $(0.000)$ & $(0.839)$ \\
\hline
\end{tabular}

Notes: In panel A, the shaded area indicates that STEO projections have a lower MAPE than the other forecasting models. In panel B, the shaded area shows that nochange forecasts have a lower MAPE relative to the other forecasting models. In parenthesis are $p$-values derived from the modified Diebold-Mariano test. Statistical differences are examined using the MDM test, and $* * * 0.01, * * 0.05$, and $* 0.10$ indicate significance levels. 
Table 2-5. Performances of composite forecasts, Jan 2009-Dec 2020

\begin{tabular}{lcccc}
\hline Forecasting horizons & OLS & IMSPE & CLS & SA \\
\hline & Panel A. MAPE of composite forecasts, in \$/MMBtu & \\
1 month-ahead & 0.0917 & 0.3640 & 0.3993 & 0.3951 \\
3 month-ahead & 0.6553 & 0.5324 & 0.5452 & 0.5195 \\
6 month-ahead & 0.8638 & 0.7687 & 0.8241 & 0.7426 \\
12 month-ahead & 0.8879 & 1.0628 & 1.1113 & 0.9728 \\
\hline
\end{tabular}

Panel B. Differences in MAPE between forecasting models and STEO projection

\begin{tabular}{lcccc}
1 month-ahead & $-0.3167 * * *$ & $-0.0444 * * *$ & $-0.0091 * * *$ & -0.0133 \\
& $(0.000)$ & $(0.003)$ & $(0.000)$ & $(0.504)$ \\
3 month-ahead & $0.0841^{*}$ & $-0.0388^{*}$ & 0.026 & $-0.0517 * *$ \\
& $(0.062)$ & $(0.059)$ & $(0.208)$ & $(0.017)$ \\
6 month-ahead & 0.0721 & -0.023 & 0.0324 & $-0.0491^{*}$ \\
& $(0.299)$ & $(0.358)$ & $(0.149)$ & $(0.097)$ \\
12 month-ahead & $-0.2423^{* *}$ & $-0.067 *$ & -0.0189 & $-0.1579 * * *$ \\
& $(0.014)$ & $(0.022)$ & $(0.552)$ & $(0.000)$ \\
\hline \multicolumn{1}{c}{ Panel C. Differences in MAPE between forecasting models and no-change forecast } \\
1 month-ahead & $-0.2087^{*}$ & $0.0636^{* * *}$ & $0.0989 * * *$ & $0.0947 * * *$ \\
& $(0.093)$ & $(0.004)$ & $(0.000)$ & $(0.000)$ \\
3 month-ahead & $0.1 * *$ & -0.0229 & -0.0101 & -0.035 \\
& $(0.022)$ & $(0.32)$ & $(0.56)$ & $(0.131)$ \\
6 month-ahead & 0.0587 & 0.0364 & 0.019 & $-0.0625^{* *}$ \\
& $(0.321)$ & $(0.215)$ & $(0.647)$ & $(0.025)$ \\
12 month-ahead & $-0.2651^{* *}$ & $-0.0902^{* *}$ & -0.0417 & $-0.1802^{* * *}$ \\
& $(0.036)$ & $(0.038)$ & $(0.476)$ & $(0.000)$ \\
\hline
\end{tabular}

Notes: In panel A, the shaded area represents the forecast that has the lowest MAPE. In panel B, the shaded area indicates that STEO projections have a lower MAPE relative to the other forecasting models. In panel C, the shaded area shows that nochange forecasts have a lower MAPE relative to the other forecasting models. In parenthesis are $p$-values derived from the modified Diebold-Mariano test. Statistical differences are examined using the MDM test, and $* * * 0.01, * * 0.05$, and $* 0.10$ indicate significance levels. 


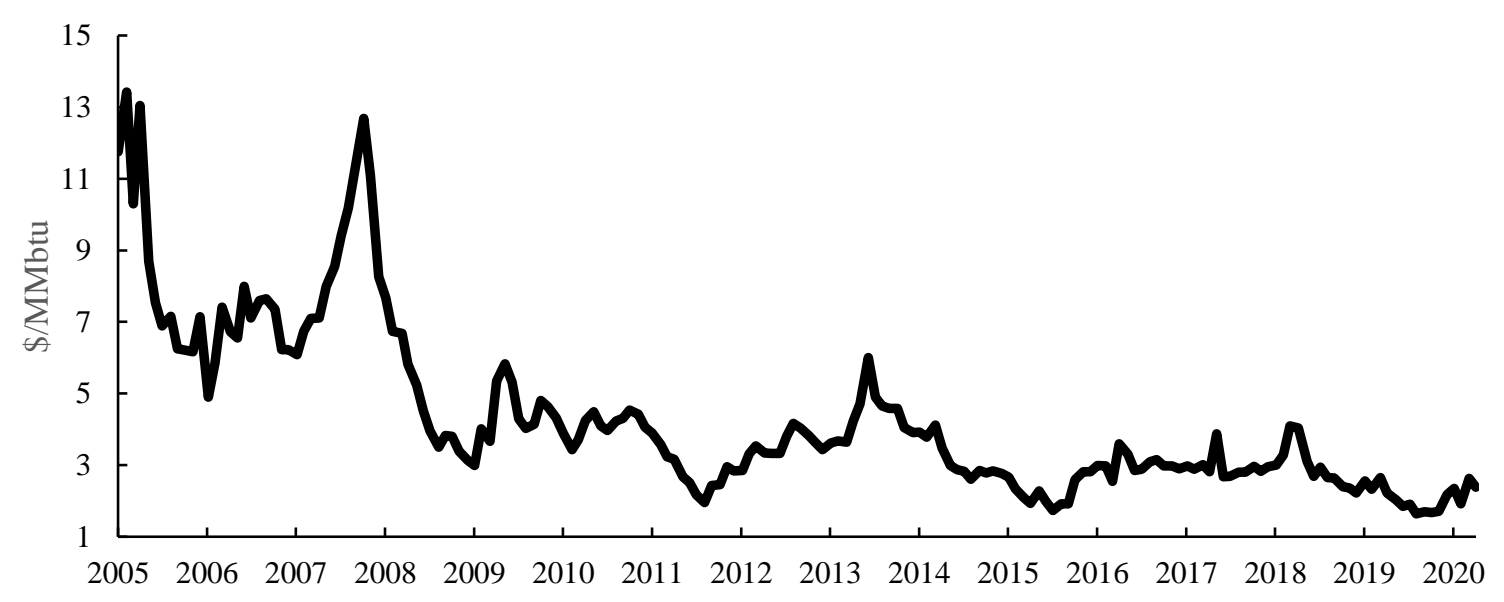

Figure 2-1. Monthly natural gas cash price at Henry Hub, Sep. 2005-Dec. 2020 

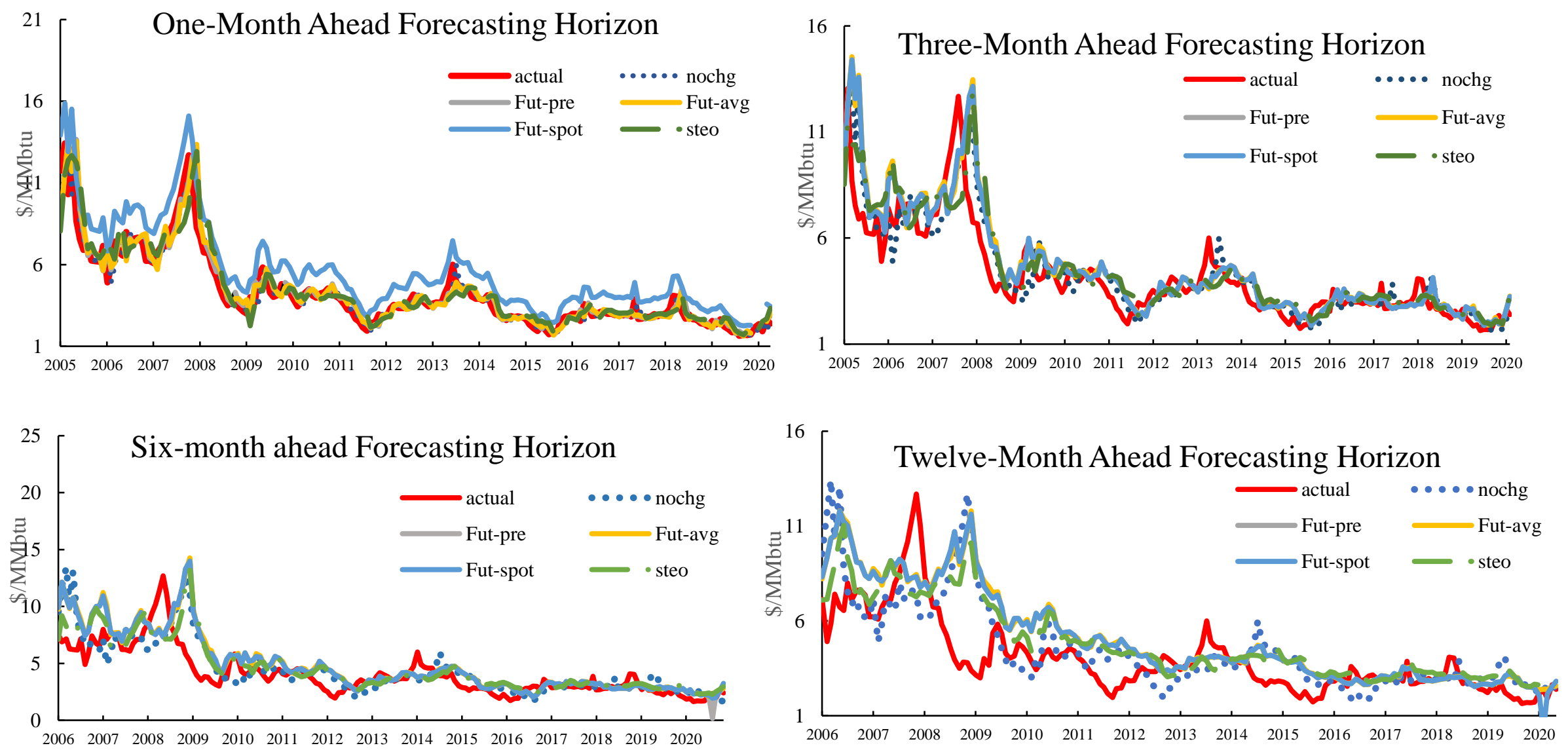

Figure 2-2. Futures-based, STEO projections, and no-change forecasts, Sep. 2005-Dec. 2020 

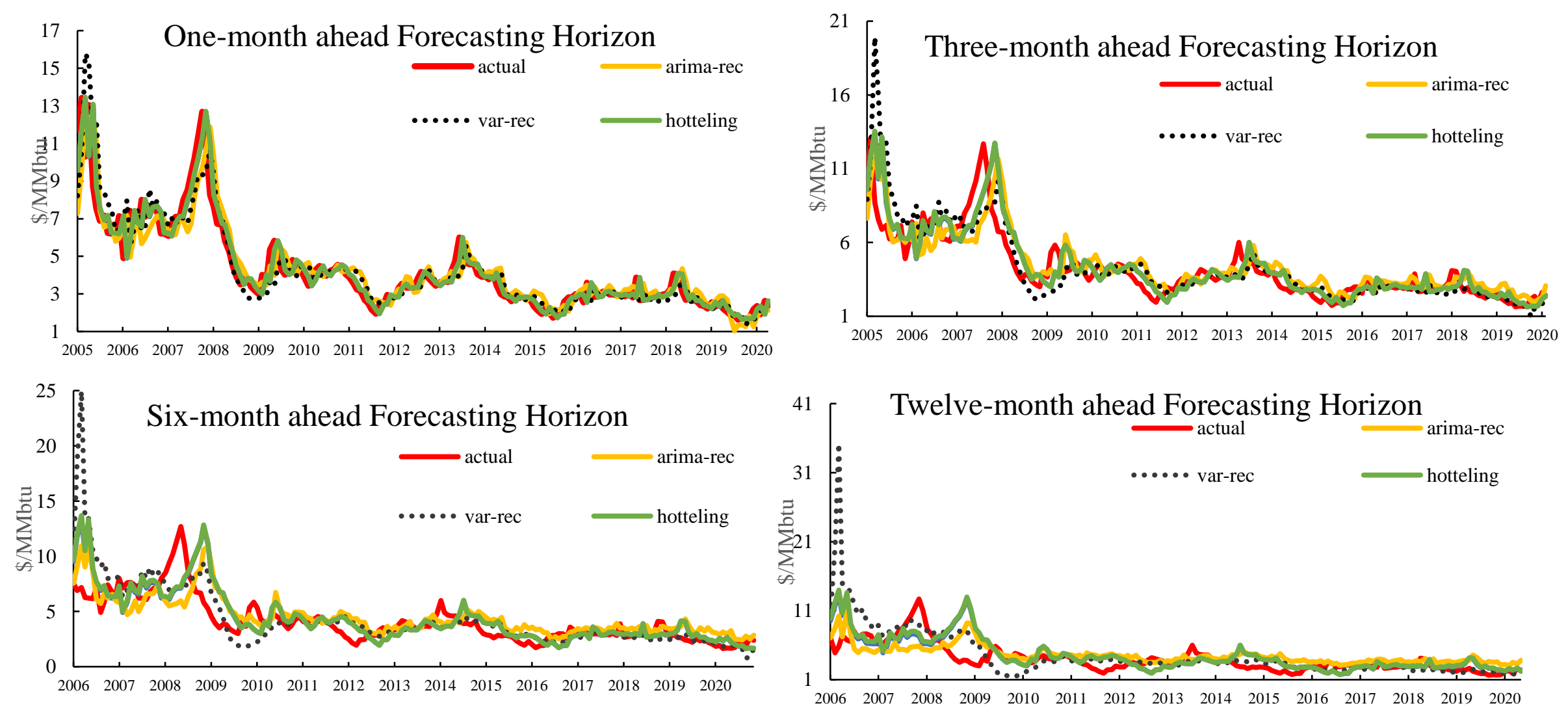

Figure 2-3. Alternative individual forecasts, Sep. 2005-Dec. 2020 

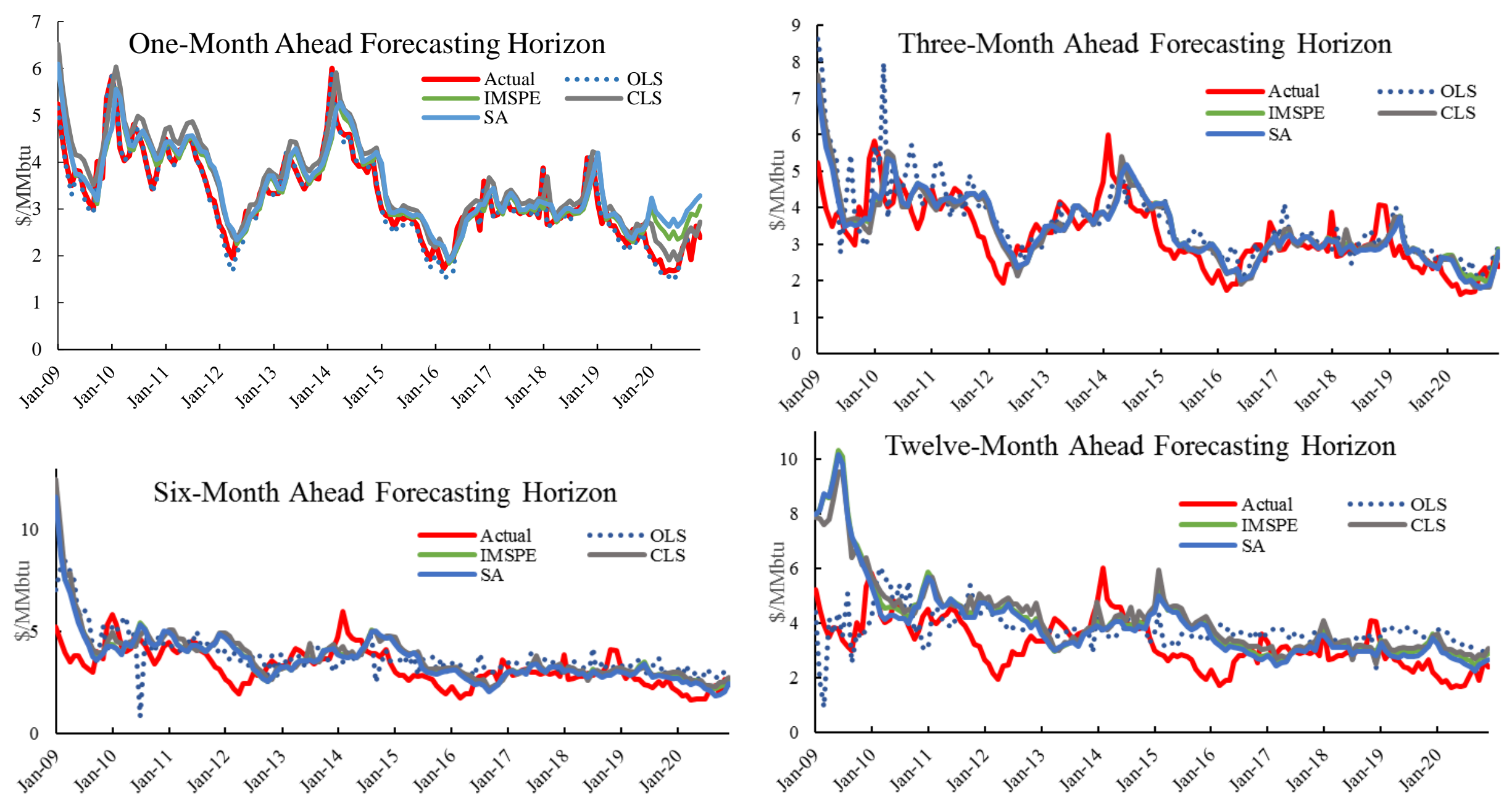

Figure 2-4. Composite forecasts, Jan. 2009-Dec. 2020 

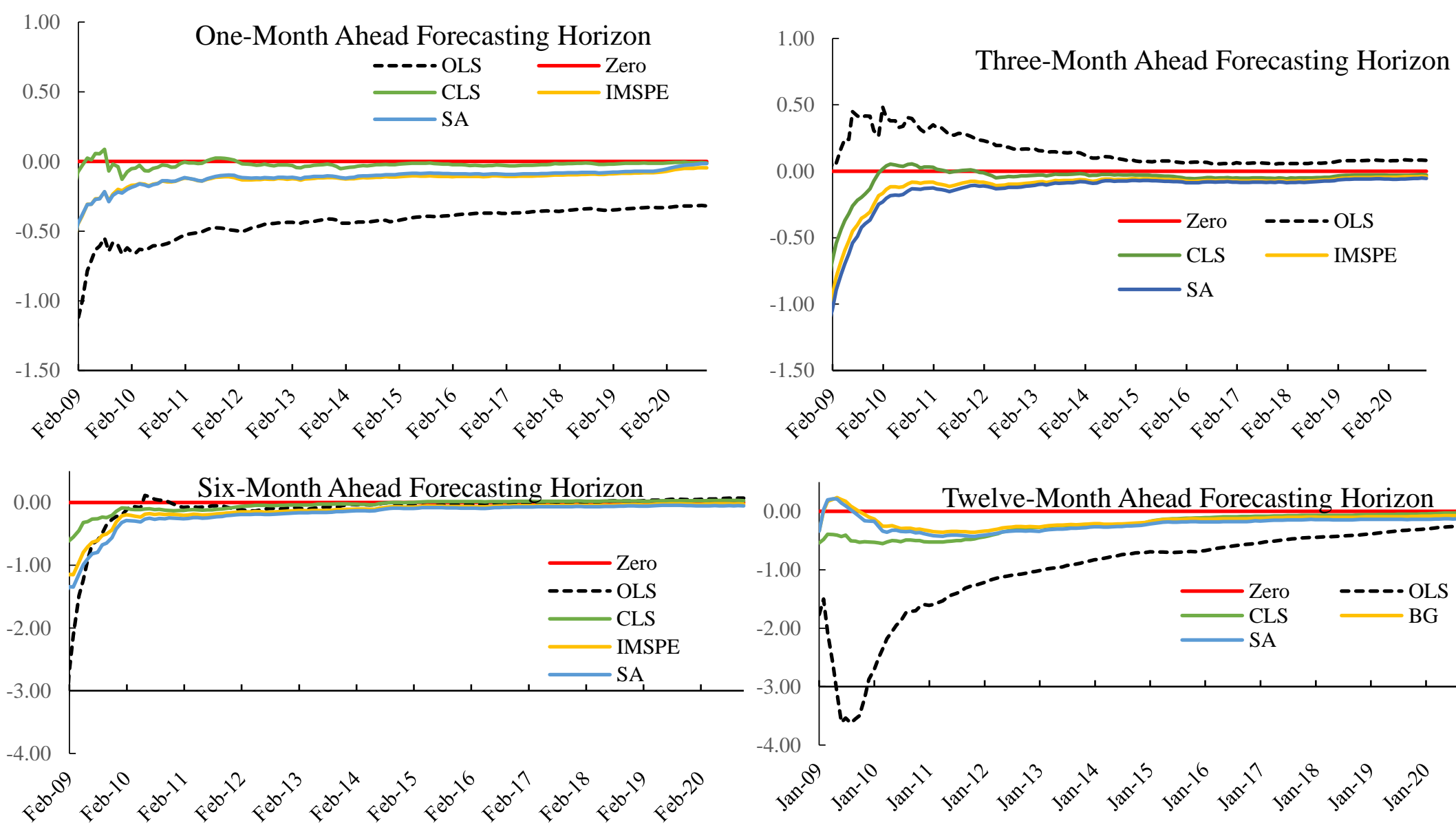

Notes: The plot shows the difference in recursive MAPE between composite and STEO forecasts. A value below 0 indicates an improvement relative to the STEO forecast.

Figure 2-5. Differences in recursive MAPE between combination forecasts and STEO forecast 

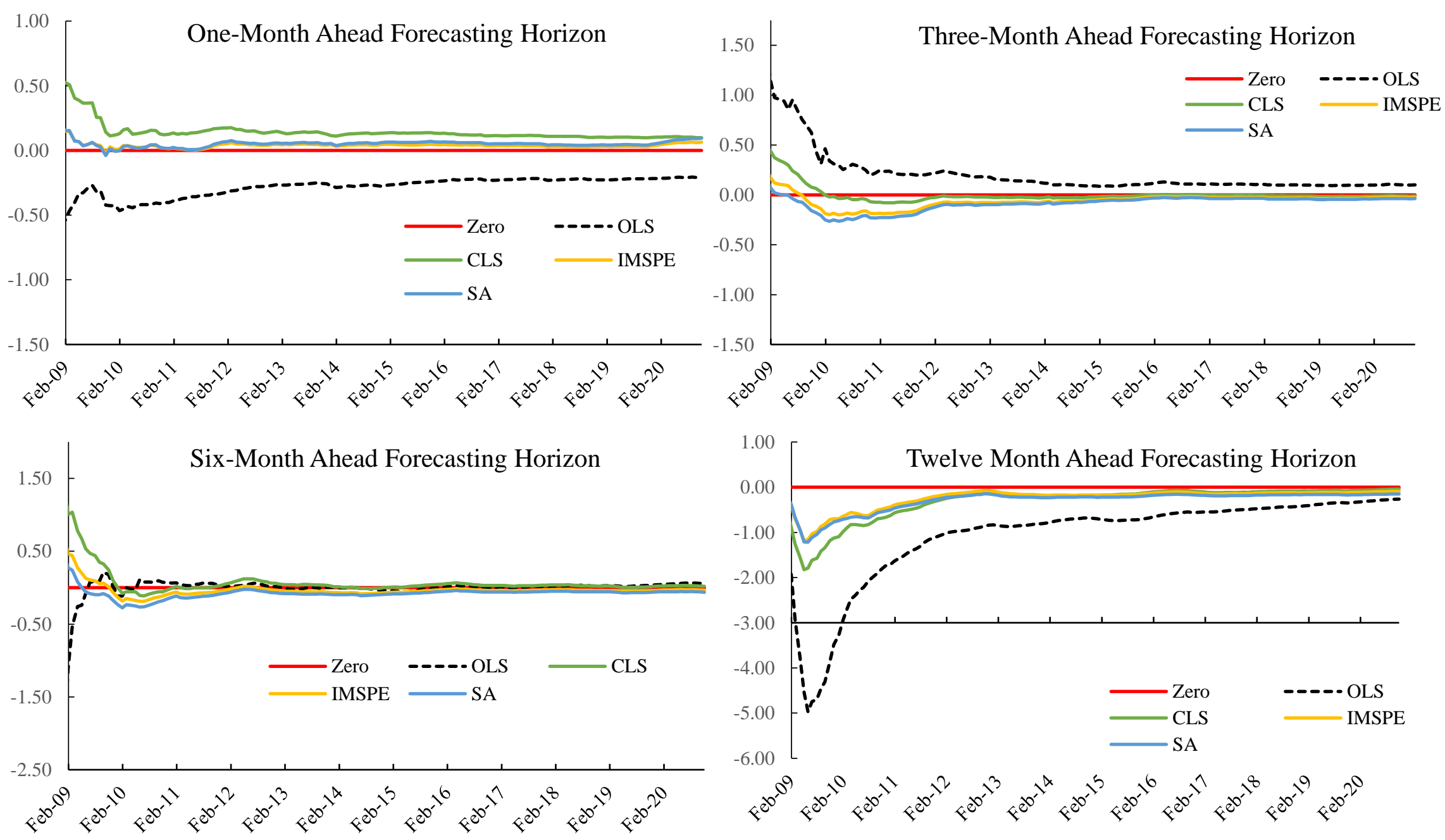

Notes: The plot shows the difference in recursive MAPE between composite and no-change forecasts. A value below 0 indicates an improvement relative to the No-change forecast.

Figure 2-6. Differences in recursive MAPE between combination forecasts and no-change forecast 
Table 2-6. Changes in MAPE of "Leave-One-Out" forecast combinations relative to original combination

\begin{tabular}{|c|c|c|c|c|c|c|c|c|}
\hline \multicolumn{2}{|c|}{ Model Left Out: } & $\begin{array}{c}\text { Fut- previous and Fut- } \\
\text { average }\end{array}$ & Fut-spot & ARIMA & VAR & Hotelling & No change & STEO \\
\hline \multirow{4}{*}{ OLS } & 1 month-ahead & 0.00357 & $0.3258 * * *$ & 0.00351 & $-0.0088^{*}$ & 0.0005 & -0.00146 & -0.0009 \\
\hline & 3 month-ahead & 0.0034 & $-0.0015 * * *$ & 0.008 & 0.2122 & -0.0264 & -0.0259 & 0.033 \\
\hline & 6 month-ahead & $-0.0294 * *$ & -0.0582 & 0.0527 & 0.0037 & -0.0302 & -0.0308 & -0.0109 \\
\hline & 12 month-ahead & $-0.0109 * *$ & $-0.0019 * *$ & -0.0344 & $0.0215^{*}$ & -0.0405 & -0.0343 & -0.0041 \\
\hline \multirow{4}{*}{ CLS } & 1 month-ahead & 0 & $-0.0803 * * *$ & $-0.0273 * * *$ & -0.0004 & $-1 \mathrm{E}-04 * * *$ & 0.00079 & -0.0007 \\
\hline & 3 month-ahead & 0 & 0 & -0.0103 & 0 & 0 & $0.0029 * *$ & $0.0166 * *$ \\
\hline & 6 month-ahead & $-0.0025^{* *}$ & $-0.1007 * * *$ & $-0.0598 * * *$ & 0.0024 & -0.0025 & -0.0011 & 0.0462 \\
\hline & 12 month-ahead & $-0.0045 * * *$ & $-0.0045 * * *$ & -0.0114 & $0.041 * * *$ & $-0.0045 * * *$ & $-0.0045^{* * *}$ & 0.0554 \\
\hline \multirow{4}{*}{ IMSPE } & & $0.0185^{* * *}$ & $0.0006^{* * *}$ & -0.009 & $0.0095^{* *}$ & $0.0488 * * *$ & $0.0482 * * *$ & 0.036 \\
\hline & 1 month-ahead & $0.0014 * * *$ & 0.0008 & $-0.0108 *$ & $0.0157 * *$ & -0.0031 & $-0.0028 * *$ & 0.1559 \\
\hline & 6 month-ahead & & -0.1122 & $-0.0348 * * *$ & $0.0259 * * *$ & -0.0276 & -0.0296 & -0.0205 \\
\hline & 12 month-ahead & $-0.0927 * * *$ & $-0.0641 * * *$ & -0.06189 & $0.0245 * * *$ & -0.0995 & -0.2092 & -0.0931 \\
\hline \multirow{4}{*}{ SA } & 1 month-ahead & $0.0291 * * *$ & $-0.0064 * * *$ & -0.0209 & $-0.0224 * *$ & 0.0007 & 0.0008 & $-0.0091 *$ \\
\hline & 3 month-ahead & $0.0029 * *$ & -0.0090 & $-0.0176^{* *}$ & $0.0245^{*}$ & -0.0106 & -0.0105 & -0.0115 \\
\hline & 6 month-ahead & -0.0055 & $-0.0151 * *$ & -0.0207 & 0.0510 & $-0.0169 * * *$ & $-0.0163 * * *$ & $-0.013 * * *$ \\
\hline & 12 month-ahead & $-0.0118^{*}$ & $-0.0236 * * *$ & -0.0144 & $0.1228 * * *$ & $-0.0277 * * *$ & $-0.0254 * * *$ & $-0.018 * * *$ \\
\hline
\end{tabular}

Notes: Shaded area indicates increases relative to the MAPE of forecast combination based on all combination forecasting models (shown in Table 5 panel A). Positive values mean that the model left out would have improved forecast accuracy if included, whereas negative values mean that it would have 


\section{Chapter 3. \\ The Effect of EIA Storage Announcement on Natural Gas Returns: A Comprehensive Analysis}

\subsection{Introduction}

Natural gas prices in the U.S. have undergone significant volatility since the market deregulation in the early 1980s. Understanding natural gas price volatility and the contributing factors to these price movements are of considerable interest to both financial practitioners and market participants, as they affect decisions made by producers and consumers in strategic planning and project appraisals, as well as gas-related investments, portfolio allocation, and risk management by investors (Lin et al., 2014). A key variable that determines commodity price volatility is the level of inventory. According to the theory of storage (Working, 1927), changes in the amount of a commodity under storage, driven by either supply or demand shocks, significantly affect commodity price movements. Depending on the speed of inventory changes, the prices of storable commodities such as natural gas are often characterized by phases of volatility levels with varying lengths (Karali and Thurman, 2009). Linn and Zhu (2004) note that information about changes in the amount of natural gas in storage may result in shifts in both the mean and volatility of prices, especially if participants in the market do not interpret the information in the same fashion, i.e., when the interpretations are heterogeneous.

Information on natural gas inventory changes is provided weekly by the U.S. Energy Information Administration (EIA). Each week, typically on Thursday, EIA publishes the Weekly Natural Gas Storage Report, which contains the change in the amount of natural gas held in underground storage in the preceding week. The report, closely watched by market participants and industry practitioners, often leads to significant subsequent price changes. For example, on 
March 19, 2009, the price of natural gas futures for April delivery jumped almost 13\% after EIA data showed a larger than expected gas withdrawal from inventories (Halova et al., 2014). Linn and Zhu (2004) and Halova et al. (2014) find that the weekly gas storage report was responsible for considerable price volatility at the time of the report release. Prokopczuk et al. (2021) further find that more than $50 \%$ of the annual natural gas market return is generated on the dates of EIA announcement. Given the significant impact of the EIA inventory report on natural gas prices, it is not surprising that major news outlets, such as Yahoo! Finance, and Bloomberg, periodically analyze the report and provide commentaries on the numbers released in the report.

This paper aims to compressively analyze the effect of EIA's natural gas inventory report on natural gas prices. Specifically, we seek to understand whether the impact of EIA natural gas inventory report 1) varies by the nature of the surprise components of the report, 2) changes during different seasons of the year, 3) shows different patterns under low and high inventory scenarios, and 4) displays time-varying patterns over time. Our work is closely related to several previous papers on the effect of EIA inventory announcements on energy market prices. For instance, Gay et al. (2009) and Chebbi (2019) show that energy market returns are negatively related to inventory surprises, i.e. when the reported inventory level is higher than market expectations, futures returns tend to be negative and vice versa. Bjursell et al. (2015) provide evidence that the volatility and trading volume of natural gas futures contracts increased on days with a jump at the inventory announcement. Miao et al. (2018) investigate the effect of the weekly EIA crude oil inventory surprises on oil futures and options prices, finding futures price return significantly decreasing with more-than-expected inventory surprises and increasing with less-than-expected surprises. Rousse and Sévi (2019) find WTI crude oil futures markets react more significantly to larger-than- 
expected inventory news than lower-than-expected inventory surprises in the hours following the EIA inventory announcement.

Overall, the existing papers find a statistically significant effect of unexpected inventory changes on energy futures prices. However, most of the studies only focus on the average impact of the EIA inventory report, without examining whether and how the effect may differ depending on the nature of the news and the underlying market conditions. In this study, we build upon previous papers and comprehensively examine how natural gas prices react to unexpected news about changes in the amount of natural gas in storage. Specifically, we propose and test four hypotheses that 1) natural gas prices respond asymmetrically to positive surprise (less-thanexpected) and negative surprise (more-than expected) inventory news; 2) inventory surprises have a more significant impact during the injection season than the withdrawal season; 3) prices react more significantly to inventory news when the level of inventory is low; 4) inventory surprises have a smaller price impact over time, particularly after shale production.

Using data from May 2003 to December 2020, we first assess the overall response of natural gas futures returns ${ }^{2}$ to positive and negative inventory surprises at different seasons of the year by using OLS models. We next use threshold regression models to investigate whether futures return responds to shocks heterogeneously at different underlying inventory levels. Finally, to address the potential time-varying impact of EIA's inventory report, we analyze the magnitude of price responses to EIA inventory report releases using time-varying models.

Overall, we find a positive (negative) relationship between lower-than-expected (higherthan-expected) storage surprise (actual change minus expected change) and natural gas futures

\footnotetext{
${ }^{2}$ Natural gas "returns" are used to measure price changes.
} 
return on the day of the EIA storage announcement. However, prices are more responsive to negative $^{3}$ (higher-than-expected) than positive (lower-than-expected) storage surprises during withdrawal season and the full sample. We also find the impact of EIA's report on natural gas prices is larger under tighter market conditions during the withdrawal season. Further, the announcement effects appear to be overall larger during the injection season compared to withdrawal season. Finally, we show that the EIA's inventory report still contains valuable information for the natural gas market; however, its impact on prices has diminished over time. Potential reasons include the increasing availability of information providers in the market, the relatively over-supply in the U.S. natural gas market since the shale boom, and the more integrated regional market that can transport natural gas from production to consumption regions more efficiently.

The rest of the chapter is organized as follows. The next section discusses the proposed hypotheses of this study. Data are discussed in section three. Section four introduces the main empirical methods employed in the analysis. Finally, the last two sections present the results and summarize the key findings of our study.

\subsection{Literature Review and Hypotheses}

A large amount of literature has investigated the asymmetric impact of good (which leads to higher prices) and bad (which leads to lower prices) news in the stock market. (Black, 1976; Christie, 1982; French et al., 1987; Nelson, 1991; Schwert, 1990; Campbell and Hentschel, 1992; Damodaran, 1993; and Koutmos, 1998). Christie (1982) explains this asymmetric response based

\footnotetext{
${ }^{3}$ Since higher-than-expected (lower-than-expected) inventory surprises will decrease (increase) prices, we define this event as a negative (positive) inventory surprise.
} 
on the leverage hypothesis and argues that volatility negatively correlates with stock returns. The rationale behind this argument is that a fall in the market value of a firm's equity increases financial leverage, which makes the stock riskier and increases its volatility. Additionally, Szeto and Fong (2000) note that the arrival of bad news in the stock market makes investors who want to buy the stock at today's price (as they expected a rise in the stock price in the future) sell or hold his cash instead of buying today. This immediate behavioral reaction to bad news, in reality, triggers panic selling and increases market volatility. The asymetric response in the stock market has found empirical support in the literature. Feunou et al. (2017) and Hatemi-J et al. (2017), for instance, show that good and bad news has different predictability for future volatility and that stock volatility increases more in response to past negative shocks ('bad' news) than to positive shocks ('good' news) of the same magnitude.

The asymmetric market reaction to negative and positive news has also been tested in the energy market. Compared to the stock market, energy commodities present several distinct characteristics. First, the lack of substitutes makes the demand for energy commodities highly inelastic (L'Hégaret et al., 2003). Second, supply is often physically constrained in the short run due to production constraints, making energy commodities vulnerable to exogenous shocks (Van Goor and Scholtens, 2014). These fundamental differences suggest that energy prices may react strongly to even a small, unexpected change in inventory levels, and that the degree of asymmetric response may present rather distinct patterns from those found in the stock market.

Existing studies in general agree that the asymmetric response exists in energy markets, but the evidence on the direction of asymmetry is mixed. Several papers find that positive shocks (less-than-expected inventory) increase volatility more than negative shocks (more-than-expected 
inventory) for crude oil and natural gas markets, such as Fan et al. (2008), Zhang et al. (2008), and Nomikos and Andriosopoulos (2012). These papers argue that an increase in the price of nonrenewable energy will reinforce the expectation for the supply deficit, making traders buy the nonrenewable energy as soon as possible, which, in turn, increases the prices more and accelerates the market volatility.

Meanwhile, Kao and Wan (2009), Reboredo (2011), Kristoufek (2014), Chkili et al. (2014), Rousse and Sévi (2019), and Carnero and Pérez (2019) show that negative shocks have a higher impact than positive shocks in energy markets, including crude oil, heating oil, and natural gas. Kao and Wan (2009) note that despite the non-renewable nature, the proven reserves for natural gas are more than sufficient to meet projected demand increases in the next few decades. The abundant supply, and the expectation that supply will continue to outpace demand, may change the market sentiment on the decreasing level of gas stocks and help compromise the impact of positive shocks on prices. Moreover, the natural gas market is still largely considered a suppliers' market that tends to suffer more from a decreasing product price. Lower prices increase gas company's operation risk and financial risk due to the low values of their assets. Because of the short-sale constraints in spot trading, negative shocks may harm the market to a larger extent than positive ones. Given the linkage between spot and futures prices, these negative responses may subsequently spill over onto futures markets, leading to larger responses to negative than positive shocks. Rousse and Sévi (2019) alternatively link the larger price response to larger-thanexpected inventory surprises in WTI crude oil markets to order imbalance and informed trading. They note that informed traders are naturally hedged when they speculate on price drops and owning the commodity simultaneously when news that would increase the price arrives. When 
news that would decrease the price arrives, on the other hand, hedging is not feasible because speculation is risky.

Following the discussions above, we expect that natural gas prices respond asymmetrically to the unexpected component of the EIA news depending on the nature of the surprises. Specifically, we propose and test hypothesis 1:

Hypothesis 1: Natural gas prices respond differently to positive surprises versus negative surprises with respect to inventory news.

For storable commodities, the inventory level is widely considered a measure of supply and demand balance in the market (Linn and Zhu, 2004; Chiou-Wei et al., 2014). A high (low) inventory is often associated with an abundant (tight) supply, sluggish (strong) demand, and low (high) prices. Any unexpected changes in storage level could immediately impact prices and volatility, especially if all market participants do not interpret the information in the same manner (Linn and Zhu, 2004). The level of natural gas in storage exhibits a strong seasonal pattern and involves two calendar periods. The first period starts from April to October, or more commonly known as the "injection season." Natural gas storage typically accumulates during the injection season because demand is lower in the warmer months, and new inventories are being added in advance of the following winter heating season. "Withdrawal season," on the other hand, starts from November to March when the demand for natural gas for heating rises sharply and the inventory quickly falls. The supply during the withdrawal season is essentially fixed due to storage constraints (Gay et al., 2009).

Changes in storage levels occur due to supply and demand shocks. Gay et al. (2009) and Linn and Zhu (2004) suggest that for natural gas, the demand shocks are mainly a result of changes 
in weather conditions, and are often less predictable and of a larger magnitude. Given that the majority of natural gas is used for heating in the winter, demand shocks mostly occur in the withdrawal season. Meanwhile, supply shocks, which mainly occur in the injection season, can be attributed to pipeline capacity, operational difficulties, and imperfect information among suppliers that are mostly technology driven.

Figure (3-1) panels $\mathrm{A}$ and $\mathrm{B}$ plot how natural gas prices react to inventory shocks in injection and withdrawal seasons. Recent empirical work shows that natural gas supply has become more elastic in both the short and long runs due to the dramatic rise in proven natural gas reserves in the U.S. (Joutz, 2009 and Arora, 2014). Meanwhile, the demand curve remains highly inelastic due to a lack of substitutes for natural gas. During the withdrawal season (panel A), storage surprises due to demand shocks shift the demand curve from $D_{0}$ to $D_{1}$ and changes the price from $P_{0}$ to $P_{1}$. During injection season (panel B), most of the storage surprises are supplydriven, which causes a shift in the supply curve from $S_{0}$ to $S_{1}$ and decrease the price from $P_{0}$ to $P_{1}$. As can be seen in panels $\mathrm{A}$ and $\mathrm{B}$ of figure (3-1), since the demand curve for natural gas is more inelastic than the supply curve, for the same magnitude of shock, a supply shock to inventory affects prices more than a demand shock of the same magnitude. Furthermore, Gay et al. (2009), and Halova et al. (2014) provide evidence that natural gas prices react more strongly in injection seasons than withdrawal seasons. However, due to tremendous changes to the natural gas market such as improvement in infrastructure and dramatic rise in shale production during the past decades, it might be useful to re-test the following hypothesis with up-to-date data:

Hypothesis 2: Natural gas prices respond more strongly to storage surprises during injection than during withdrawal season. 
Seasonal patterns of natural gas storage may further be complicated by different underlying market conditions. The theory of storage pioneered by Holbrook Working $(1927 ; 1948)$ argues that inventory level plays a vital role in smoothing production, stabilizing demand and supply shocks, and absorbing price fluctuations. The theory of storage has since been examined by various authors, including Brennan and Schwartz (1985), Telser (1958), Cootner (1960). According to the theory, when inventory is low (i.e., supplies are tight), price volatility in response to exogenous shocks tends to be high due to concerns about the availability of the commodity for future consumption. On the other hand, when supplies are abundant (i.e., no scarcity), prices tend to be relatively stable, displaying minimum responses to exogenous shocks. Such relationship may exist for the natural gas market in general, as well as during either injection or withdrawal season separately.

This nonlinear relationship between inventory and price volatility in response to external shocks has been empirically examined in the literature. For instance, Symeonidis et al. (2012) use a large physical inventory dataset to analyze the behavior of commodity prices and their relationship to volatility, finding that lower inventory has a more pronounced impact on volatility than a high level of inventory, especially for energy, animal, and agricultural commodities. Rubaszek and Uddin (2020) apply a structural threshold vector autoregression model to document the nonlinearity of natural gas price responses, finding that the impact of structural shocks on natural gas prices is stronger in the low-inventory regime in comparison to the high-inventory environment. Furthermore, Guerra et al. (2015) and Gouel and Legrand (2017) show that when the inventory level is high, inventory surprises are likely to lead to a much milder price response than when the market has abundant inventory. In other words, the relationship between futures 
returns and inventory surprise does not follow a single pattern, and the level of inventory may strengthen or weaken the EIA announcement effects on natural gas price returns.

Following the discussion above, we propose hypothesis 3:

Hypothesis 3: Inventory surprises have a larger impact when the underlying market is in tight supply.

The widespread exploitation of shale gas through horizontal drilling and hydraulic fracturing in the U.S. over the past two decades has not only shifted the natural gas supply curve but also increased its supply elasticity (Newell et al., 2019). In other words, the U.S. natural gas supply has become more responsive to price changes. Newell et al. (2019) note several fundamental differences in shale drilling compared to conventional gas exploration are behind this change in supply elasticities. First, while conventional gas drilling often resembles a high-risk, high-reward game, drilling into shale reserves is considerably less risky due to the largely uniform nature of shale resources. The lower risk of "dry holes" motivates energy firms to quickly respond to exogenous shocks and to drill more unconventional wells for natural gas when profit opportunity emerges. Second, the investment horizon for unconventional drilling is much shorter than conventional drilling due to the faster depletion rate of unconventional wells. Newell et al. (2019) find that in their first full month of production, unconventional gas wells on average produced 2.3 times as much as conventional gas wells. Because shale producers can quickly get in and out of production, they are also able to respond more rapidly to price changes than conventional gas producers. Recent empirical work by Arora (2014), Wiggins and Etienne (2017), Mason and Roberts (2018), and Newell et al. (2019) estimate the price elasticity of natural gas supply after 
the shale boom, finding evidence in support of a flatter supply curve due to the higher degree of production flexibility with unconventional wells.

Figure 3-2 plots this change, where the natural gas supply curve becomes flatter $\left(S_{1}\right)$ after the shale boom. As can be seen, price changes due to demand shock have a smaller effect when the supply curve is more elastic $\left(\Delta P_{1}<\Delta P_{2}\right)$. As a result, we expect EIA's inventory news had a large effect on natural gas prices prior to 2010. After 2010, lower uncertainty about well productivity, faster production rate, and more flexibility to trade and produce natural gas may have lowered the impact of inventory surprises on natural gas prices over time.

Furthermore, the emergence of private market advisory firms, which compete and complement the public information providers, has significantly increased the availability of information to all market participants. This increased availability may have helped market participants form better predictions on energy market changes, thereby decreasing the impact of the EIA inventory report. Recent empirical work also documents an increasing level of regional market integration in the U.S. natural gas sector. With the rising information transmission between production and consumption regions, external shocks are likely to exert a less significant impact on natural gas prices over time. Given the discussion above, we propose hypothesis 4 :

Hypothesis 4: Inventory surprises have a smaller price impact over time, particularly after shale production.

\subsection{Data}

The U.S. natural gas inventory data are obtained from EIA's Weekly Natural Gas Storage Report, typically released at 10:30 AM (Eastern Time) every Thursday, except for certain weeks 
that contain Federal holidays. ${ }^{4}$ The report includes estimates of the volume of working natural gas held in underground storage facilities in the lower 48 states and the net change in storage for the week ending the previous Friday. Given the significance of the report, numerous analysts actively forecast the forthcoming EIA storage figures prior to the report's release, to help market participants form expectations (Fernandez-Perez et al., 2020). The Bloomberg forecast, computed as the median of individual analyst forecasts, is generally considered the best amongst practitioners and represents the forecasts most readily available to market participants (Chiou-Wei et al., 2007 and Gay et al., 2009).

Following Halova et al. (2014), Bloomberg's natural gas inventory consensus forecasts are used as a proxy for the market expectations on future storage levels at the time of the inventory announcement. We follow Kilian and Vega (2011) and calculate storage surprises as the difference between the actual and expected change in inventory, normalized by the standard deviation of the surprises:

$$
S_{t}=\frac{A_{t}-E_{t}}{\widehat{\sigma}}
$$

where $A_{t}$ is the actual inventory level in week $t$ and $E_{t}$ is the market's expectation of inventory level measured by the median survey forecast data available on Thursday morning prior to the release of the EIA report. $\hat{\sigma}$ is the sample standard deviation of the surprise component, $A_{t}-E_{t}$. Because $\hat{\sigma}$ is constant, this standardization affects neither the statistical significance of the estimated response coefficients nor the fit of the regressions compared to the results based on the raw surprise.

\footnotetext{
${ }^{4}$ The releases are delayed by one day for the case of Federal holidays.
} 
The inventory surprises are categorized into two groups based on i) the nature of the surprise (i.e., more-than-expected vs. less-than-expected) and ii) the season of the year (i.e., injection vs. withdrawal). Following the convention in prior literature, we define positive (negative) surprise as events that drive up (down) the prices, which occurs when the storage level reported by EIA is lower (larger) than the Bloomberg forecast, or the expected level. As discussed earlier, natural gas storage presents seasonal variations-low in withdrawal seasons (November through March) and high during injection seasons (April through October).

We use intraday settlement price data of nearby (next-to-expire) natural gas futures contracts traded on the New York Mercantile Exchange (NYMEX) to calculate price returns. Flowing Gay et al. (2009) and Halova et al. (2014), a 15-minute event time interval is used. The 15-minute event interval allows us to compare our results with the existing studies. ${ }^{5}$ The EIA weekly inventory report is released on Thursdays at 10:30 AM eastern time, and the event time interval starts from 5 minutes before to 10 minutes after the announcement time. The returns are calculated based on:

$$
R_{t}=100 \times\left(\ln P_{t}-\ln P_{t-1}\right),
$$

where $P_{t}$ and $P_{t-1}$ are natural gas futures prices at 10:40 AM and 10:25 AM, respectively. Since returns are likely to be autocorrelated, we also calculate the lagged price returns for the event window, which is the logarithmic price changes between 10:25 AM and 10:10 AM, eastern time.

Sample period considered runs from May 22, 2003 to December 12, 2020, when the EIA inventory data are available. Figure (3-3) plots the natural gas inventory level and inventory

\footnotetext{
${ }^{5}$ We also conducted the analysis with longer event window (30-minute event interval). The results are qualitatively similar to those from using the 15-minute intraday interval.
} 
surprises over the sample period. Seasonality is evident in natural gas storage levels (panel A) and inventory surprises (panel B). Natural gas inventory levels tend to increase during the injection seasons (shaded area) and decrease during withdrawal seasons. Meanwhile, inventory surprises (panel B) show considerably lower volatility during the injection season (shaded area). This pattern is further illustrated by the summary statistics in table (3-1). As can be seen, inventory surprises in the withdrawal season are on average larger and more volatile relative to the injection season.

Figure (3-4) plots the natural gas returns at three 15-minutes intervals: 10:10 AM. 10:25 (5 minutes before EIA natural gas inventory report release time) and 10:40 AM (10 minutes after EIA's release time). While all three return sequences fluctuate around zero, returns at 10:40 AM, incorporating the release of the EIA storage report, are significantly more volatile compared to returns at the other two time periods. Table (3-1) shows that the standard deviation of returns after the EIA report release is almost five times as big as that of before the report release.

\subsection{Empirical Method}

We start our empirical analysis by regressing the returns against the positive and negative news embedded in the EIA inventory report, as in equation (3-3):

$$
R_{t}=\alpha_{0}+\alpha_{1}^{+}\left|S_{t}^{+}\right|+\alpha_{2}^{-}\left|S_{t}^{-}\right|+\varepsilon_{t}
$$

where the dependent variable, $R_{t}$, is the intraday natural gas futures return at 10:40 AM, and the independent variables, $\left|S_{t}^{+}\right|$and $\left|S_{t}^{-}\right|$are the computed absolute value of positive (or less-thanexpected) and negative (or more-than-expected) surprises, respectively. ${ }^{6} \varepsilon_{t}$ is the error term and

\footnotetext{
${ }^{6}$ We use absolute surprises for easier interpretation. Positive and negative surprises are expected to have opposite impact on price returns. Using "surprises", instead of "absolute surprises" would imply that the coefficients for both positive and negative surprises to be of the same sign, which would complicate the interpretation.
} 
$\alpha_{0}$ is the intercept. Positive inventory surprises (less-than-expected inventory) are expected to increase natural gas price returns, while negative inventory surprises (larger-than-expected inventory) are expected to decrease the return. In other words, $\alpha_{1}^{+}$and $\alpha_{2}^{-}$are expected to be positively and negatively significant, respectively. Further, Hypothesis $\mathbf{1}$ suggests that the magnitudes of $\alpha_{1}^{+}$and $\alpha_{2}^{-}$should be statistically different from each other.

We further differentiate the surprises based on the two calendar seasons of the year, i.e., the withdrawal and injections seasons. Equation (3-4) is used to test Hypothesis 2.

$$
R_{t}=\alpha_{0}+\alpha_{1}^{w+}\left|S_{t}^{w+}\right|+\alpha_{1}^{I+}\left|S_{t}^{I+}\right|+\alpha_{2}^{w-}\left|S_{t}^{w-}\right|+\alpha_{2}^{I-}\left|S_{t}^{I-}\right|+\varepsilon_{t},
$$

where $\left|S_{t}^{w+}\right|$ and $\left|S_{t}^{w-}\right|$ represent the absolute value of positive and negative surprises in withdrawal seasons and $\left|S_{t}^{I+}\right|$ and $\left|S_{t}^{I-}\right|$ are the absolute value of positive and negative surprises during the injection seasons, respectively. $R_{t}, \alpha_{0}$ and $\varepsilon_{t}$ are defined as in equation (3-3). Based on Hypothesis 2, we expect $\alpha_{1}^{w+}$ and $\alpha_{2}^{w-}$ to have smaller magnitudes than $\alpha_{1}^{I+}$ and $\alpha_{2}^{I-}$.

To determine whether futures prices respond to surprises differently at different underlying inventory levels (Hypothesis 3), we use the threshold model ${ }^{7}$ developed by Hansen (2000) which considers the relationship between the dependent and independent variables at different regimes, with the regimes determined based on the value of a threshold variable. In the present study, we use the inventory-to-use ratio, or the level of inventory divided by the total amount of monthly natural gas demand, as a threshold variable. The inventory-to-use ratio is often used as a normalized measure of the underlying market condition, with a higher value suggesting greater availability of natural gas given the current demand.

\footnotetext{
7 The threshold regression analysis is conducted in STATA 16.0. Further information on the estimation of parameters in thereshold model can be found here: https://www.stata.com/manuals/tsthreshold.pdf
} 
Consider a two-regime threshold model:

$$
\begin{aligned}
& R_{t}=\alpha_{0}+\alpha_{1}^{+}\left|S_{t}^{+}\right|+\alpha_{2}^{-}\left|S_{t}^{-}\right|+\varepsilon_{1 t} \text { if } q_{t} \leq \gamma, \\
& R_{t}=\alpha_{0}+\alpha_{3}^{+}\left|S_{t}^{+}\right|+\alpha_{4}^{-}\left|S_{t}^{-}\right|+\varepsilon_{1 t} \text { if } q_{t}>\gamma
\end{aligned}
$$

where $q_{t}$ is the threshold variable that splits the observations into two regimes, $\gamma$ is the optimal threshold value which is estimated by minimizing the sum of squared residual (SSR) for all possible thresholds, and $R_{t},\left|S_{t}^{+}\right|$and $\left|S_{t}^{-}\right|$are defined as in equation (3-3). The effect of EIA announcement surprises is captured by $\alpha_{1}^{+}, \alpha_{2}^{-}, \alpha_{3}^{+}$, and $\alpha_{4}^{-}$in equations (3-5) and (3-6). Additionally, $\alpha_{1}^{+}$and $\alpha_{2}^{-}$are expected to be different from $\alpha_{3}^{+}$and $\alpha_{4}^{-}$if natural gas prices respond to EIA announcement surprises differently in the two regimes. Hypothesis 3 suggests that $\alpha_{3}^{+}$and $\alpha_{4}^{-}$should be of smaller magnitudes than $\alpha_{1}^{+}$and $\alpha_{2}^{-}$.

To evaluate whether the impact of EIA's inventory report on natural gas prices has changed over time (Hypothesis 4), we consider two commonly used methods in the literature. Firstly, we include a linear trend in the regression model, as in equation (3-7). This approach is employed by Ying et al. (2019) to determine the announcement effect of USDA reports on corn and soybean futures prices and Smith and Ubilava (2019) to analyze how weather-related news affects corn and soybeans and wheat futures prices over time.

$$
R_{t}=\beta_{0}+\beta_{1}\left|S_{t}\right|+\beta_{2}\left(\left|S_{t}\right| \times t\right)+\varepsilon_{t}
$$

where $t$ is the time indicator computed as the number of weeks divided by the total number of weeks in the sample and $\left|S_{t}\right|$ is the pooled inventory surprises (including both positive and negative surprises). We also test the potential time-varying effect of EIA's inventory report during withdrawal and injection seasons and for positive and negative inventory surprises separately. 
Depending on the signs of $\beta_{1}, \beta_{2}$ can be either positively or negatively significant so that the combined effect $\left(\beta_{1}+\beta_{2}\right)$ has a smaller magnitude over time (Hypothesis 4$)$.

The second approach is the time-varying parameter (TVP) model which relaxes the constancy restriction on the parameters. TVP models, whose coefficients vary continuously over the sample period, are typically specified in a state-space form (SSF). The linear state-space representation of the TVP model is shown by the following system equations:

$$
\begin{aligned}
& R_{t}=\beta_{t}\left|S_{t}\right|+\varepsilon_{t}, \\
& \beta_{t+1}=\beta_{t}+u_{t}, u_{t} \sim N\left(0, \sigma_{u}^{2}\right),
\end{aligned}
$$

where $\left|S_{t}\right|$ is a vector of $k$ explanatory variables (absolute value of positive and negative inventory surprises), and $\beta_{t}$ is a $k$ dimensional vector of regression coefficients at time $t$ that follows a random walk specification. Equation (3-8) is commonly referred to as the measurement or observation equation while equation (3-9) is the transition equation. The state-space presentation allows unobserved variables to be included in, and estimated along with, the observable variables (Durbin and Koopman, 2001). Kalman filter, a recursive procedure for calculating the optimal estimator of the state vector given all the information available at time $t$ (Arisoy and Ozturk, 2014), is used to estimate the TVP model (Kalman, 1960).

To differentiate the effect of positive and negative surprises in the two seasons (withdrawal vs. injection), we estimate the TVP model (observation equation) in the following form:

$$
R_{t}=\beta_{0}+\beta_{1}\left|S_{t}^{+}\right|+\beta_{2}\left|S_{t}^{-}\right|+\beta_{3}\left(D \times\left|S_{t}^{+}\right|\right)+\beta_{4}\left(D \times\left|S_{t}^{-}\right|\right)+\varepsilon_{t}
$$

The estimated time-varying coefficient for positive (negative) inventory surprise during the withdrawal season is $\widehat{\beta_{1}}+\widehat{\beta_{3}}\left(\widehat{\beta_{2}}+\widehat{\beta_{4}}\right)$ and during the injection season is $\widehat{\beta_{1}}\left(\widehat{\beta_{4}}\right)$. 


\subsection{Estimation Results}

The models discussed in Section 3.4 are estimated using the data from May 22, 2003, to December 12, 2020. For each model, we conduct the analysis for the full sample, as well as the injection and withdrawal seasons. We also separate inventory surprises into pooled, higher-thanexpected (or negative), and lower-than-expected (or positive) inventory surprises. Further, we include lagged returns at 10:25 AM to account for potential autocorrelations in the return sequence in both OLS and threshold models. Finally, we evaluate whether the differences between estimated coefficients of positive and negative surprises, as well as in withdrawal and injection seasons, are statistically significant.

As shown in table (3-2) panel A, natural gas price returns react strongly to the EIA inventory news. The estimated coefficients of the full-sample, positive, and negative inventory surprises are all statistically significant with the expected sign. Consistent with previous literature (Gay et al., 2009; Halova et al., 2014; Gu and Kurov, 2018; Chebbi, 2019), natural gas returns on average negatively react to inventory shocks (pooled inventory surprises) over the sample period.

The negative coefficient for negative inventory surprise implies that returns tend to decrease following a larger-than-expected inventory level from the EIA report. Meanwhile, a lower-than-expected inventory level increases returns. Comparing the estimated coefficients across models, we find that a higher-than-expected inventory surprise leads to larger price responses than a lower-than-expected in the full sample and withdrawal seasons. Furthermore, as shown from table (3-2) panel B, the differences in the magnitude of coefficients between positive and negative surprises in the full sample and withdrawal season are statistically significant. In contrast, a lower-than-expected inventory level (positive surprise) impacts prices during the injection season more than higher-than-expected inventory levels. However, the differences in the 
magnitude between the two estimated coefficients are not statistically significant. Overall, except for the injection season, we find that negative surprise news (higher-than-expected inventory) has a larger market impact than positive surprise news, which confirms the asymmetric effects of inventory surprises proposed in Hypothesis 1.

We now test the second hypothesis that natural gas prices respond differently to inventory surprises depending on the seasons of the year. Consistent with previous studies (e.g., Gay et al., 2009; and Halova et al., 2014), OLS regression results in table (3-2) suggest that responses to positive and negative inventory surprises are larger during the injection than the withdrawal season, with the magnitude of the estimated coefficients for the two seasons statistically different from each other. Overall, our analysis provides strong empirical evidence supporting Hypothesis 2 that inventory shocks generate a larger impact during the injection season than the withdrawal season. As shown in figure (3-1), the differential impact is driven largely due to the relative magnitude of elasticity between supply and demand curves.

Table (3-3) panel A shows the results of the threshold model for the full sample, injection, and withdrawal seasons. The threshold value, which divides the sample period into high- and lowinventory regimes, is slightly higher during the injection $(0.92$, or when the natural gas in storage can meet $92 \%$ of the existing demand) than the withdrawal season (0.89). In all models considered, inventory surprises significantly affect natural gas returns in both "low" and "high" storage levels, and the signs of the estimated coefficients are consistent with the expectation. Table (3-3) again suggests a stronger market response to inventory surprises in injection seasons, as illustrated by the larger magnitudes of the surprise coefficients during the injection than the withdrawal season. 
We further test whether the impact of storage surprises on prices varies depending on the underlying market condition, or the level of inventory (Hypothesis 3). Table (3-3) panel A suggests that the magnitudes of the impacts of EIA inventory surprises, both positive and negative news, appear to be larger in regime 1 (lower inventory scenario) during the withdrawal season. By contrast, in the full sample the responses to positive inventory surprises and in the injection season to both positive and negative inventory surprises are stronger in regime 2 (higher inventory scenario). Table (3-3) panel B further suggests that the differences of positive inventory surprises between regimes 1 and 2 in the injection season and the differences of negative inventory surprises during the withdrawal season are statistically significant at the $10 \%$ significance level. Results in table (3-3) provide empirical support for Hypothesis 3 that inventory surprises have a larger impact when the underlying market is in tight supply in withdrawal season, but not during the injection season.

Our findings from the threshold regression models during the injection and withdrawal seasons are in general consistent with Efimova and Serletis (2014) and Ergen and Rizvanoghlu (2016) who find a seasonally asymmetric impact of storage levels on natural gas prices. Ergen and Rizvanoghlu (2016) show that storage levels lower than the five-year historical average increase short-term volatility during the winter months, while in other seasons high storage levels tend to cause excess volatility. They attribute the heterogeneous responses to the changing concerns of market practitioners during different seasons. In the winter, low storage levels are perceived as signaling an environment of scarce supply that causes excess volatility. At other times, the market is mainly concerned with the supply of storage space. Therefore, higher-than-expected storage levels may cause excess volatility in the injection season. 
Finally, we run the regression model with a time trend and the TVP model to uncover the time-varying effect of EIA's inventory news on the natural gas market. Estimation results of the OLS model are presented in table (3-4). The estimated coefficients associated with the time trend are either non-significant or acting to decrease the combined estimated effects of inventory surprises when significant. Our results suggest that the market reactions to EIA's inventory news have decreased significantly or remained the same over time. In particular, the value of EIA's inventory report has declined in the full sample and during the injection seasons. Further, negative surprises overall exert a smaller impact over the sample period.

For the TVP model, we first use a dummy variable ( 1 being in the withdrawal seasons and 0 in the injection seasons) to remove seasonality from the data. Additionally, we estimate two versions of the TVP model, with parameters assumed to follow 1) a random walk specification and 2) an integrated second-order random walk. The results of these time-varying coefficients are presented in figures (3-5) and (3-6). The estimated parameters for more-than-expected (negative) inventory surprises are negative since a larger inventory represents a negative shock to the market. At first glance, the parameter estimates have been somewhat volatile over the entire sample period, suggesting that the effect of EIA inventory surprises has undergone significant changes over the sample period.

While it is hard to generalize a trend of the estimated coefficient, the impact of EIA inventory news is decaying over certain sub-periods. For instance, the effect of positive surprises in both withdrawal and injection seasons gradually declined between 2003 and 2005, and this reduction becomes more evident after 2012 until the end of the sample. For larger-than-expected inventory surprises, since the coefficients for the estimated announcement effects are negative, a 
closer to zero value means the impact is smaller. As can be seen, the impact of negative surprises, or the magnitude of the estimated coefficients for larger-than-expected inventories, decreased in 2003-2008 and again in 2012-2020 during the withdrawal and injection seasons.

The declining impact of EIA inventory report may be driven, in part, by the greater availability of public and private information providers, especially in the era of big data, which has made EIA inventory surprises less important. Further, as noted earlier, the lower uncertainty about well productivity, faster production rate, and more flexibility to trade and produce natural gas may have flattened the natural gas supply curve in the U.S. Compared to before the shale revolution, a same magnitude of external shocks may now exert a much smaller impact on prices. The increasing availability of natural gas, together with the tremendous improvement in pipeline infrastructure over the past decade, has further strengthened the linkage in regional U.S. natural gas markets. The impact of EIA inventory surprises may have been further mitigated by the faster and more efficient information flow between production and consumption regions.

\subsection{Conclusions and Discussions}

This study seeks to comprehensively analyze the effect of EIA's natural gas inventory report on natural gas returns. To this end, we propose, and test four hypotheses based on previous literature and theoretical frameworks. The first hypothesis focuses on the difference between the price responses to positive surprise (lower-than-expected inventory level) and negative surprise (higher-than-expected inventory level). The second hypothesis concerns whether the impact of inventory surprises varies during injection and withdrawal seasons. In the third hypothesis, we explore whether the effect of inventory surprises differs depending on underlying market 
conditions. Finally, the last hypothesis focused on natural gas price reaction to the EIA's inventory report over the years.

Overall, we find natural gas prices react differently to positive versus negative storage surprises. Negative surprises (more-than-expected) have larger impacts than positive surprises (less-than-expected) during withdrawal season and full sample, confirming the asymmetric response of prices to good and bad news in the natural gas market. We also find the impact of EIA's report on natural gas prices is more prominent in low inventory regimes for withdrawal seasons. Further, announcement effects are, on average, larger during the injection season than the withdrawal season. The results of time-varying analyses indicate that while the EIA inventory report is still influential in natural gas futures markets, these impacts generally decreased over the sample period studied.

Understanding the inventory shocks transmission mechanism in natural gas markets is essential to financial practitioners and market participants involved in natural gas trading, exploration, production, and transportation. Our results show that the EIA inventory report still provides valuable information and significantly affects market prices. By processing and trading on the information contained in the inventory report, market participants assist in price discovery in futures trading (e.g., Gay et al., 2009; Ederington et al., 2019). On the other hand, our results also indicate that the natural gas futures market's reaction to EIA inventory reports has declined over some specific time periods. Future research may be useful in evaluating the importance of EIA inventory reports relative to alternative information providers, as recently conducted by Alturki and Kurov (2020) for oil market inventory announcements. 
Tables and Figures

Table 3-1 Summary statistics of inventory surprise and futures return

\begin{tabular}{|c|c|c|c|c|c|}
\hline & Mean & Min & Max & SD & No.Obs \\
\hline \multicolumn{6}{|l|}{ Inventory Surprise (Injection Season) } \\
\hline Negative Surprise (higher-than-expected) & 0.637 & 0.111 & 2.67 & 0.476 & 252 \\
\hline Positive Surprise (lower-than-expected) & -0.58 & -3.46 & -0.11 & 0.417 & 224 \\
\hline \multicolumn{6}{|l|}{ Inventory Surprise (Withdrawal Season) } \\
\hline Negative Surprise (higher-than-expected) & 0.968 & 0.111 & 5.79 & 0.811 & 157 \\
\hline Positive Surprise (lower-than-expected) & -0.94 & -6.8 & -0.11 & 0.818 & 154 \\
\hline \multicolumn{6}{|l|}{ Futures Return } \\
\hline 10:25-10:40 (including EIA announcement) & -0.186 & -7.04 & 7.57 & 1.59 & 834 \\
\hline 10:10-10:25 (before EIA announcement) & 0.0083 & -1.35 & 1.18 & 0.337 & 834 \\
\hline \multicolumn{6}{|l|}{ Absolute Return } \\
\hline 10:25-10:40 (including EIA announcement) & 1.168 & 0 & 7.57 & 1.09 & 834 \\
\hline 10:10-10:25 (before EIA announcement) & 0.0083 & 0 & 1.18 & 0.06 & 834 \\
\hline
\end{tabular}


Table 3-2. Impacts of EIA inventory reports on natural gas return using OLS model

Panel A: impacts of pooled, positive, and negative inventory surprises on natural gas return (dependent variable: $y_{t}$ (15- minute natural price returns at 10:40 AM))

\begin{tabular}{|c|c|c|c|c|c|c|c|c|c|c|c|c|}
\hline \multirow[t]{2}{*}{ RHS Var } & \multicolumn{4}{|c|}{ Full Sample } & \multicolumn{4}{|c|}{ Injection Season } & \multicolumn{4}{|c|}{ Withdrawal Season } \\
\hline & (1) & (2) & (3) & (4) & (5) & (6) & (7) & (8) & (9) & (10) & (11) & (12) \\
\hline$\left|S_{t}\right|$ & $-0.23 * * *$ & $-0.23 * *$ & & & -0.16 & -0.15 & & & $-0.25 * *$ & $-0.25 * *$ & & \\
\hline$\left|S_{t}^{-}\right|$ & & & $-1.06 * * *$ & $-1.07 * * *$ & & & $-1.14 * * *$ & $-1.14 * * *$ & & & $-0.93 * * *$ & $-0.94 * * *$ \\
\hline$\left|S_{t}^{+}\right|$ & & & $0.75^{* * *}$ & $0.77 * * *$ & & & $1.52 * * *$ & $1.62 * * *$ & & & $0.46^{* * *}$ & $0.45^{* * *}$ \\
\hline$R_{t-1}$ & & $0.3^{* *}$ & & -0.1 & & 0.22 & & $-0.3^{*}$ & & $0.42 * *$ & & 0.04 \\
\hline Constant & -0.02 & $0.73 * * *$ & -0.03 & -0.02 & -0.03 & -0.03 & $-0.15^{*}$ & $-0.17 *$ & 0.04 & -0.03 & $-0.04 * * *$ & -0.023 \\
\hline $\mathrm{N}$ & 834 & 834 & 834 & 834 & 505 & 505 & 505 & 505 & 329 & 329 & 329 & 329 \\
\hline
\end{tabular}

Panel B: statistically significant test of the differences between the magnitudes of estimated coefficients of inventory surprise variable

\begin{tabular}{|c|c|c|c|c|c|c|}
\hline$\left|\alpha_{t}^{-}\right|-\left|\alpha_{t}^{+}\right|$ & $0.31 * *$ & $0.3 * *$ & -0.38 & -0.48 & $0.47 * *$ & $0.45 * * *$ \\
\hline$\left|\alpha_{t}^{-}\right|_{I}-\left|\alpha_{t}^{-}\right|_{W}$ & & & $0.21 * *$ & $0.2^{*}$ & $0.21 * *$ & $0.2^{*}$ \\
\hline$\left|\alpha_{t}^{+}\right|_{I}-\left|\alpha_{t}^{+}\right|_{W}$ & & & $1.06 * *$ & 1.17 & $1.06 * *$ & 1.17 \\
\hline
\end{tabular}

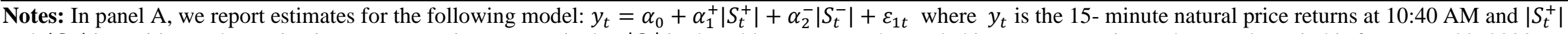

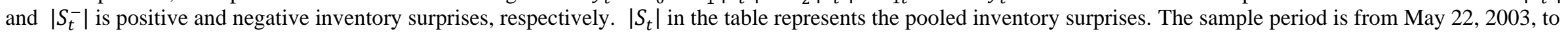
December 12, 2020, resulting in 834 observations. Panel B reports the statistical significance of the differences between estimated coefficients of inventory surprises.

$* * * 0.01, * * 0.05$, and $* 0.10$ indicate significance levels. 
Table 3-3. Impacts of EIA inventory reports on natural gas volatility using threshold model

Panel A: impacts of pooled, positive, and negative inventory surprises on natural gas return (dependent variable: $R_{t-1}(15-$ minute natural price returns at 10:40 AM))

\begin{tabular}{|c|c|c|c|c|c|c|c|c|c|c|c|c|}
\hline \multirow[b]{3}{*}{ RHS Var } & \multicolumn{4}{|c|}{ Full sample (threshold=0.92) } & \multicolumn{4}{|c|}{ Injection season $($ threshold=0.92) } & \multicolumn{4}{|c|}{ Withdrawal season $($ threshold=0.89) } \\
\hline & \multicolumn{2}{|c|}{ (1) } & \multicolumn{2}{|c|}{ (2) } & \multicolumn{2}{|c|}{ (3) } & \multicolumn{2}{|c|}{ (4) } & \multicolumn{2}{|c|}{ (5) } & \multicolumn{2}{|c|}{ (6) } \\
\hline & $<\mathrm{TR}$ & > TR & $<\mathrm{TR}$ & $>\mathrm{TR}$ & $<\mathrm{TR}$ & $>\mathrm{TR}$ & $<\mathbf{T R}$ & > TR & $<\mathbf{T R}$ & $>T R$ & $<\mathbf{T R}$ & $>\mathrm{TR}$ \\
\hline$\left|S_{t}\right|$ & $-0.47 * *$ & $-0.16^{*}$ & & & 0.03 & -0.21 & & & $-0.55^{* *}$ & $-0.14^{*}$ & & \\
\hline$\left|S_{t}^{-}\right|$ & & & $-1.09 * * *$ & $-1.08 * * *$ & & & $-1.23 * *$ & $-1.28 * * *$ & & & $-1.2 * * *$ & $-0.8 * * *$ \\
\hline$\left|S_{t}^{+}\right|$ & & & $0.30 *$ & $0.85 * * *$ & & & $0.73 * *$ & $1.33 * * *$ & & & $0.60 *$ & $0.56 * * *$ \\
\hline Constant & 0.18 & -0.07 & 0.17 & -0.09 & 0.07 & -0.05 & 0.13 & $-0.15^{*}$ & 0.11 & -0.07 & 0.12 & -0.09 \\
\hline $\mathrm{N}$ & 190 & 644 & 190 & 644 & 67 & 438 & 67 & 438 & 116 & 213 & 116 & 213 \\
\hline
\end{tabular}

Panel B: statistically significant test of the differences between estimated coefficients of inventory surprise variable

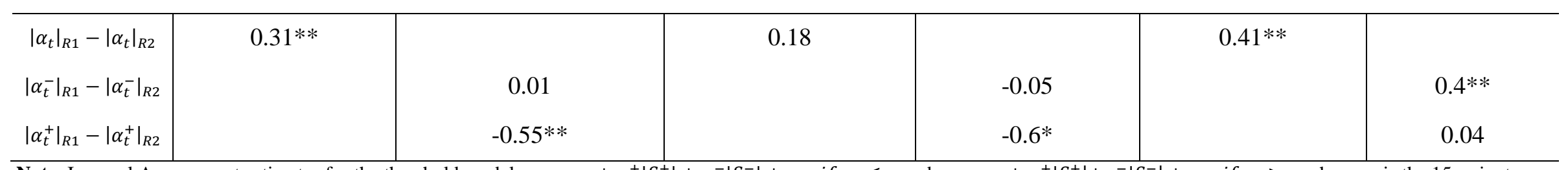

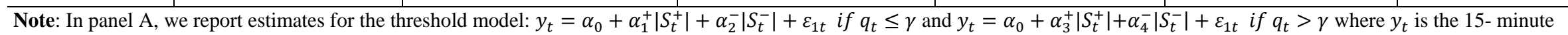

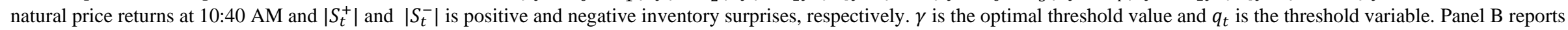

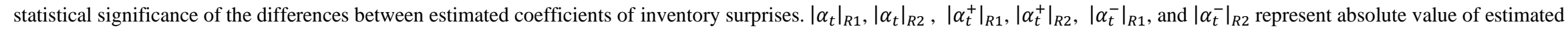
coefficient of pooled surprise in regime 1 , absolute value of estimated coefficient of pooled surprise in regime 2 , absolute value of estimated coefficient of positive surprise in regime 1 ,

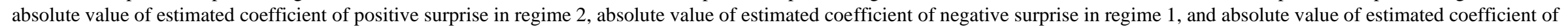
negative surprise in regime 1 , respectively. ${ }^{* * *} 0.01, * * 0.05$, and $* 0.10$ indicate significance levels. 
Table 3-4. Time-varying impact of EIA inventory reports on natural gas futures market (dependent variable: Returns)

\begin{tabular}{|c|c|c|c|c|}
\hline & Estimate & Std.Err & t-stat & P-value \\
\hline \multicolumn{5}{|c|}{ Panel A: Full sample (N=834) } \\
\hline Const & -0.03 & 0.078 & -0.39 & 0.695 \\
\hline$|\mathbf{S}|$ & $-0.366^{* * *}$ & 0.102 & -3.56 & 0.000 \\
\hline$|\mathbf{S}| * \mathbf{t}$ & $0.349 * *$ & 0.1805 & 1.94 & 0.004 \\
\hline \multicolumn{5}{|c|}{ Panel B: Injection season $(\mathrm{N}=505)$} \\
\hline Const & -0.019 & 0.103 & -0.19 & 0.851 \\
\hline$|\mathbf{S}|$ & $-0.384 * *$ & 0.178 & -2.15 & 0.032 \\
\hline$|\mathbf{S}| * \mathbf{t}$ & $0.429 *$ & 0.258 & 1.67 & 0.096 \\
\hline \multicolumn{5}{|c|}{ Panel C: Withdrawal season $(\mathrm{N}=329)$} \\
\hline Const & -0.0708 & 0.132 & -0.53 & 0.001 \\
\hline$|\mathbf{S}|$ & $-0.329 * *$ & 0.132 & -2.49 & 0.013 \\
\hline$|\mathbf{S}| * \mathbf{t}$ & 0.251 & 0.261 & 0.99 & 0.597 \\
\hline \multicolumn{5}{|c|}{ Panel D: Negative Surprise $(\mathrm{N}=409)$} \\
\hline Const & $-0.411 * * *$ & 0.091 & -4.49 & 0.000 \\
\hline$|\mathbf{S}|$ & $-0.972 * * *$ & 0.113 & -8.55 & 0.000 \\
\hline$|\mathbf{S}-|^{*} \mathbf{t}$ & $0.553 * *$ & 0.193 & 2.86 & 0.004 \\
\hline \multicolumn{5}{|c|}{ Panel E: Positive Surprise (N=378) } \\
\hline Const & $0.338 * * *$ & 0.109 & 3.09 & 0.000 \\
\hline$\left|\mathbf{S}^{+}\right|$ & $0.359 * *$ & 0.133 & 2.69 & 0.008 \\
\hline$\left|\mathbf{S}^{+}\right| * \mathbf{t}$ & 0.204 & 0.238 & 0.86 & 0.391 \\
\hline
\end{tabular}

Note: This table reports the estimates for the following model: : $y_{t}=\beta_{0}+\beta_{1}\left|S_{t}\right|+\beta_{2}\left(\left|S_{t}\right| \times t\right)+\varepsilon_{t}$ where $y_{t}$ is 15-minute natural price returns at 10:40 AM. $\left|S_{t}\right|$ is the inventory surprises and $t$ is the time indicator which is calculated as the number of weeks divided by the total number of weeks in our series. 
Panel A: Withdrawal Season:

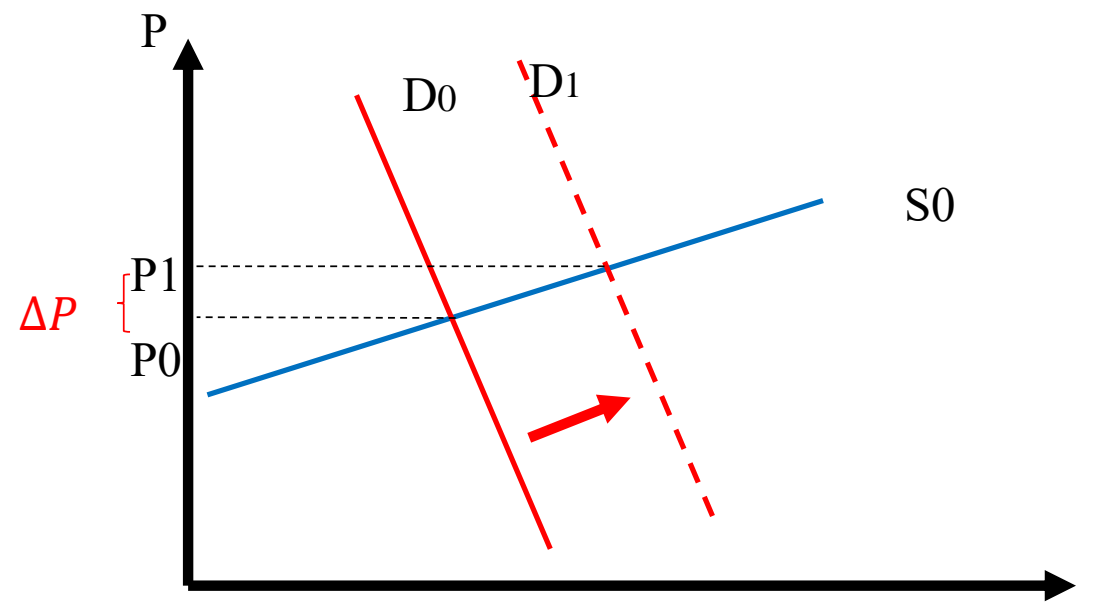

Q

Panel B: Injection Season:

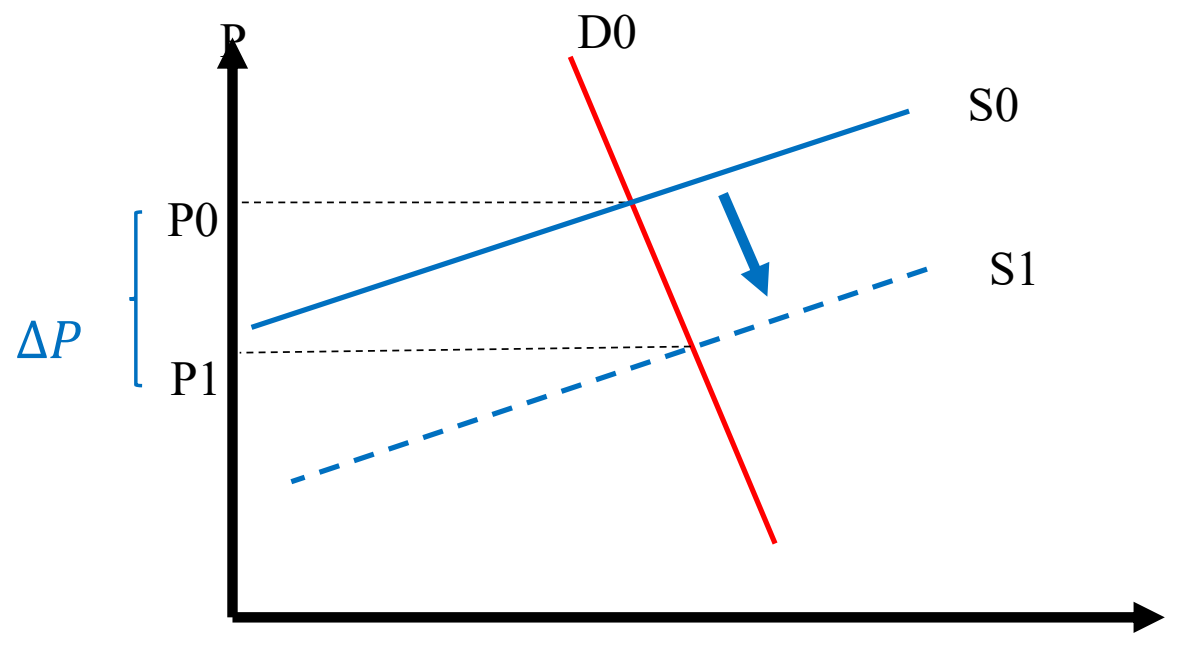

Q

Figure 3-1. Supply and demand shift during withdrawal and injection season 


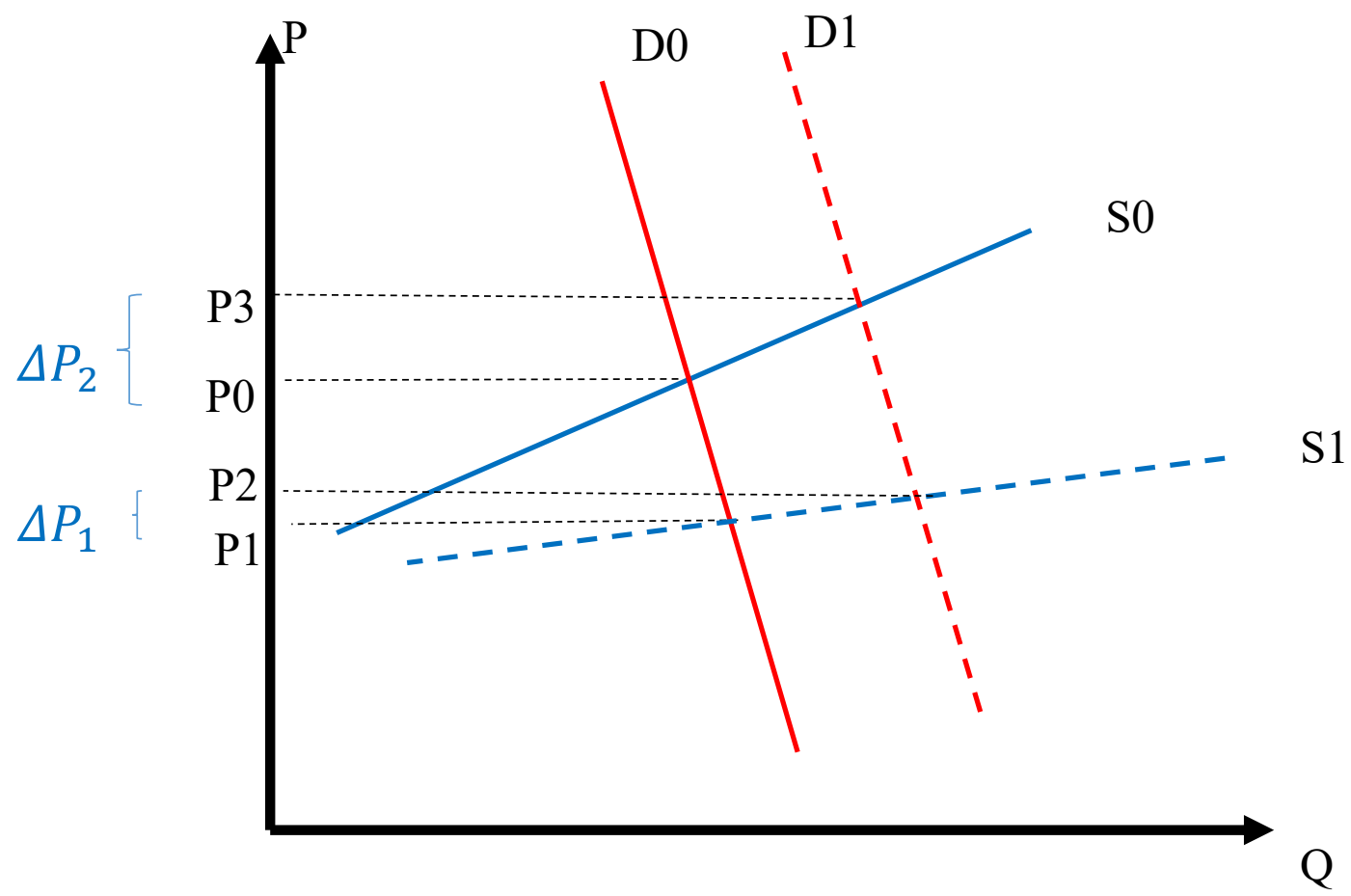

Figure 3-2. Supply and demand for natural gas 


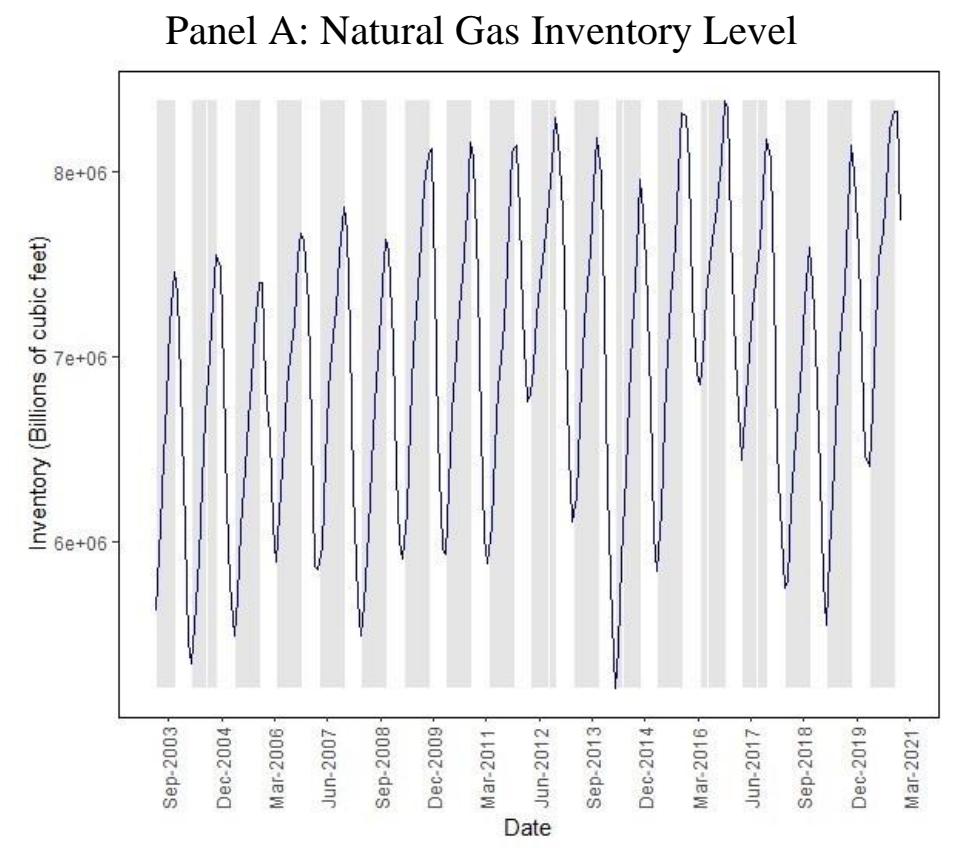

Panel B: Natural Gas Inventory Surprises

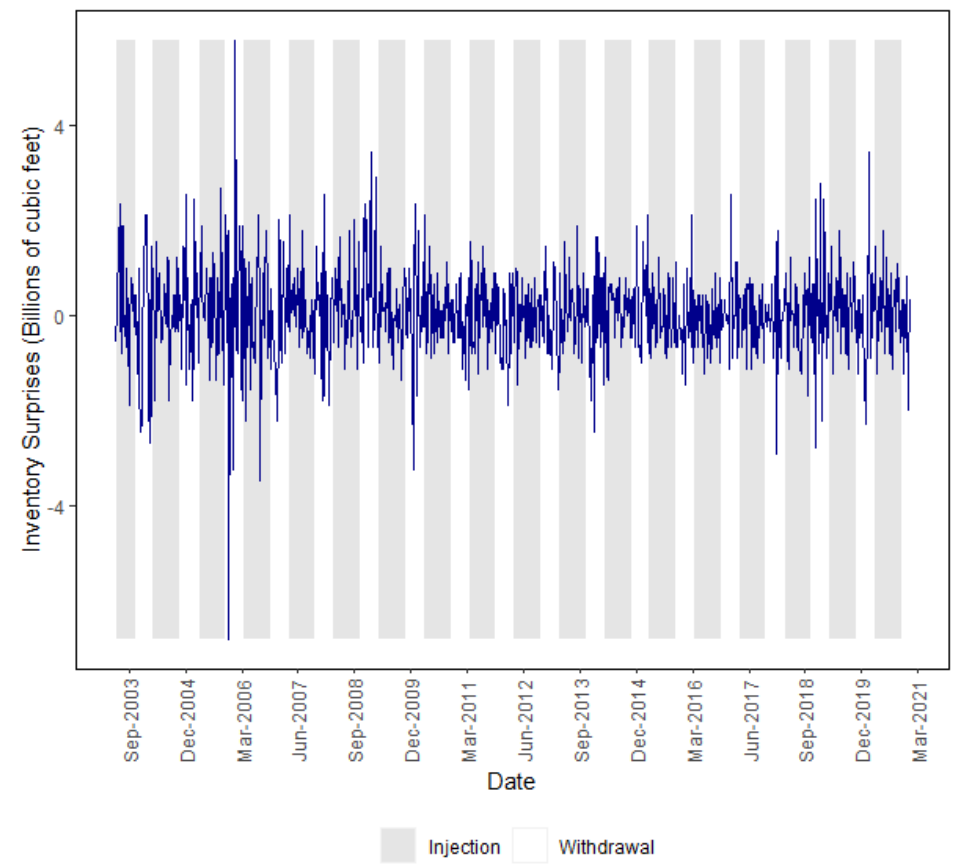

Figure 3-3. Natural gas inventory changes

Note: Figure (3-3) Panel A depicts the natural gas inventory level surprises. Panel B shows the natural gas inventory Surprises. The shaded area shows the natural gas inventory surprises during injection season. 


\section{Return 10:10 AM}

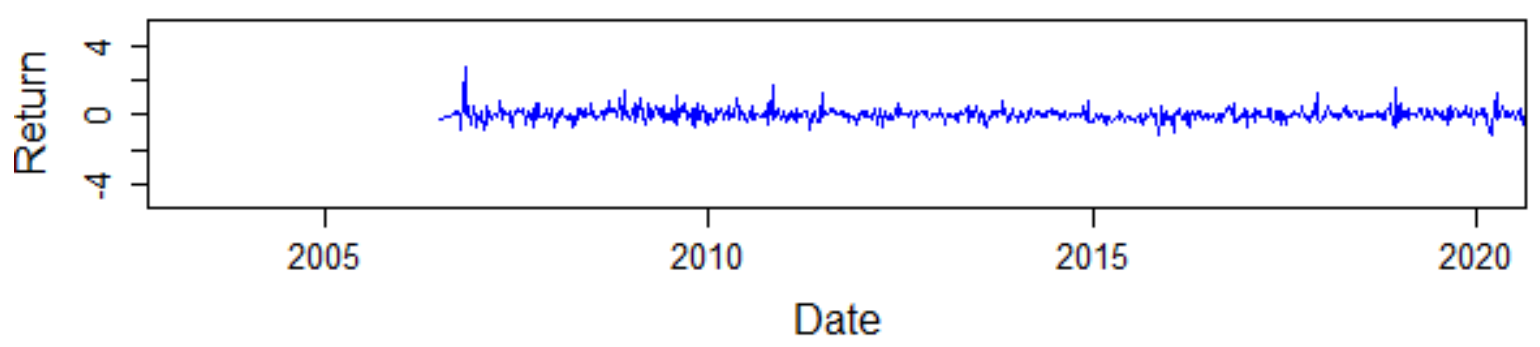

\section{Return 10:25 AM}

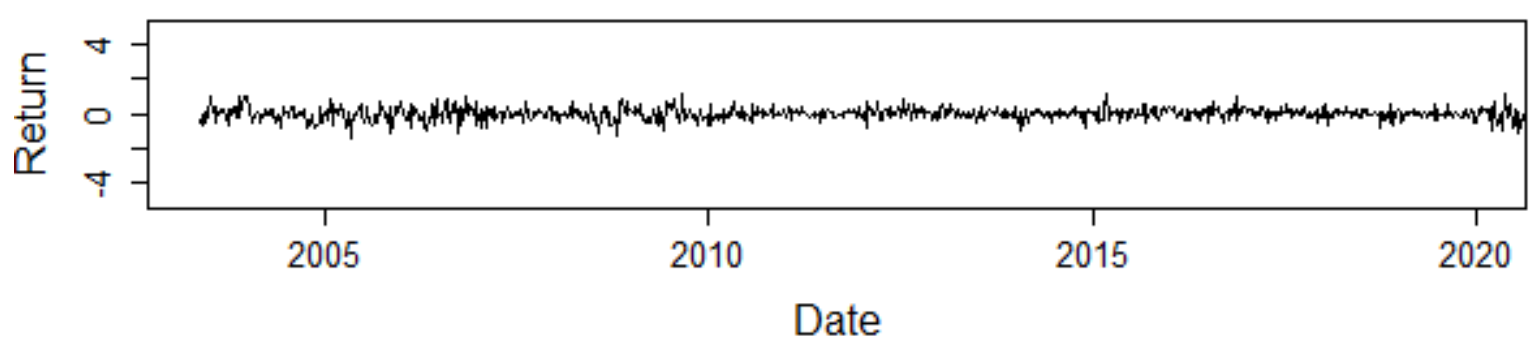

\section{Return 10:40 AM}

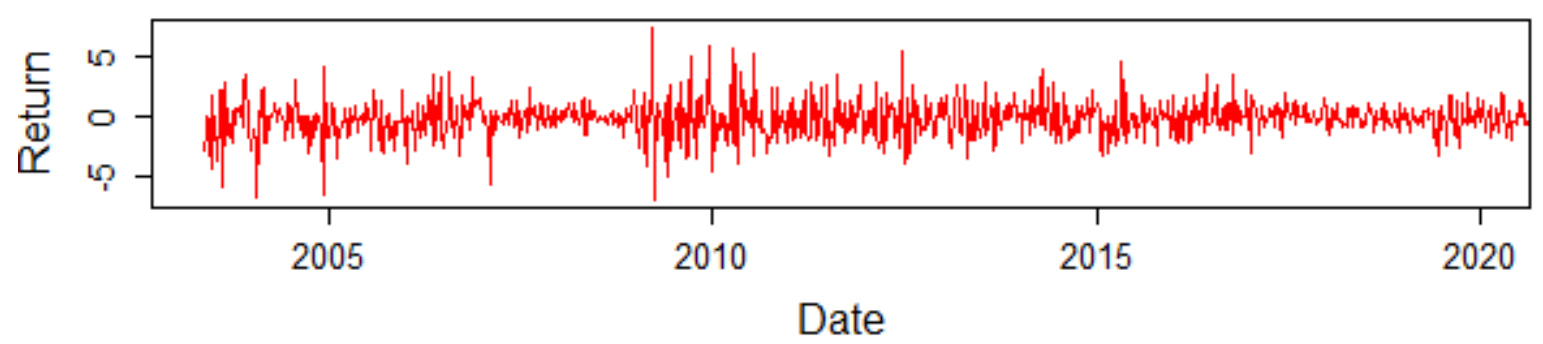

Figure 3-4. Intraday natural gas return

Note: Figure (3-4) plots the natural gas returns at three times (10:10 AM. 10:25 and 10:40 AM). Returns are calculated based on a 15-minute event time interval. 
Panel A: Negative (more-than-expected) Surprises
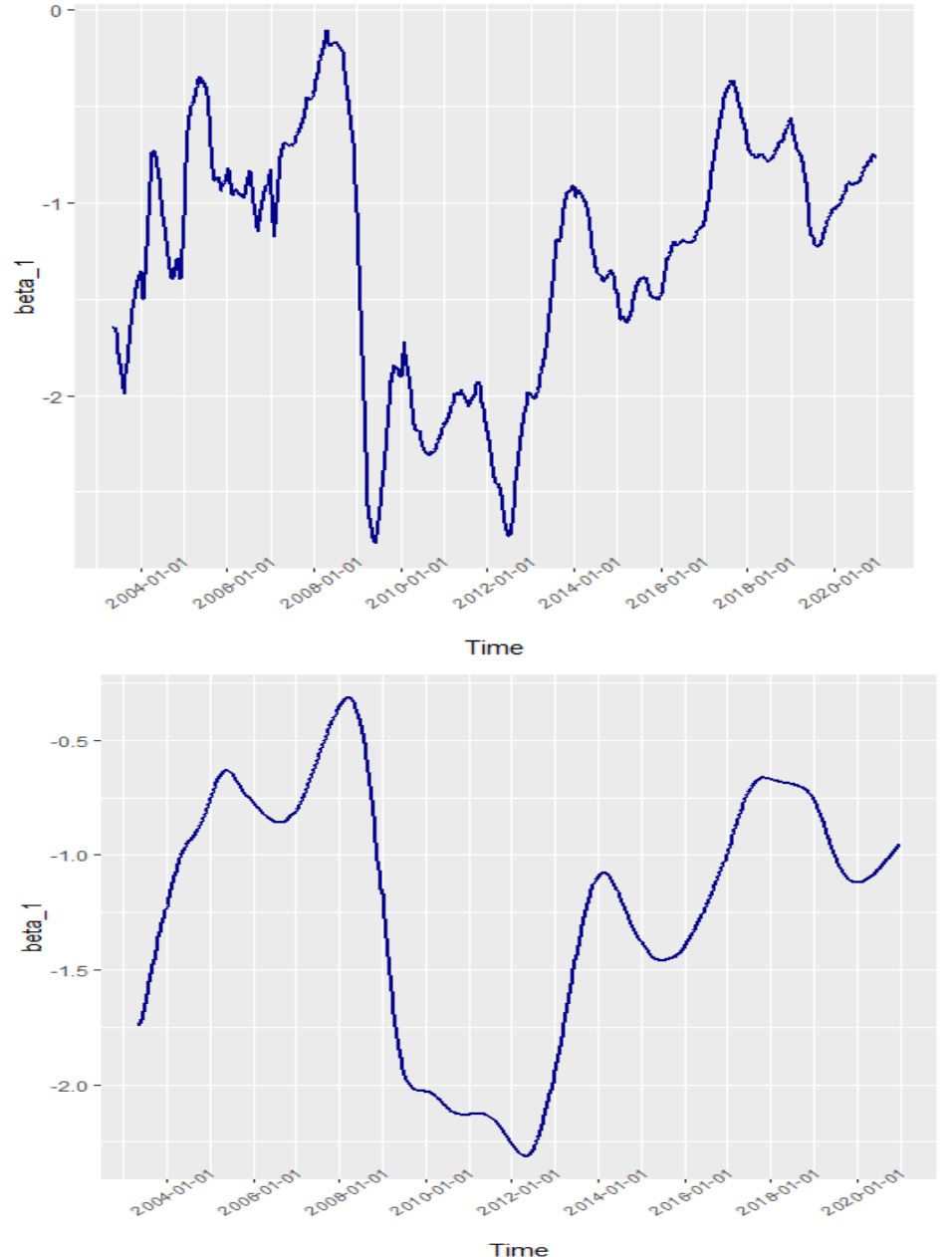

Panel B: Positive (less-than-expected) Surprises
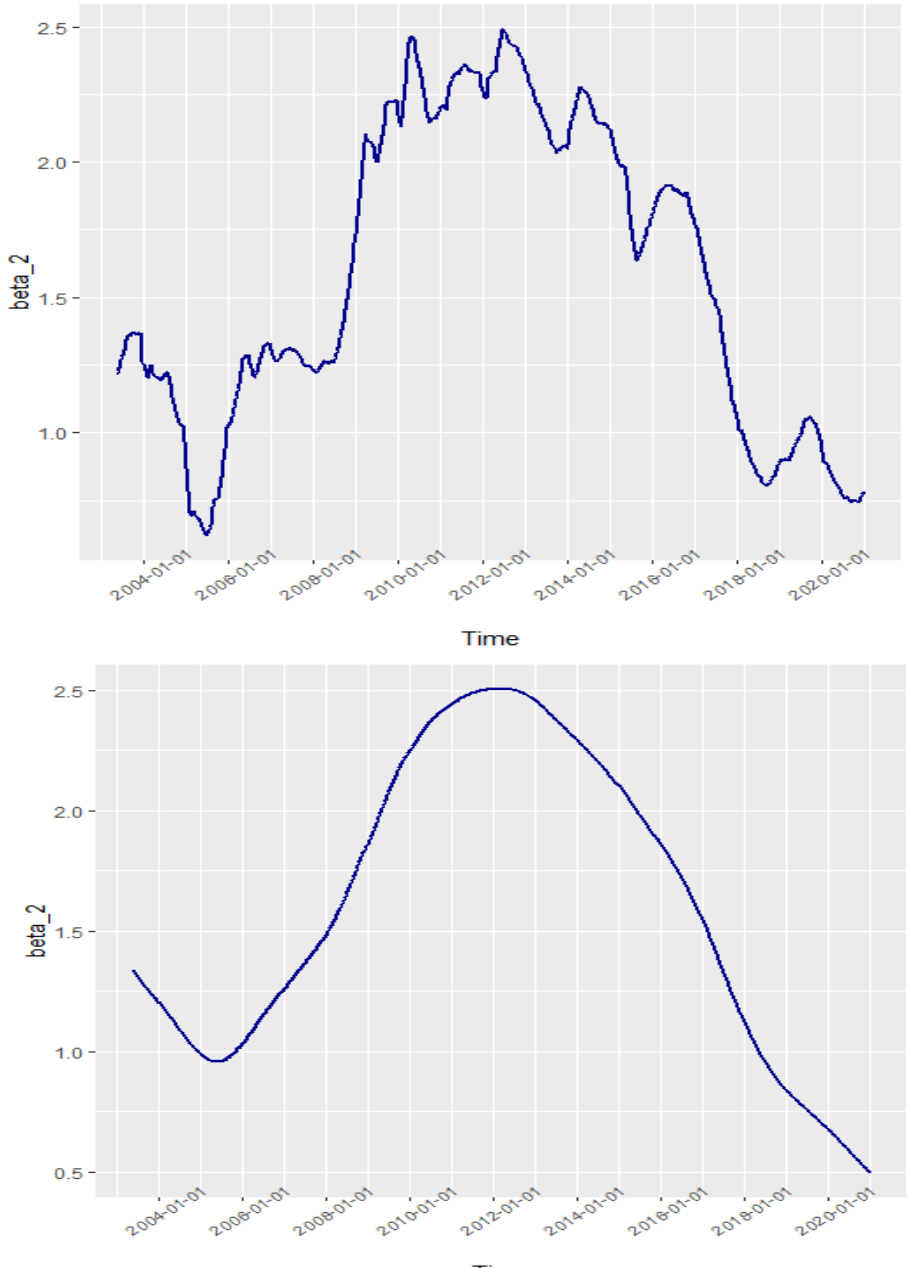

Time

Figure 3-5. Time-varying parameters for withdrawal season

Note: The figure plots time-varying coefficients for negative (panel A) and positive surprises (panel B) during withdrawal seasons. The bottom figures of each panel show smoothed estimates. 
Panel A: Negative (more-than-expected) Surprises
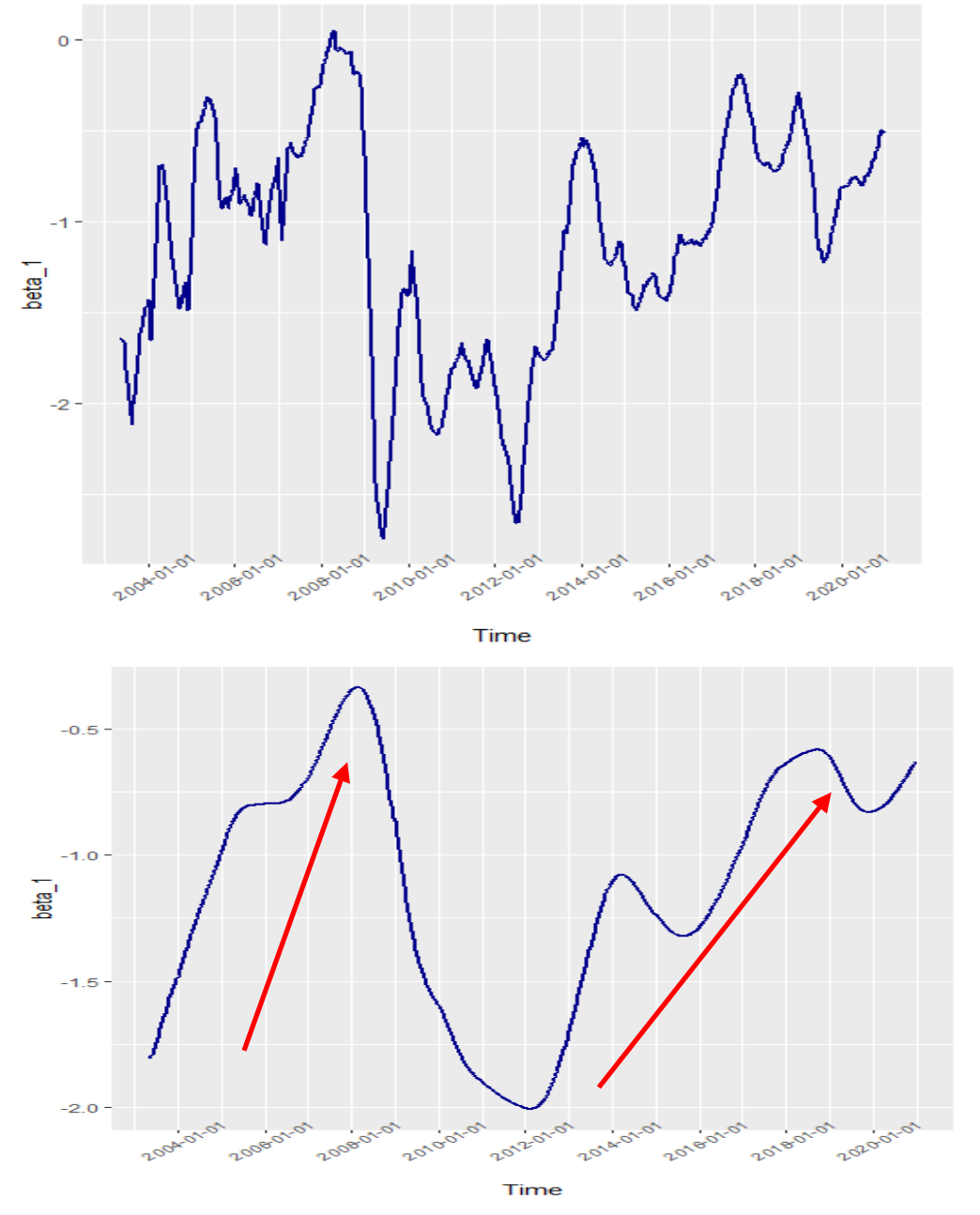

Panel B: Positive (less-than-expected) Surprises
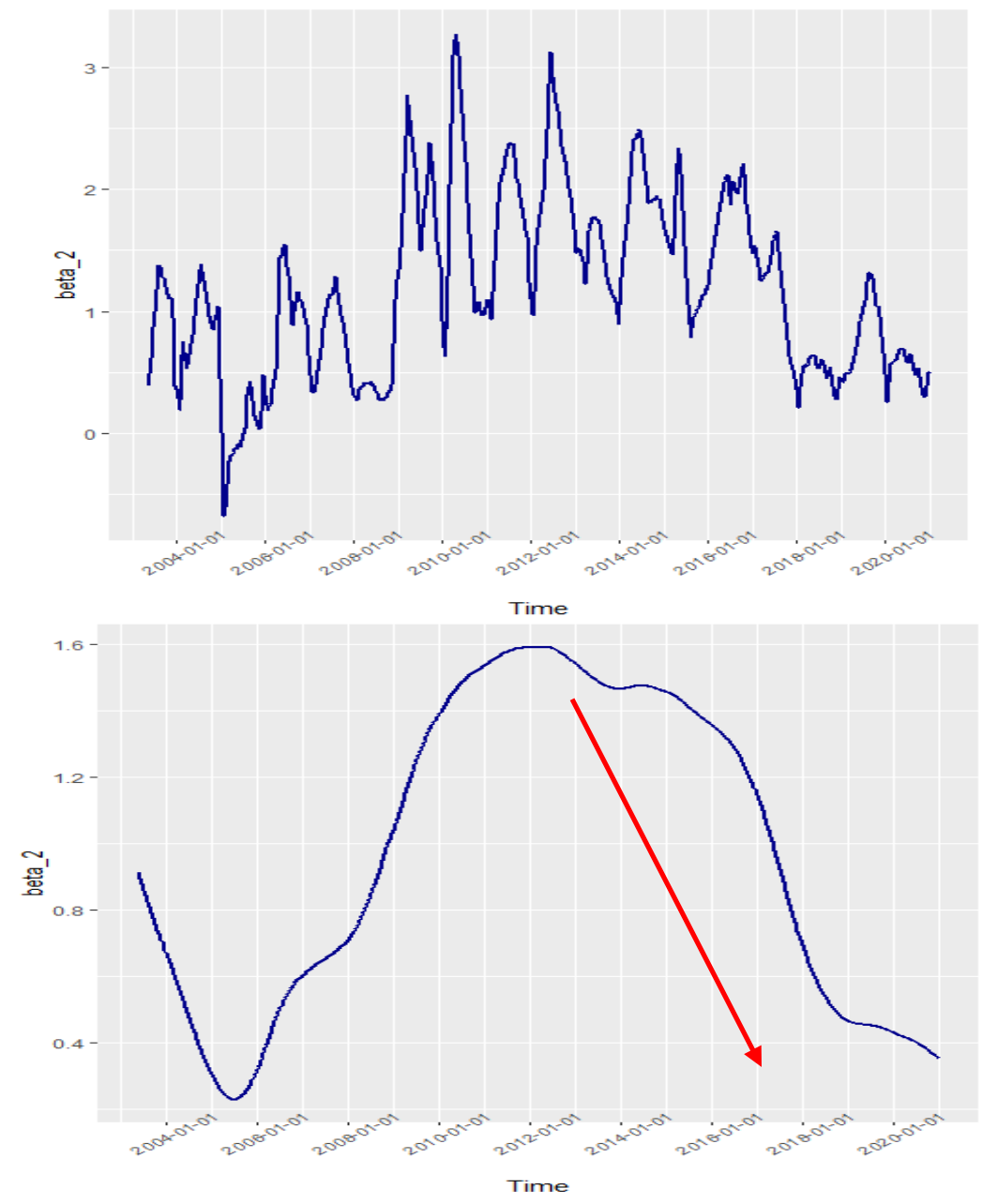

Figure 3-6. Time-varying parameters for injection season

Note: The figure plots time-varying coefficients for negative (panel A) and positive surprises (panel B) during withdrawal seasons. The bottom figures of each panel show smoothed estimates. 


\section{Chapter 4. Forecasting the U.S. Season-Average Farm Price of Corn: Derivation of an Alternative Futures based Forecasting Model}

\subsection{Introduction}

Perhaps one of the most challenging but important tasks for agricultural economists is to provide a timely and reliable forecast of future commodity prices. Accurate price forecasts not only aid market participants in making production and risk management decisions but also help optimize resource allocation and improve overall market efficiency. Over the past few decades, price forecasting has been conducted for almost all agricultural commodities, at various stages along the marketing chain (e.g., farm, wholesale, retail, etc.), for commodities of different qualities and grades (e.g., winter and spring wheat), in different locations (e.g., U.S. Midwest, Gulf Coast, etc.), and at various frequencies (daily, monthly, quarterly, and yearly). Despite a large amount of research (e.g., Garcia et al., 1988; Bessler and Brandt, 1992; Sanders and Manfredo, 2005; Isengildina-Massa et al., 2013; Hoffman et al., 2015; Xu, 2018), the existing literature has found mixed results toward the best practices to follow when generating agricultural commodity prices' forecasts, and whether any forecasts based on econometric or structural models can consistently outperform futures-based forecasts.

In this paper, we develop an alternative futures-based procedure to forecast the seasonaverage farm price (SAFP) for corn in the US. Corn is the most widely produced feed grain in the U.S., accounting for over 95 percent of total production and use (ERS, 2018), and is used as an input for ethanol production, animal feed, and many related industries. Corn price fluctuations have ripple effects that extend well beyond the corn industry itself. The past decade has witnessed high volatility in many agricultural commodities, with corn futures prices jumping to a record high 
in the first half of 2008 and subsequently more than halved in the following months. In 2010-2012, corn prices experienced another bout of volatility when prices rose above $\$ 8 /$ bushel. Over the past few years, corn prices have fluctuated between $\$ 3.5$ and $\$ 5.5 /$ bushel. These large price swings have generated much concern about market participants' ability to manage adverse price movements, as the risk associated with grain merchandising and the cost of hedging at commodity futures exchanges had dramatically increased (McPhail et al., 2012).

While price forecasts cannot eliminate all risks associated with adverse price movement, a reliable price signal provides the necessary information for market participants to make more informed decisions that could help mitigate the ramifications of price volatility. The SAFP, sometimes known as the marketing year average price, represents the average price received by U.S. producers throughout the marketing year for all grades and qualities of the crop. Information regarding SAFP is crucial to a variety of market participants, including producers who make production and marketing decisions, elevator operators and millers who make purchase and storage decisions, market analysts who assess the impacts of domestic and international developments, and policymakers who administer commodity programs. The SAFP for corn, in particular, is a key parameter used to assess the financial health of the U.S. corn sector and determine the commodity program payments. For example, under the Agricultural Act of 2014 and Agricultural Improvement Act of 2018, the SAFP for corn is a core input for calculating the Price Loss Coverage (PLC) payment rates and Agriculture Risk Coverage (ARC) payment rates (Claassen and Effland, 2014, Zulauf and Schnitkey, 2014).

Currently, there are two main SAFP forecasts closely watched by market participants: the U.S. Department of Agriculture's (USDA) monthly World Agricultural Supply and Demand Estimates (WASDE), a benchmark for industry comparisons, and the USDA Economic Research 
Services (ERS) futures-based forecast developed by Hoffman (2005) and Hoffman et al. (2007). Hoffman et al. (2015) show that not only do both SAFP forecasts contain large prediction errors, with the root mean squared error during growing season ranging from $\$ 0.32$ to $\$ 0.51 /$ bushel over the 1980-2012 period, but the forecasts tend to perform poorly during periods of volatile prices. It is necessary to develop alternative forecasting procedures to complement these existing SAFP forecasts.

We propose to forecast corn SAFP by weighting the monthly cash price forecasts generated through nearby futures and previous-period cash prices, using monthly marketing weights for a given marketing year. The rationale behind this approach is that both futures and cash markets both contribute significantly to commodity price discovery (Arnade and Hoffman, 2015; Garbade and Silber, 1983), and a time-varying composite forecast based on futures and cash prices could potentially improve the performance of existing procedures, in particular those based primarily on futures prices. Similar to the Hoffman model, the proposed model uses only publicly available information and hence may fail to outperform forecasts with superior/private information if the market is weakly efficient. (Fama, 1991; Malkiel and Fama, 1970)

We find that our proposed model performs well against the WASDE and the Hoffman futures-based forecast, especially at the beginning of the post-harvest season. Further, the proposed forecast appears to perform similarly or better than the Hoffman futures-based forecasts in almost all months except for July and October. We attribute the satisfactory performance of the proposed model forecasts to the assignment of heterogeneous weights to futures and cash prices depending on the underlying market conditions. Additionally, we find that the relative performance of the proposed forecast improves when the market becomes more volatile. Compared to 1990/19912004/05, the proposed forecasts demonstrated better performance in 2005/06-2019/20, a period 
marked with significantly higher volatility. Overall, the proposed method complements and provides incremental information to the existing SAFP forecasts for corn.

The next section discusses the existing SAFP forecasts and the proposed forecasting method. Section three presents the forecast evaluation framework. Results are discussed in section four, and section five concludes the paper.

\subsection{Season Average Price Forecasts and Proposed Forecasting Model}

Season average prices represent the weighted average monthly prices of a crop received by farmers for a given marketing year, which starts in September and ends in the following August for corn. At the end of each month, the National Agricultural Statistics Service (NASS) of the USDA publishes the Agricultural Prices report that contains the cash prices received by farmers for various agricultural commodities in preceding months. The sales data are collected from a sample of about 1,900 mills and elevators, with the States being surveyed accounting for over 90 percent of the total U.S. production (NASS, 2018). The survey data are further adjusted using appropriate weights (based on the quantity) to produce the monthly cash prices at both the state and national levels. Typically, the cash price for a given month is available in the Agricultural Prices report released at the end of the following month. Prior to January 2015, the report also contained the mid-month cash prices received by farmers in the current month. After the conclusion of the marketing year, NASS publishes the SAFP in the preceding year, which is a quantity-weighted average of monthly cash prices.

A typical SAFP forecast for grain commodities starts prior to the beginning of a marketing year as market participants need such information to make sales, procurement, and risk management strategies. Table (4-1) shows the timeline of corn SAFP forecasts for the 2010/11 
marketing year (September 2010-August 2011). The first SAFP forecast was released in May 2010, just after most of the corn crop in the U.S. had been planted. The forecast was then updated monthly until reaching the end of the marketing year. In September 2011, the actual SAFP for corn in 2010/11 was released as all sales information had been known. In total, one SAFP forecast cycle for corn includes 16 forecasts, with the $1^{\text {st }}$ forecast made in May preceding the marketing year and the $16^{\text {th }}$ made in the last month of the marketing year (August).

The SAFP forecast cycle for corn covers the growing season (May to August), the harvest season (September to December), and the post-harvest season (January to August of the following year). If we define the forecast made in August 2011 as the 1-month ahead forecast, then the forecasts made in the growing season represent the projections made 16- to 13-months ahead, while in the harvest and post-harvest seasons, the forecasts represent the projections made 12- to 9-months ahead and 8- to 1-month ahead, respectively. Unlike monthly or quarterly forecasts typically available only a few periods prior to the actual date, evaluating the performance of the SAFP forecasts, therefore, requires assessing the accuracy of 16 consecutive forecasts through any given forecast cycle, although these forecasts tend to be highly correlated (Hoffman et al., 2015).

Additionally, the SAFP forecast involves analyzing and predicting the cash prices received by farmers for each month during the marketing year, as well as determining their relative importance in the marketing cycle. These added complexities make the SAFP forecast a challenging task for practitioners and market analysts.

\subsection{WASDE Season-Average Price Forecasts For Corn}

The USDA periodically publishes market reports for various agricultural commodities. One such report is the World Agricultural Supply and Demand Estimates (WASDE), typically 
released around the second week of each month. The WASDE report contains forecasts on production, consumption, inventory, and prices for major agricultural commodities, including monthly estimates of the SAFP for various crops, a benchmark for industry comparisons.

The specific procedure used by the WASDE to generate the SAFP forecast is complicated. Briefly, USDA Interagency Commodity Estimates Committees (ICECs), one for each commodity, compile and use information from a diverse set of USDA and other domestic/foreign official sources to produce the report. Hoffman et al. (2015) note that the projection process "involves the interaction of expert judgment, econometric price forecasting models, futures prices, market information, and in-depth research by USDA analysts on key domestic and international issues." 8 Because of its potential impact on the market, the WASDE report is prepared under strict confidentiality, not known to any entities (except the analysts preparing the report) until its release time through a "lock-up" procedure.

As the ICECs may have access to information not known to the public, WASDE price projections may outperform alternative SAFP forecasts. Indeed, previous studies find that commodity futures prices react significantly to WASDE reports and that the reports lead to better resource allocation decisions by realigning market participants' expectations (Adjemian, 2012; Garcia et al., 1997; Mattos-Silveira, 2016; Summer and Mueller, 1989). However, the informational value of USDA reports has been constantly debated in the literature as the private industry increasingly participates in the collection and distribution of agricultural market information (Garcia et al., 1997).

\footnotetext{
${ }^{8}$ Further information on how the WASDE is prepared can be found here: https://www.usda.gov/oce/commodity/wasde/prepared.htm accessed on 12/7/2019.
} 
WASDE SAFP forecasts are reported as a range of expected high and low prices. Isengildina-Massa et al. (2010) note that although the price ranges are constructed symmetrically, the distribution of the forecasted prices is asymmetric and the confidence intervals may differ from report to report. Following previous work (Hoffman et al., 2015; Colino et al., 2012), we use the midpoint of the range as WASDE's point forecast for SAFP.

\subsection{Hoffman Futures-Based Forecasts}

The second SAFP projection closely watched by market analysts is the USDA Economic Research Service (ERS) forecast based on Hoffman (2005) and Hoffman et al. (2007) model. ${ }^{9}$ The Hoffman model builds on futures price quotes of nearby contracts, which is subsequently adjusted by a forecasted basis (i.e., the expected differences between cash and futures prices) to produce the expected monthly cash price at the farm level. The monthly cash price forecasts are further aggregated into season-average farm price forecasts using the forecasted monthly marketing weights. When available, actual monthly cash prices are used to replace the forecasted prices. Although the Hoffman forecast is typically released every Thursday, it can be generated daily using the settlement price for the nearby futures contract, as well as generated monthly before and after the WASDE release date to match the WASDE forecast timeline.

The Hoffman SAFP forecast uses existing publicly available data and draws the majority of information from futures price quotes in months when cash prices are unknown. In theory, the futures price provides an unbiased estimate of the cash price for a given delivery location and time period when the market is efficient (Fama, 1991; Malkiel and Fama, 1970). The conventional view

\footnotetext{
${ }^{9}$ The Hoffman forecasts are available here: https://www.ers.usda.gov/data-products/season-average-price-forecasts/
} 
is that forecasts based on structural or econometric models using existing publicly available data cannot beat futures forecasts (e.g., Tomek, 1997). This argument has found its empirical support in the price forecasting literature (e.g., Just and Rausser, 1981; Zulauf et al., 1999). However, Chavas et al. (1983) argue that futures prices are not good proxies for expected future cash prices in the presence of government programs. Additionally, due to the nature of the Hoffman SAFP forecast, which requires aggregating twelve-monthly cash price forecasts, the futures-based model may fail to generate the most accurate forecast.

The academic literature so far has paid little attention to SAFP forecasts. Hoffman et al. (2015) compare the performance of the Hoffman futures-based and WASDE forecasts, finding that WASDE projections provide lower forecast errors in 9 out the 16 forecast periods, and contain marginal information not already included in futures prices. However, both forecasts appear to contain large forecast errors, in particular during periods of volatile prices. Irwin and Good (2015) evaluate the historical accuracy of the USDA's 10-year baseline forecasts and the corn futures market forecasts. They find that accurately forecasting corn SAFP several years ahead is challenging due to the difficulty in anticipating the magnitude and timing of market supply-anddemand shocks. Adjemian et al. (2016) show that between 1995/96 and 2014/15, the actual SAFP received by farmers fell outside WASDE's projected intervals $31 \%$ of the time, and that price density forecasts based on implied volatility improve the informational value of WASDE reports.

\subsection{An Alternative Futures-Based Forecasting Model}

The alternative SAFP forecasting model proposed in the present study makes use of a similar set of variables as the Hoffman model. However, instead of relying primarily on futures price forecasts, we generate a composite futures and cash price forecast, using data-determined 
weights for the two prices from historical data. The rationale behind constructing such a forecast is four-fold. First, futures and cash prices jointly contribute to price discovery, i.e., the impounding of new information into prices. Garbade and Silber (1983) devise a method to estimate the contribution of cash and futures prices in the price discovery process, finding that futures prices dominate cash prices, with about $75 \%$ of new information incorporated first in futures prices and $25 \%$ into cash prices for corn, wheat, and orange juice markets. In a recent study, Arnade and Hoffman (2015) contend that the relative importance of futures and cash markets in the overall price discovery process varies with the underlying market conditions, highlighting the importance of allowing for time-varying parameters when estimating the relationship between cash and futures prices. They find that from 1992 to 1999 the soybean cash market played a slightly more important role in price discovery, while the futures market had dominated the information transmission since 2000. However, the importance of the cash market increased between 2005-2013 compared to the period prior.

Second, commodity prices are highly autocorrelated as factors that determine the fundamental supply and demand tend to be correlated over time. In addition, speculators often use historical prices to determine their trading strategies, leading to further autocorrelation in prices. Cash prices may therefore have a higher correlation with previous-period cash prices than with prices for future delivery. Third, although futures prices are in general considered an unbiased estimator of future cash prices, in recent years the futures market has been plagued by nonconvergence (Adjemian et al., 2013; Garcia et al., 2015; Irwin, 2018; Irwin et al., 2011). Irwin (2018) documents several historically unprecedented episodes of non-convergence in various grain futures markets in 2005-2010 and attributes them to manipulation, structural imbalances, and low storage rates. In Hoffman's model, futures price forecasts are adjusted by an expected basis to 
arrive at the monthly cash price forecasts. Under non-convergences historical basis may be a biased predictor of current-period cash and futures price differences, skewing the SAFP forecast.

The fourth reason to use a composite cash and futures price forecast is that futures markets may fail to accurately reflect the fundamentals when it contains a high level of speculative activity (Arnade and Hoffman, 2015). Etienne et al. (2014, 2015) show that between January 2004 and June 2013, corn futures markets experienced a bubble approximately two percent of the time. Although most of the bubbles were short-lived and small in magnitude, it does raise the possibility that the role of futures markets in price discovery may have been weakened.

In the proposed forecasting model, we use equation (4-1) to generate the weights for cash and futures prices for each month $(i)$ during a marketing year, for $i=1 \ldots \ldots$ :

$$
\operatorname{Cash}_{i}=\beta_{0}+\beta_{1} \text { Futures }_{i}+\beta_{2} \text { Cash }_{i-1}+u_{i}
$$

where $u_{i}$ is the error term, the $\beta^{\prime} s$ are the coefficients to be estimated, $\operatorname{Cash}_{i}$ is the cash price in month $i$ and Futures $s_{i}$ is the average nearby futures price in month $i$. In other words, cash price in month $i$ is modeled as a function of the nearby futures contract prices in the same month and the cash price from the previous month. The regression is initiated on a 15 -year rolling window or recursive basis, ${ }^{10}$ with weights continuously updated for each month of the forecasting cycle. These regression coefficients are then used to forecast the cash price at month $m$.

One critical input to the SAFP forecast is the monthly marketing weight, which represents the proportion of the marketing year's crop marketed in a given month and contains information

\footnotetext{
${ }^{10}$ For recursive estimation, we use the data from $1975 / 79$ to $1989 / 90$ marketing year to generate the model parameters and use the results to generate the forecasts for 1990/91; we then extend the estimation data set by one period, re-estimate the model, and make a new set of forecasts. This process is repeated until the sample is exhausted.
} 
on the relative importance of each month in calculating the season-average producer price. While Hoffman (2005) and Hoffman et al. (2007) use a 5-year monthly average marketing weight, we explore alternative methods, including last year's weight, 3-year average marketing weight, 7-year average weight, 5- or 7-year Olympic average weight, 15-year rolling-window-based regression weight, etc. We found that the 5-year moving average weight used in the Hoffman model performs satisfactorily well against other alternative forecasts based on mean absolute forecast errors (Hoffman et al., 2015). We therefore use the 5-year moving-average marketing weight to construct the SAFP forecast. New marketing weights are typically released in September following the conclusion of the marketing year, and the weights are updated in the forecast model whenever the new data are available. For ease of discussion, we term the new forecast described above as the "proposed SAFP forecast."

Table (4-2) presents two examples of the proposed SAFP forecasts for the marketing year 2010/11. In panel A, the forecast was made on 5/10/2010, a day prior to WASDE's release date. This is also the first, or the 16-month ahead forecast, for marketing year 2010/11. In step (1), we use the past 15 years' data (September monthly cash prices, September average monthly nearby futures prices at closing, and August monthly cash prices from 1995/96-2009/10) to estimate equation (4-1). In step (2), average futures prices from 5/1/2010 to 5/10/2010 are computed for each corn futures contract traded on the Chicago Board of Trade (CBOT). These prices are assigned to each month during the marketing year in step (3) to arrive at the average nearby futures contract prices. We follow previous studies (e.g., Colino and Irwin, 2010) and move to the next contract if the month to be forecasted is a delivery month. ${ }^{11}$ The average monthly nearby futures

\footnotetext{
${ }^{11}$ As an example, for December 2010, the prices for March 2011 contract are used.
} 
prices in step (3) and the cash price in the previous month (i.e., April 2010) in step (4) are then plugged into the regression equation obtained in step (1), to generate the forecasted monthly cash prices in step (5). Since none of the actual cash prices for the marketing year 2010/11 are known on the forecast date (step (6)), the forecasted cash prices in step (5) will be weighted by 5-year marketing weight in step (8) to generate the weighted monthly forecast, with the SAFP forecast in step (9) calculated as the sum of these weighted forecasts.

In panel B, the forecast is made in the post-harvest season of March 2011. It is the $11^{\text {th }}$ forecast, or the 6-month ahead forecast during the 2010/11 forecast cycle. On the date of the forecast, the actual cash prices for September 2010-January 2011 and a mid-month cash price for February were already known, and they are directly used to compute the SAFP forecast (steps (6) and (7)). Additionally, the marketing weights have been updated to reflect the newest information available to the public.

Two complications arise during the forecast process. First, in table (4-2), the regression coefficients for equation (4-1) are generated based on 15-year rolling window data in which each estimation window is updated with the newest observation while dropping the first observation. However, there is no a priori as to the most appropriate method for generating the regression coefficients. For sensitivity analysis, we also consider 10 and 12-year windows, as well as both rolling-window and recursive analysis in which the first observation is fixed while the newest observation is added for the next forecast cycle. Additionally, we consider restricting regression coefficients in equation (4-1) so that the regression coefficients for the futures and previous month cash prices sum to unity, as in equation (4-2), using constrained regression:

$$
\text { Cash }_{t}=\beta_{1} \text { Futures }_{t}+\beta_{2} \text { Cash }_{t-1}+u_{t} \text {, such that } \beta_{1}+\beta_{2}=1 \text {. }
$$


Second, from 1977 the Agricultural Prices report (released at the end of each month) had been publishing a mid-month cash price for the current month together with the cash prices in preceding months. Cash $_{t-1}$ in equation (4-1) as well as in step (4) of table (4-2) refers to the midmonth cash price from the previous month. Since our forecast date typically falls in the second week of the month (to coincide with the WASDE forecast timeline), we only have access to the previous month's mid-month cash price on the forecast date. However, starting in January 2015 the NASS discontinued the mid-month price data. As a result, starting from January 2015 we rely on the full-month cash price from two months ago (the most recent cash price available) in the regression model, i.e., Cash $_{t-2}$. A similar adjustment is made in step (4) of table (4-2) when calculating the forecasted cash prices.

Table (4-3) lists the data used in the forecast model and their sources. The WASDE reports are available since the mid-1970s. Monthly cash and futures prices (in dollars per bushel) from $1975 / 76$ to $1989 / 90$ marketing years are used in the 15-year rolling-window and recursive analyses to generate the parameters in equations (4-1) and (4-3), with the forecasting period starting in marketing year 1990/91 and ending in 2019/20. Although earlier data are available, futures trading prior to the 1980s for distant contracts was sparse, potentially biasing the futures-based forecasts and the proposed forecasts that rely on price quotes for contracts maturing more than a year later. We hence generate SAFP forecasts starting from the 1990/1991 marketing year.

In total, we generate several sets of forecasts: 1) the ERS Hoffman futures-based forecast using autoregressive moving average (ARMA) basis, 2) the ERS Hoffman futures-based forecast using 5-year moving average basis, 3) the no-change forecast, 4) the proposed forecast based on rolling-window analysis, 5) the proposed forecast with recursive estimation, 6) the proposed forecast with rolling-window and parameter restrictions, and 7) the proposed forecast with 
recursive estimation and coefficient restrictions. The no-change forecast is included in the comparison as Alquist and Kilian (2010) and Pak (2018) show that previous-period price often performs well against alternative forecasts, and are often used as the benchmark for forecast comparisons. These forecasts are compared against the USDA WASDE SAFP projections.

\subsection{Forecast Evaluations}

Common forecast evaluation methods often fall into two categories, those that compare the relative performance of competing forecasts and those that determine the absolute performance of a given forecast. Here we focus on the relative performance by comparing the forecasts generated from the proposed method to the Hoffman futures-based forecasts and the WASDE projections. We define the prediction error for a given SAFP forecast made in month $m$ during the forecast cycle for marketing year $t$ as,

$$
e_{m}^{t}=p^{t}-f_{m}^{t}
$$

where $m=1,2, \ldots, 16$ represents the 16 forecasts for each marketing year, $t=1,2, \ldots, T$ is the marketing year to be forecasted, $p^{t}$ is the actual SAFP of year $t$ available after the conclusion of the marketing year, $f_{m}^{t}$ is the forecast made at month $m$ for marketing year $t$. We calculate three measures, namely the mean absolute errors (MAE), mean absolute percentage errors (MAPE), and the root mean squared errors (RMSE). The MAE avoids the cancellation of positive and negative prediction errors when computing mean prediction error. The MAPE accounts for the price level change by representing the forecast errors on a percentage basis. The RMSE places higher penalties on less-accurate forecasts. 
Following previous studies (e.g., Colino and Irwin, 2010; Colino et al., 2012; Sanders and Manfredo, 2005), we use the modified Diebold Mariano (MDM) test of Harvey et al. (1997) that accounts for small sample bias to determine whether the prediction errors of two forecasts are statistically different. Specifically, denote the differences in absolute errors of two competing forecasts as $d_{t}^{t}=\left|e_{1 m}^{t}\right|-\left|e_{2 m}^{t}\right|$. The MDM test is formulated as in equation (4-5):

$$
\begin{aligned}
M D M_{t} & =\left[\frac{T+1-2 h+h(h-1) / T}{T}\right]^{\frac{1}{2}}\left[V\left(\bar{d}_{t}\right)\right]^{-\frac{1}{2}}\left[\bar{d}_{t}\right], \\
V\left(\bar{d}_{t}\right) & =\left[T^{-1}\left(\gamma_{0}+2 \sum_{s=1}^{t-1} \gamma_{s}\right)\right],
\end{aligned}
$$

where $\gamma_{0}$ and $\gamma_{s}$ are the variance and $s^{\text {th }}$-order auto-covariance, respectively. Under the null hypothesis of equal absolute forecast errors, the MDM test statistic follows a $t$ distribution with $T-1$ degrees of freedom. Rejection of the null hypothesis is evidence of the superior performance of the forecast model with smaller prediction errors. A similar test can be carried out for other loss functions, including the absolute percentage errors and quartic errors.

Even if a forecast has a higher MAE/MAPE/RMSE compared to the alternative forecast, it may still contain information not already present in the superior forecast. In such cases, a combination of the two forecasts may generate more accurate predictions than either forecast alone. Harvey et al. (1998) propose using equation (4-6) to test whether one forecast encompasses the other:

$$
e_{1 m}^{t}=\lambda\left(e_{1 m}^{t}-e_{2 m}^{t}\right)+u_{m}^{t}
$$

where $e_{1 m}^{t}$ and $e_{2 m}^{t}$ are the prediction errors of forecasts 1 and 2 generated in month $m$ during the forecast cycle for marketing year $t$, respectively. A test of the null hypothesis, $\lambda=0$, in equation (4-6) is equivalent to testing whether the second forecast contains incremental information not 
included in the first forecast. Failure to reject the null hypothesis suggests that a composite forecast cannot be constructed from the two series that outperform the first forecast. In such a case, forecast 1 is said to be "conditionally efficient" or to "encompass" the competing forecast. Harvey et al. (1998) further contend that traditional regression-based test statistics often have size and power problems in small samples or when forecast errors are non-moral. We hence follow their suggestion and use the MDM test to evaluate the statistical significance of $\lambda$ in equation (4-6).

\subsection{Results}

To conserve space, we only report the results obtained from the 15-year rolling window and recursive analyses for the alternative forecasting model. Results from the 12-year and 10-year analyses were qualitatively similar. Furthermore, although we computed the forecasts made prior to and after the WASDE release date for both the futures-based and the proposed methods, we present only the forecasts made before the WASDE release. The performance of the forecasts made after the WASDE release shows only a marginal improvement over those made prior. Additionally, we focus our discussion on MAE since the results are similar across three forecast performance metrics.

In total, we evaluate the performance of eight different forecasts, including the WASDE projections (WASDE), the ERS Hoffman futures-based forecast using ARMA basis (fut-ARMA), the ERS Hoffman futures-based forecast using 5-year moving average basis (fut-5yr), the nochange forecast (no change), the proposed forecast based on rolling-window analysis (newrolling), the proposed forecast with recursive estimation (new-recur), the proposed forecast with rolling-window and parameter restrictions (new-rolling, res), and the proposed forecast with recursive estimation and coefficient restrictions (new-recur, res). 
Figure (4-1) plots the proposed forecast with the rolling window analysis, the Hoffman (5year basis) forecast, WASDE projections, and the no-change forecast in selected forecast months (May, October, March, and August) during the full sample period (1990-2019). Overall, the four forecasts appear to be highly correlated and follow a similar trend. Except for the no-change forecast, the forecasts become more accurate toward the end of the forecast cycle as more production and consumption data become available. In May before the marketing year (panel A), the SAFP forecasts tend to follow the actual SAFP from the previous year as little information is available in May (16-month ahead forecast). Thus, at this point in the forecast cycle, SAFP forecasts for the upcoming marketing year rely primarily on previous years' prices.

Table (4-4) presents the mean absolute errors for the eight competing forecasts during the full sample period. In all forecasting sample periods, except for the no-change forecast, the forecasts become more accurate as we move further along the forecast cycle in three sample periods and the improvement in forecast accuracy is greatest from May to November, with gradual declines afterward. Corn production is highly dependent on weather, since extreme weather conditions can significantly affect the yield. With the majority of the corn planted by May/June in the main production areas, the large forecast errors in these two months in all sample periods primarily reflect the uncertainty of corn yield due to weather fluctuations in the growing season. The no-change forecasts in all sample periods tend to perform well in these months as compared to the futures and proposed futures forecasts, but their performance quickly lags other forecasts starting from August, just one month before the marketing year starts. Overall, WASDE projections are the most accurate during the first three months of the forecast cycle, May through July. 
Table (4-4) suggests that the new forecast models generate lower MAEs in the last two months of the harvest season and from January to April during the marketing year. The Hoffman futures-based forecast outperforms WASDE projections in August and September through December in the harvest season. Notably, the months that the WASDE projections outperform the other forecasts are either at the beginning of the forecast cycle (May-July prior to the marketing year) when little information is publicly available, or toward the end of the forecast cycle (MayAugust in the marketing year) when most of the production and supply data have become known to the public. Comparing the new forecasts with those from Hoffman futures-based forecasts, the latter tend to perform better in the earlier part of the forecast cycle. However, in the post-harvest season the new forecasts, regardless of the procedures used, consistently have a lower MAE than Hoffman futures-based forecasts.

Since corn prices have become considerably more volatile over the past decade, we evaluate the forecast performances for each procedure during two sub-periods: 1990/91-2004/05, and 2005/06-2019/20 marketing years. We chose 2005 as the cut-off year because commodities have become considerably more volatile around that time and ensure that there are enough observations for statistical analysis in each sub-period. For the first sub-period, table (4-5) indicates that the Hoffman futures-based forecast is the most accurate forecast from August to November. The new forecast models outperform other forecasting models only in December and January. During this sample period, WASDE forecast achieves the highest accuracy among all prediction models for the first three months of the growing season and during the last seven months of the post-harvest season.

Table (4-6) evaluates the forecast performances across different models in 2005/062019/20, the period when corn prices experienced significant price volatility. As can be seen, the 
relative performance of the new forecasting models significantly improved in the second subperiod. The MAE of the new models is lowest compared with other forecasting models in almost all months during harvest season and in the first four months of the post-harvest season. Similar to the full sample period, the WASDE forecasts are the best forecasts in the first three months of the forecast cycle; however, in the post-harvest season they have the highest accuracy only in May, July and August. Additionally, the Hoffman futures-based forecast has the lowest forecast errors in August (growing season) and September through November of the (harvest season).

Figure (4-2) provides further evidence in support of the relative accuracy of the three types of forecasts throughout the forecast cycle. In panels A, C, and E, the differences in MAEs between Hoffman futures-based/new forecasts and the WASDE price projections are plotted for 1990/912019/20, 1990/91-2004/05 and 2005/06-2019/20 marketing years, respectively. In panels B, D, and F, we plot the differences in MAPEs when compared to the WASDE forecasts. A greater than zero value suggests that the WASDE projections have a lower MAE/MAPE, while a negative value indicates the WASDE produces less accurate SAFP forecasts. Regardless of the metrics used, WASDE projections consistently outperform the other forecasts in the beginning and at the end of the forecast cycle in all three sample periods. The new forecasts, however, perform better than the futures-based forecasts starting from December, or the 9-month ahead forecast, to the first few months after the post-harvest season. Furthermore, compared with WASDE and Hoffman futures-based forecasts, the new forecasts perform better in more months of the forecast cycle during 2005/06-2019/20 marketing year.

We next evaluate whether the differences presented in figure (4-2) are statistically significant using the MDM test in equation (4-4). Figure (4-3) plots the $p$-values of the MDM test for the full sample, 1990/91-2004/05 and 2005/06-2019/20 marketing years, respectively. As can 
be seen, although there are differences in MAEs between different forecasts, some of these differences are not statistically significant at the $10 \%$ significance level. Interestingly, in all three sample periods, starting from March (the 6-month-ahead forecast), the WASDE projections perform statistically better than Hoffman futures-based forecasts, while the differences in MAEs between WASDE and the proposed forecasts show much less statistical significance during these months. In other words, the proposed forecasts perform no worse than the WASDE forecasts in most of the post-harvest season forecasting months. However, the Hoffman futures-based forecasts present a statistically significant lower MAE than the WASDE forecasts in October during the full sample (1990/91-2019/20), and in August and October during the two sub-periods.

Comparing the Hoffman futures-based and the proposed forecasts (panels B, D, and E of figure (4-3)), the Hoffman futures-based forecast performed statistically better in July and October in the full sample period and only in October in the 1990/91-2004/05 sample. Meanwhile, the MAEs of the proposed forecast is statistically significantly lower than futures-based forecasts between February and June during the marketing year. Finally, in the 2005/06-2019/20 sub-period, the new proposed forecasts show statistically significant superior performance relative to Hoffman futures-based forecasts in September, November (harvest season) and between February to May (post-harvest season).

Figure (4-4) presents the $p$-value of the encompassing test in equation (4-6) using the MDM test for the full sample and the two sub-periods. $P$-values based on Newey-West regressions ${ }^{12}$ are also computed, and they appear to show more statistical significance than the MDM test. In panels A, C, and E, we test whether alternative forecasts contain incremental information not already

\footnotetext{
12 The Newey-West (1987) procedure is used on all regression-type models where it is needed to generate a consistent variance-covariance matrix for testing (Brittain et al. 2012).
} 
present in the WASDE forecasts. In general, results suggest that during the harvest season the Hoffman futures-based forecasts can help improve the WASDE forecast, while the proposed forecast contains additional information at the beginning of the post-harvest season for all three sample periods, in particular 2005/06-2019/20. In panels B, D, and F of the figure, we test whether the proposed forecasts help improve the existing futures-based forecasts of the Hoffman model. Overall, the null hypothesis of no additional information is rejected from January to July in the full sample, between February and June during the 1990/91-2004/05 and 2005/06-2019/20 marketing years, suggesting that during these months a composite forecast based on the two types of forecasts can improve the performance of the existing forecasts.

Our various forecast evaluations so far consistently point to the satisfactory performance of the proposed forecasts at the beginning of the post-harvest season. To understand why forecasts during these months tend to perform better than in other periods, we go back to our model and evaluate each component of the forecast. Starting from January (the 9-month ahead forecast), the actual monthly cash prices for the harvest season are known. As can be seen in Table (4-2) panel B, these actual prices are used directly in step (7) to construct the SAFP, eliminating much of the uncertainty when the size of the harvested crops are yet to be known. For the remaining months of the marketing year (i.e., January-August), equations (4-1) and (4-2) are used to forecast cash prices. As shown in figure (4-5), parameter estimates for Futures $s_{m}$ and Cash $_{m-1}$ have been rather volatile at the beginning of the post-harvest season (January-April), whereas in other months the mean parameter estimates are much more stable. The satisfactory performance of the proposed forecast in January-April may therefore be attributed to the model's ability to assign heterogeneous weights to futures and cash prices depending on the underlying market conditions. Notably, the 
estimated coefficients appear to be in general higher for previous-period cash prices than the current-period nearby futures prices.

Finally, since corn prices have undergone enormous volatility over the past decade and Hoffman et al. (2015) find the existing forecasts contain large forecast errors under volatile market conditions, we examine whether the performance of the proposed model changes with the level of market volatility. We use a fixed-effect model to link the relative forecast accuracy of the proposed forecasts as compared to the WASDE projections with market volatility. Specifically, we estimate equation (4-7):

$$
y_{t}=\beta_{0}+\beta_{1} \text { Volatility }_{t}+u_{t}
$$

where the dependent variable $y_{t}$ is the difference in absolute forecast errors between the proposed forecast and WASDE projections at time $t$, and the independent variable is the market volatility, calculated as the standard deviation of prices during a given marketing year. The cross-sectional unit in the regression equation is the 16 months during the forecast cycle, and the time dimension is the marketing year. Since a decrease in the dependent variable suggests that the proposed SAFP forecast becomes more accurate relative to WASDE projections, significant coefficient estimates for $\beta_{1}$ that are negative indicates that the proposed forecasts become more accurate when the market volatility is larger.

Table (4-5) presents the regression results for the proposed forecasts. The standard errors are calculated using bootstraps with 1,000 replications. Estimation results suggest that as the volatility increases, the absolute forecast errors of the proposed forecasts become smaller relative to the WASDE price projections. Given a one standard deviation increase in price volatility, which is $\$ 0.27 /$ bushel, the difference in absolute prediction errors between the proposed and the WASDE 
forecasts would decrease (i.e., less positive or more negative) by $\$ 0.025 /$ bushel to $\$ 0.032 /$ bushel each forecast month.

\subsection{Conclusions}

Price forecasts are critical to market participants when making production and marketing decisions and to policymakers who administer commodity programs and assess the market impact of domestic or international events. With the exceptionally volatile conditions experienced in the corn market since 2006, the need for price forecasting has become even more critical. The purpose of this paper is to explore an alternative procedure to forecast the season-average price for U.S. corn producers, a relatively under-researched price forecast that plays a key role in many crop programs in the U.S. The proposed method first generates a cash price forecast for each month during the marketing year using historical nearby futures prices and previous-months' cash prices based on either recursive or rolling window analyses. These monthly forecasts are then aggregated into season-average price forecasts based on historical marketing weights for each month.

The proposed forecasts are compared to the WASDE and the futures-based forecasts of Hoffman (2005) and Hoffman et al. (2007) using a variety of forecast evaluation tools. We find that the proposed method performs similarly or demonstrates an improvement in forecast accuracy compared to the Hoffman model in almost all months except for July and October, or the 15- and 11-months ahead forecasts. Compared to the WASDE projections, the proposed method performs similar or better in November through April during the marketing year. Additionally, the relative forecast performances of the proposed procedure improved significantly during the 2005/062019/20 subperiod, as compared to the 1990/91-2004/05 period. Notably, the 2005/06-2019/20 period is characterized with significantly more volatile price behavior compared to the earlier sub- 
sample. The no-change forecast appears to be useful or perform well only at the beginning of the forecast cycle.

The superiority of the WASDE forecast in some forecast months is not surprising as the USDA Interagency Commodity Estimates Committees may have access to information not known to the public. Our results seem to confirm prior research that the USDA reports, including the WASDE, still contain valuable information to the market (e.g., Adjemian, 2012). It is, however, surprising that the proposed forecasts tend to perform slightly better than the WASDE forecast at the beginning of the post-harvest season. The performance of the proposed forecast during these months may be partially attributed to the model's ability to assign heterogeneous weights to futures and cash prices depending on the underlying market conditions, as illustrated by the wide range of estimated coefficients during these months. Our regression analysis suggests that the proposed forecasts become relatively more accurate as the market becomes more volatile, again likely due to the model's flexibility in adjusting the weights for futures and cash prices in generating monthly cash price forecasts.

This research provides some much-needed information on season-average price forecasts that are important to farmers, elevator managers, grain merchandisers, exporters, and policymakers. From the practitioner's perspective, the present analysis suggests that it is important to compare different forecasts as each tends to perform well during different time periods. At the beginning of the forecast cycle, the WASDE is clearly the forecast to follow. At the end of the growing season and in the entire harvest season, the Hoffman futures-based forecast appears to perform slightly better than the competing forecasts. The proposed forecast seems to be the best performer in the first half of the post-harvest season, namely January to April. In other words, an online tool that reports various SAFP forecasts and selects the best-performing model based on 
historical data may prove to be helpful for market participants. Additionally, composite forecasts that use all the existing procedures, including the one proposed in the present study, may help improve the season-average forecasts. In the era of big data and more connected commodity markets, it is possible that other variables, in particular those related to the production and price information in the southern hemisphere (Mattos-Silveira, 2016), could significantly improve the overall performance of season-average price forecasts of grain commodities. 


\section{Tables and Figures}

Table 4-1. Forecasting cycle for corn season-average farm price, including marketing year and crop season

\begin{tabular}{|c|c|c|c|}
\hline \multirow[b]{2}{*}{ Month/Year } & \multicolumn{3}{|c|}{ Marketing year 2010/11 } \\
\hline & $\begin{array}{c}\text { Marketing year } \\
\text { month }=i\end{array}$ & $\begin{array}{c}\text { Forecast cycle } \\
\text { month }=m\end{array}$ & Months ahead \\
\hline May-10 & & Forecast 1 & 16 \\
\hline Jun-10 & & Forecast 2 & 15 \\
\hline Jul-10 & & Forecast 3 & 14 \\
\hline Aug-10 & & Forecast 4 & 13 \\
\hline Sep-10 & M 1 & Forecast 5 & 12 \\
\hline Oct-10 & M 2 & Forecast 6 & 11 \\
\hline Nov-10 & M 3 & Forecast 7 & 10 \\
\hline Dec-10 & M 4 & Forecast 8 & 9 \\
\hline Jan-11 & M 5 & Forecast 9 & 8 \\
\hline Feb-11 & M 6 & Forecast 10 & 7 \\
\hline Mar-11 & M 7 & Forecast 11 & 6 \\
\hline Apr-11 & M 8 & Forecast 12 & 5 \\
\hline May-11 & M 9 & Forecast 13 & 4 \\
\hline Jun-11 & M 10 & Forecast 14 & 3 \\
\hline Jul-11 & M 11 & Forecast 15 & 2 \\
\hline Aug-11 & M 12 & Forecast 16 & 1 \\
\hline Sep-11 & & for $10 / 11 \mathrm{know}$ & \\
\hline
\end{tabular}

Notes: $\mathrm{SAFP}=$ season-average price. and represents the post-harvest season. 
Table 4-2. Examples of price forecasts (\$/bushel) using the proposed procedure for marketing year 2010/11

\begin{tabular}{|c|c|c|c|c|c|c|c|c|c|}
\hline \multicolumn{4}{|c|}{ Panel A. Forecast date: 5/10/2010, forecasting cycle: 16-month ahead } & \multicolumn{4}{|c|}{ WASDE release date: $5 / 11 / 2011,8: 30$ am Eastern time } & \multirow[b]{2}{*}{$\begin{array}{c}(8) \\
\text { Marketing } \\
\text { weight } \\
\end{array}$} & \multirow[b]{2}{*}{$\begin{array}{l}\text { (9) Weighted } \\
\text { monthly forecast } \\
(7)^{*}(8)\end{array}$} \\
\hline & (1) Regression results using past 15 -year data & $\begin{array}{c}\text { (2) Average } \\
\text { futures close price, } \\
5 / 1 / 10-5 / 10 / 10\end{array}$ & $\begin{array}{l}(3) \\
\text { Futures } \\
\text { price }\end{array}$ & $\begin{array}{l}\text { (4) Previous } \\
\text { month cash price } \\
(\text { Apr' 10) }\end{array}$ & $\begin{array}{l}\text { (5) Forecasted } \\
\text { monthly price: plug } \\
\text { (3) and (4) into (1) }\end{array}$ & $\begin{array}{l}\text { (6) Actual } \\
\text { cash price }\end{array}$ & $\begin{array}{l}\text { (7) Spliced actual/ } \\
\text { forecasted } \\
\text { monthly price }\end{array}$ & & \\
\hline Sep '10 & $C_{t}=0.03+0.44 F_{t}+0.51 C_{t-1}$ & & 3.87 & 3.51 & 3.50 & N/A & 3.50 & 0.07 & 0.24 \\
\hline Oct' 10 & $C_{t}=-0.18+0.63 F_{t}+0.39 C_{t-1}$ & & 3.87 & 3.51 & 3.61 & N/A & 3.61 & 0.12 & 0.44 \\
\hline Nov'10 & $C_{t}=-0.13+0.33 F_{t}+0.70 C_{t-1}$ & & 3.87 & 3.51 & 3.61 & N/A & 3.61 & 0.12 & 0.42 \\
\hline Dec' 10 & $C_{t}=0.08+0.27 F_{t}+0.70 C_{t-1}$ & 3.87 & 4.00 & 3.51 & 3.61 & N/A & 3.61 & 0.08 & 0.30 \\
\hline Jan'11 & $C_{t}=-0.09-0.02 F_{t}+1.09 C_{t-1}$ & & 4.00 & 3.51 & 3.64 & N/A & 3.64 & 0.14 & 0.53 \\
\hline Feb '11 & $C_{t}=-0.06+0.52 F_{t}+0.47 C_{t-1}$ & & 4.00 & 3.51 & 3.68 & N/A & 3.68 & 0.07 & 0.27 \\
\hline Mar'11 & $C_{t}=0.01+0.18 F_{t}+0.81 C_{t-1}$ & 4.00 & 4.09 & 3.51 & 3.61 & N/A & 3.61 & 0.08 & 0.28 \\
\hline Apr'11 & $C_{t}=-0.07+0.42 F_{t}+0.57 C_{t-1}$ & & 4.09 & 3.51 & 3.68 & N/A & 3.68 & 0.06 & 0.21 \\
\hline May'11 & $C_{t}=-0.04+0.34 F_{t}+0.65 C_{t-1}$ & 4.09 & 4.16 & 3.51 & 3.66 & N/A & 3.66 & 0.06 & 0.22 \\
\hline Jun '11 & $C_{t}=-0.08+0.16 F_{t}+0.85 C_{t-1}$ & & 4.16 & 3.51 & 3.56 & N/A & 3.56 & 0.07 & 0.24 \\
\hline Jul '11 & $C_{t}=0.01+0.18 F_{t}+0.78 C_{t-1}$ & 4.16 & 4.14 & 3.51 & 3.50 & N/A & 3.50 & 0.07 & 0.24 \\
\hline Aug '11 & $C_{t}=-0.17+0.35 F_{t}+0.68 C_{t-1}$ & & 4.14 & 3.51 & 3.68 & N/A & 3.68 & 0.06 & 0.22 \\
\hline \multirow[t]{2}{*}{ Sep' 11} & $C_{t}=0.01+0.46 F_{t}+0.49 C_{t-1}$ & 4.14 & & & & & & & \\
\hline & Forecasted SAFP (sum of column (9)) & & & & & & & & 3.61 \\
\hline \multicolumn{4}{|c|}{ Panel B. Forecast date: 3/9/2011, forecasting cycle: 6-month ahead } & WASDE rele & ase date: $3 / 10 / 2011,8$ & 30 am East & ern time & & \\
\hline & (1) Regression results using past 15-year data & $\begin{array}{c}\text { (2) Average } \\
\text { futures close price, } \\
3 / 1 / 11-3 / 9 / 11\end{array}$ & $\begin{array}{l}\text { (3) } \\
\text { Futures } \\
\text { price }\end{array}$ & $\begin{array}{l}\text { (4) Previous } \\
\text { month cash price } \\
\text { (Feb' 11) }\end{array}$ & $\begin{array}{l}\text { (5) Forecasted } \\
\text { monthly price: plug } \\
\text { (3) and (4) into (1) }\end{array}$ & $\begin{array}{l}\text { (6) Actual } \\
\text { cash price }\end{array}$ & $\begin{array}{l}\text { (7) Spliced actual/ } \\
\text { forecasted } \\
\text { monthly price }\end{array}$ & $\begin{array}{l}\text { (8) } \\
\text { Marketing } \\
\text { weight }\end{array}$ & $\begin{array}{l}\text { (9) Weighted } \\
\text { monthly forecast } \\
(7)^{*}(8)\end{array}$ \\
\hline Sep '10 & $C_{t}=0.03+0.44 F_{t}+0.51 C_{t-1}$ & & & & & 4.08 & 4.08 & 0.06 & 0.26 \\
\hline Oct' 10 & $C_{t}=-0.18+0.63 F_{t}+0.39 C_{t-1}$ & & & & & 4.32 & 4.32 & 0.11 & 0.48 \\
\hline Nov'10 & $C_{t}=-0.13+0.33 F_{t}+0.70 C_{t-1}$ & & & & & 4.55 & 4.55 & 0.12 & 0.55 \\
\hline Dec' 10 & $C_{t}=0.08+0.27 F_{t}+0.70 C_{t-1}$ & & & & & 4.82 & 4.82 & 0.09 & 0.43 \\
\hline Jan '11 & $C_{t}=-0.09-0.02 F_{t}+1.09 C_{t-1}$ & & & & & 4.94 & 4.94 & 0.14 & 0.70 \\
\hline Feb '11 & $C_{t}=-0.06+0.52 F_{t}+0.47 C_{t-1}$ & & 7.14 & 5.66 & 6.33 & 5.66 & 5.66 & 0.07 & 0.39 \\
\hline Mar'11 & $C_{t}=0.01+0.18 F_{t}+0.81 C_{t-1}$ & 7.14 & 7.21 & 5.66 & 5.92 & N/A & 5.92 & 0.08 & 0.45 \\
\hline Apr'11 & $C_{t}=-0.07+0.42 F_{t}+0.57 C_{t-1}$ & & 7.21 & 5.66 & 6.23 & N/A & 6.23 & 0.06 & 0.38 \\
\hline May '11 & $C_{t}=-0.04+0.34 F_{t}+0.65 C_{t-1}$ & 7.21 & 7.25 & 5.66 & 6.12 & N/A & 6.12 & 0.06 & 0.38 \\
\hline Jun '11 & $C_{t}=-0.08+0.16 F_{t}+0.85 C_{t-1}$ & & 7.25 & 5.66 & 5.88 & N/A & 5.88 & 0.07 & 0.40 \\
\hline Jul '11 & $C_{t}=0.01+0.18 F_{t}+0.78 C_{t-1}$ & 7.25 & 6.58 & 5.66 & 5.61 & N/A & 5.61 & 0.07 & 0.40 \\
\hline Aug '11 & $C_{t}=-0.17+0.35 F_{t}+0.68 C_{t-1}$ & & 6.58 & 5.66 & 6.01 & N/A & 6.01 & 0.06 & 0.37 \\
\hline $\begin{array}{l}\text { Sep '11 } \\
\text { For }\end{array}$ & $\begin{array}{l}C_{t}=0.01+0.46 F_{t}+0.49 C_{t-1} \\
\text { casted SAFP (sum of column (9)) }\end{array}$ & 6.58 & & & & & & & 5.21 \\
\hline
\end{tabular}




\section{Table 4-3. Data used in the analysis and sources of data}

\begin{tabular}{ll}
\hline Data & Source \\
\hline Actual SAFP & $\begin{array}{l}\text { Various issues of Agricultural Prices published by the National Agricultural } \\
\text { Statistics Service (NASS): } \\
\text { https://usda.library.cornell.edu/concern/publications/c821gj76b?locale=en }\end{array}$ \\
$\begin{array}{l}\text { WASDE SAFP } \\
\text { forecasts }\end{array}$ & $\begin{array}{l}\text { World Agricultural Supply and Demand Estimates: } \\
\text { https://usda.library.cornell.edu/concern/publications/3t945q76s?locale=en }\end{array}$ \\
$\begin{array}{l}\text { ERS futures- } \\
\text { based SAFP } \\
\text { forecasts }\end{array}$ & $\begin{array}{l}\text { Generated based on Hoffman }(2005,2007) \text { also available at } \\
\text { https://www.ers.usda.gov/data-products/season-average-price-forecasts/ }\end{array}$ \\
$\begin{array}{l}\text { Monthly cash } \\
\text { prices }\end{array}$ & $\begin{array}{l}\text { Various issues of Agricultural Prices published by the National Agricultural } \\
\text { Statistics Service (NASS): }\end{array}$ \\
$\begin{array}{l}\text { https://usda.library.cornell.edu/concern/publications/c821gj76b?locale=en } \\
\text { Futures contract } \\
\text { prices }\end{array}$ & $\begin{array}{l}\text { Chicago Board of Trade, corn futures contract } \\
\text { Various issues of Agricultural Prices published by the National Agricultural }\end{array}$ \\
$\begin{array}{l}\text { Marketing } \\
\text { weights }\end{array}$ & $\begin{array}{l}\text { Statistics Service (NASS): } \\
\text { https://usda.library.cornell.edu/concern/publications/c821gj76b?locale=en }\end{array}$
\end{tabular}


Table 4-4. Mean absolute error (MAE) for each forecasting method in \$/bushel, 1990/912019/20 marketing years (full sample)

\begin{tabular}{ll|cc|cccc|c|c}
\hline \multicolumn{2}{c|}{ forecast month } & $\begin{array}{c}\text { fut- } \\
\text { 5yr }\end{array}$ & $\begin{array}{c}\text { fut- } \\
\text { ARMA }\end{array}$ & $\begin{array}{c}\text { new- } \\
\text { rolling }\end{array}$ & $\begin{array}{c}\text { new- } \\
\text { recur }\end{array}$ & $\begin{array}{c}\text { new-rolling, } \\
\text { res }\end{array}$ & $\begin{array}{c}\text { new-recur, } \\
\text { res }\end{array}$ & $\begin{array}{c}\text { no } \\
\text { change }\end{array}$ & WASDE \\
\hline \multirow{6}{*}{ growing } & May & 0.565 & 0.534 & 0.530 & 0.520 & 0.562 & 0.560 & 0.501 & 0.437 \\
& Jun & 0.623 & 0.595 & 0.571 & 0.563 & 0.602 & 0.611 & 0.538 & 0.472 \\
& July & 0.484 & 0.470 & 0.529 & 0.518 & 0.568 & 0.562 & 0.526 & 0.399 \\
& Aug & 0.386 & 0.357 & 0.434 & 0.425 & 0.471 & 0.467 & 0.519 & 0.385 \\
\hline \multirow{6}{*}{ harvest } & Sep & 0.348 & 0.347 & 0.391 & 0.388 & 0.422 & 0.417 & 0.515 & 0.354 \\
& Oct & 0.211 & 0.199 & 0.293 & 0.292 & 0.322 & 0.321 & 0.515 & 0.276 \\
& Nov & 0.164 & 0.165 & 0.157 & 0.159 & 0.170 & 0.171 & 0.515 & 0.182 \\
& Dec & 0.149 & 0.127 & 0.135 & 0.132 & 0.137 & 0.134 & 0.515 & 0.139 \\
\hline \multirow{6}{*}{ post- } & Jan & 0.126 & 0.124 & 0.107 & 0.107 & 0.112 & 0.112 & 0.515 & 0.116 \\
& Feb & 0.121 & 0.109 & 0.085 & 0.083 & 0.087 & 0.087 & 0.515 & 0.107 \\
& Marvest & 0.123 & 0.110 & 0.080 & 0.078 & 0.086 & 0.086 & 0.515 & 0.084 \\
& Apr & 0.120 & 0.116 & 0.067 & 0.065 & 0.067 & 0.067 & 0.515 & 0.071 \\
& May & 0.108 & 0.104 & 0.081 & 0.078 & 0.077 & 0.078 & 0.515 & 0.062 \\
& Jun & 0.101 & 0.101 & 0.077 & 0.075 & 0.073 & 0.075 & 0.524 & 0.066 \\
& Jul & 0.053 & 0.062 & 0.065 & 0.061 & 0.065 & 0.065 & 0.515 & 0.042 \\
& Aug & 0.037 & 0.044 & 0.044 & 0.041 & 0.044 & 0.044 & 0.515 & 0.036 \\
\hline
\end{tabular}

Notes: Shaded area represents the scenarios in which MAE of the forecast is lower than the WASDE projections. "fut-5yr" and "fut-ARMA" represent the Hoffman futures-based forecasts with 5-year moving average basis and ARMA basis, respectively. "new-rolling", "new-recur", "new-rolling, res", and "new-recur, res" are the proposed forecasts with rolling-window estimation, recursive estimation, rolling-window with restrictions, and recursive estimation with restrictions, respectively. No-change is the forecast generated using last year's SAFP. 
Table 4-5. Mean absolute error (MAE) for each forecasting method in \$/bushel, 1990/912004/05 marketing years

\begin{tabular}{ll|cc|cccc|c|c}
\hline \multicolumn{2}{c|}{ forecast month } & $\begin{array}{c}\text { fut- } \\
\text { 5yr }\end{array}$ & $\begin{array}{c}\text { fut- } \\
\text { ARMA }\end{array}$ & $\begin{array}{c}\text { new- } \\
\text { rolling }\end{array}$ & $\begin{array}{c}\text { new- } \\
\text { recur }\end{array}$ & $\begin{array}{c}\text { new-rolling, } \\
\text { res }\end{array}$ & $\begin{array}{c}\text { new-recur, } \\
\text { res }\end{array}$ & $\begin{array}{c}\text { no } \\
\text { change }\end{array}$ & WASDE \\
\hline \multirow{6}{*}{ growing } & May & 0.341 & 0.357 & 0.368 & 0.361 & 0.394 & 0.391 & 0.322 & 0.260 \\
& Jun & 0.359 & 0.345 & 0.380 & 0.376 & 0.381 & 0.382 & 0.323 & 0.253 \\
& July & 0.279 & 0.261 & 0.319 & 0.317 & 0.320 & 0.324 & 0.311 & 0.241 \\
& Aug & 0.208 & 0.212 & 0.232 & 0.233 & 0.231 & 0.232 & 0.296 & 0.232 \\
\hline \multirow{6}{*}{ harvest } & Sep & 0.222 & 0.252 & 0.266 & 0.262 & 0.293 & 0.293 & 0.340 & 0.188 \\
& Oct & 0.128 & 0.145 & 0.161 & 0.161 & 0.177 & 0.179 & 0.303 & 0.147 \\
& Nov & 0.095 & 0.109 & 0.121 & 0.123 & 0.117 & 0.117 & 0.303 & 0.101 \\
post- & Dec & 0.082 & 0.092 & 0.079 & 0.080 & 0.070 & 0.070 & 0.295 & 0.083 \\
\hline \multirow{2}{*}{ harvest } & Jan & 0.073 & 0.084 & 0.059 & 0.061 & 0.051 & 0.051 & 0.295 & 0.068 \\
& Feb & 0.072 & 0.071 & 0.063 & 0.063 & 0.057 & 0.057 & 0.303 & 0.056 \\
& Mar & 0.076 & 0.071 & 0.059 & 0.055 & 0.057 & 0.056 & 0.303 & 0.051 \\
& Apr & 0.069 & 0.064 & 0.057 & 0.053 & 0.055 & 0.055 & 0.303 & 0.050 \\
& May & 0.053 & 0.055 & 0.053 & 0.050 & 0.052 & 0.052 & 0.303 & 0.036 \\
& Jun & 0.046 & 0.046 & 0.043 & 0.042 & 0.044 & 0.045 & 0.303 & 0.035 \\
& Jul & 0.032 & 0.021 & 0.027 & 0.026 & 0.030 & 0.030 & 0.303 & 0.018 \\
& Aug & 0.026 & 0.020 & 0.019 & 0.019 & 0.022 & 0.022 & 0.303 & 0.013 \\
\hline
\end{tabular}

Notes: Shaded area represents the MAE of the forecast is lower than the WASDE projections. "fut-5yr" and "futARMA" represent the Hoffman futures-based forecasts with 5-year moving average basis and ARMA basis, respectively. "new-rolling", "new-recur", "new-rolling, res", and "new-recur, res" are the proposed forecasts with rolling-window estimation, recursive estimation, rolling-window with restrictions, and recursive estimation with restrictions, respectively. No-change is the forecast generated using last year's SAFP. 
Table 4-6. Mean absolute error (MAE) for each forecasting method in $\$ /$ bushel, 2005/062019/20 marketing years

\begin{tabular}{ll|cc|cccc|c|c}
\hline \multicolumn{2}{c|}{ forecast month } & $\begin{array}{c}\text { fut- } \\
\text { 5yr }\end{array}$ & $\begin{array}{c}\text { fut- } \\
\text { ARMA }\end{array}$ & $\begin{array}{c}\text { new- } \\
\text { rolling }\end{array}$ & $\begin{array}{c}\text { new- } \\
\text { recur }\end{array}$ & $\begin{array}{c}\text { new-rolling, } \\
\text { res }\end{array}$ & $\begin{array}{c}\text { new-recur, } \\
\text { res }\end{array}$ & $\begin{array}{c}\text { no } \\
\text { change }\end{array}$ & WASDE \\
\hline \multirow{6}{*}{ growing } & May & 0.765 & 0.710 & 0.693 & 0.682 & 0.730 & 0.730 & 0.681 & 0.615 \\
& Jun & 0.838 & 0.794 & 0.710 & 0.700 & 0.742 & 0.758 & 0.692 & 0.661 \\
& July & 0.658 & 0.646 & 0.701 & 0.694 & 0.741 & 0.726 & 0.684 & 0.549 \\
& Aug & 0.479 & 0.440 & 0.569 & 0.562 & 0.611 & 0.611 & 0.681 & 0.515 \\
\hline \multirow{6}{*}{ harvest } & Sep & 0.456 & 0.430 & 0.498 & 0.488 & 0.533 & 0.523 & 0.666 & 0.499 \\
& Oct & 0.270 & 0.230 & 0.389 & 0.367 & 0.425 & 0.421 & 0.670 & 0.382 \\
& Nov & 0.212 & 0.202 & 0.181 & 0.187 & 0.201 & 0.202 & 0.669 & 0.248 \\
post- & Dec & 0.196 & 0.147 & 0.177 & 0.179 & 0.175 & 0.175 & 0.669 & 0.185 \\
\hline \multirow{2}{*}{ harvest } & Jan & 0.166 & 0.158 & 0.143 & 0.142 & 0.154 & 0.154 & 0.669 & 0.161 \\
& Feb & 0.161 & 0.136 & 0.099 & 0.101 & 0.105 & 0.106 & 0.669 & 0.150 \\
& Mar & 0.163 & 0.142 & 0.094 & 0.100 & 0.104 & 0.104 & 0.669 & 0.112 \\
& Apr & 0.160 & 0.157 & 0.073 & 0.077 & 0.070 & 0.070 & 0.669 & 0.085 \\
& May & 0.152 & 0.143 & 0.101 & 0.101 & 0.094 & 0.094 & 0.669 & 0.084 \\
& Jun & 0.145 & 0.146 & 0.103 & 0.095 & 0.091 & 0.096 & 0.686 & 0.092 \\
& Jul & 0.068 & 0.097 & 0.097 & 0.086 & 0.091 & 0.091 & 0.669 & 0.062 \\
& Aug & 0.056 & 0.063 & 0.063 & 0.059 & 0.061 & 0.060 & 0.669 & 0.055 \\
\hline
\end{tabular}

Notes: Shaded area represents the MAE of the forecast is lower than the WASDE projections. "fut-5yr" and "futARMA" represent the Hoffman futures-based forecasts with 5-year moving average basis and ARMA basis, respectively. "new-rolling", "new-recur", "new-rolling, res", and "new-recur, res" are the proposed forecasts with rolling-window estimation, recursive estimation, rolling-window with restrictions, and recursive estimation with restrictions, respectively. No-change is the forecast generated using last year's SAFP. 
Table 4-7. Effect of price volatility on the relative performance of the proposed forecast against WASDE price projections

\begin{tabular}{lcccc}
\hline & $\begin{array}{c}(1) \\
\text { new-rolling vs. } \\
\text { WASDE }\end{array}$ & $\begin{array}{c}(2) \\
\text { new-recursive vs. } \\
\text { WASDE }\end{array}$ & $\begin{array}{c}(3) \\
\text { new-rolling, res } \\
\text { vs. WASDE }\end{array}$ & $\begin{array}{c}\text { new-recursive, res } \\
\text { vs. WASDE }\end{array}$ \\
\hline $\begin{array}{l}\text { Annualized } \\
\text { volatility }\end{array}$ & $-0.085^{*}$ & -0.077 & $-0.103^{* *}$ & $-0.101^{*}$ \\
& $(0.050)$ & $(0.049)$ & $(0.051)$ & $(0.052)$ \\
Constant & & & & \\
& 0.147 & 0.138 & $0.171^{*}$ & $0.168^{*}$ \\
\hline$N$ & $(0.092)$ & $(0.093)$ & $(0.096)$ & $(0.095)$ \\
adj. $R^{2}$ & 478 & 478 & 478 & 478 \\
\hline
\end{tabular}

Notes: The dependent variable is the difference in absolute forecast errors between the proposed forecast and the WASDE price projections. Standard errors are calculated using bootstraps with 1,000 replications and are presented in parentheses. One, two, and three stars represent statistical significance at $10 \%, 5 \%$, and $1 \%$, respectively. 

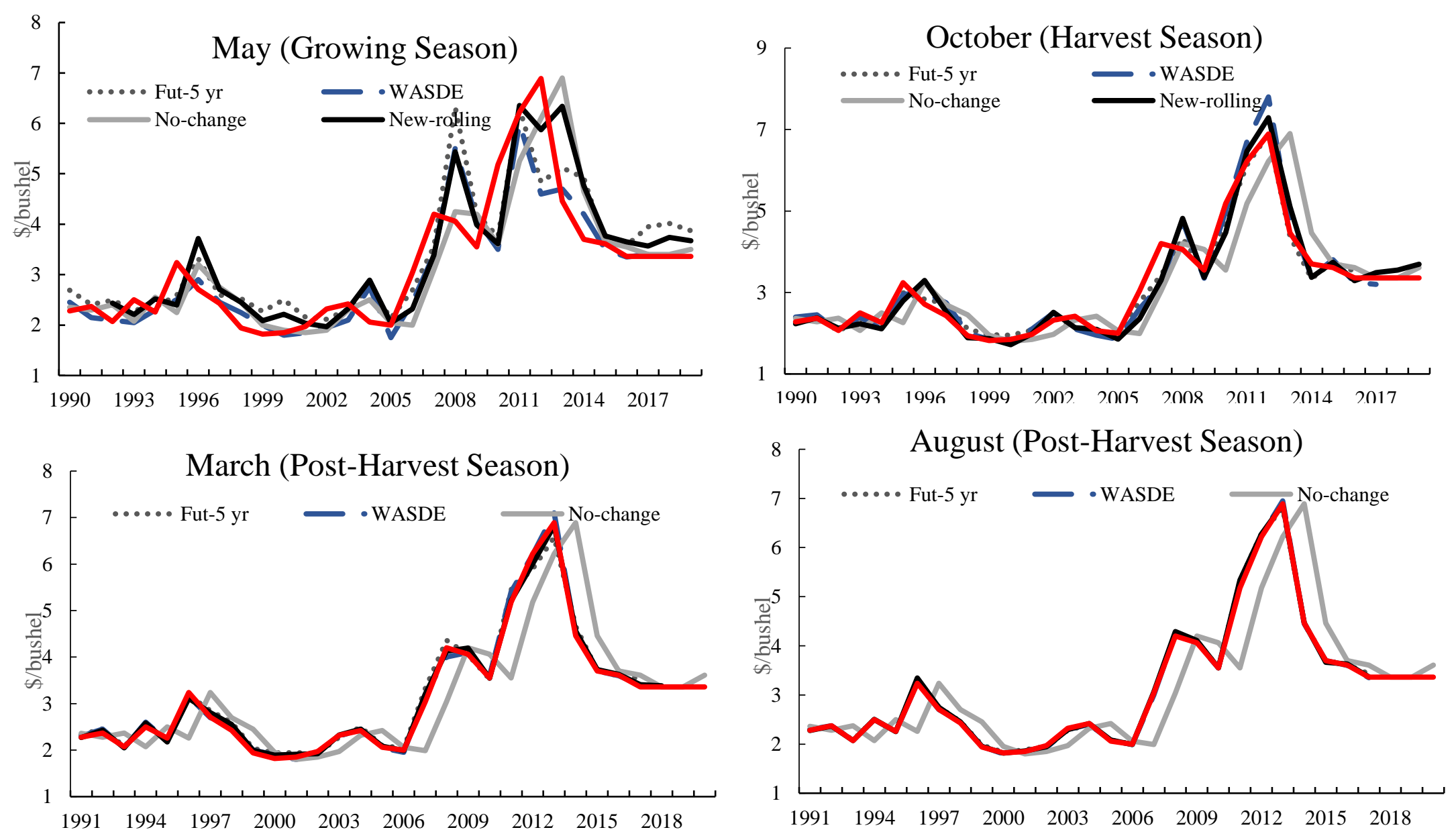

Figure 4-1. Forecasted prices (\$/bushel) in selected forecast months, 1990/91-2019/20 marketing years

Notes: "Fut-5yr" represents the Hoffman futures-based forecasts with 5-year moving average, "new-rolling" are the proposed forecasts with rolling-window estimation, No-change is the forecast generated using last year's SAFP. 

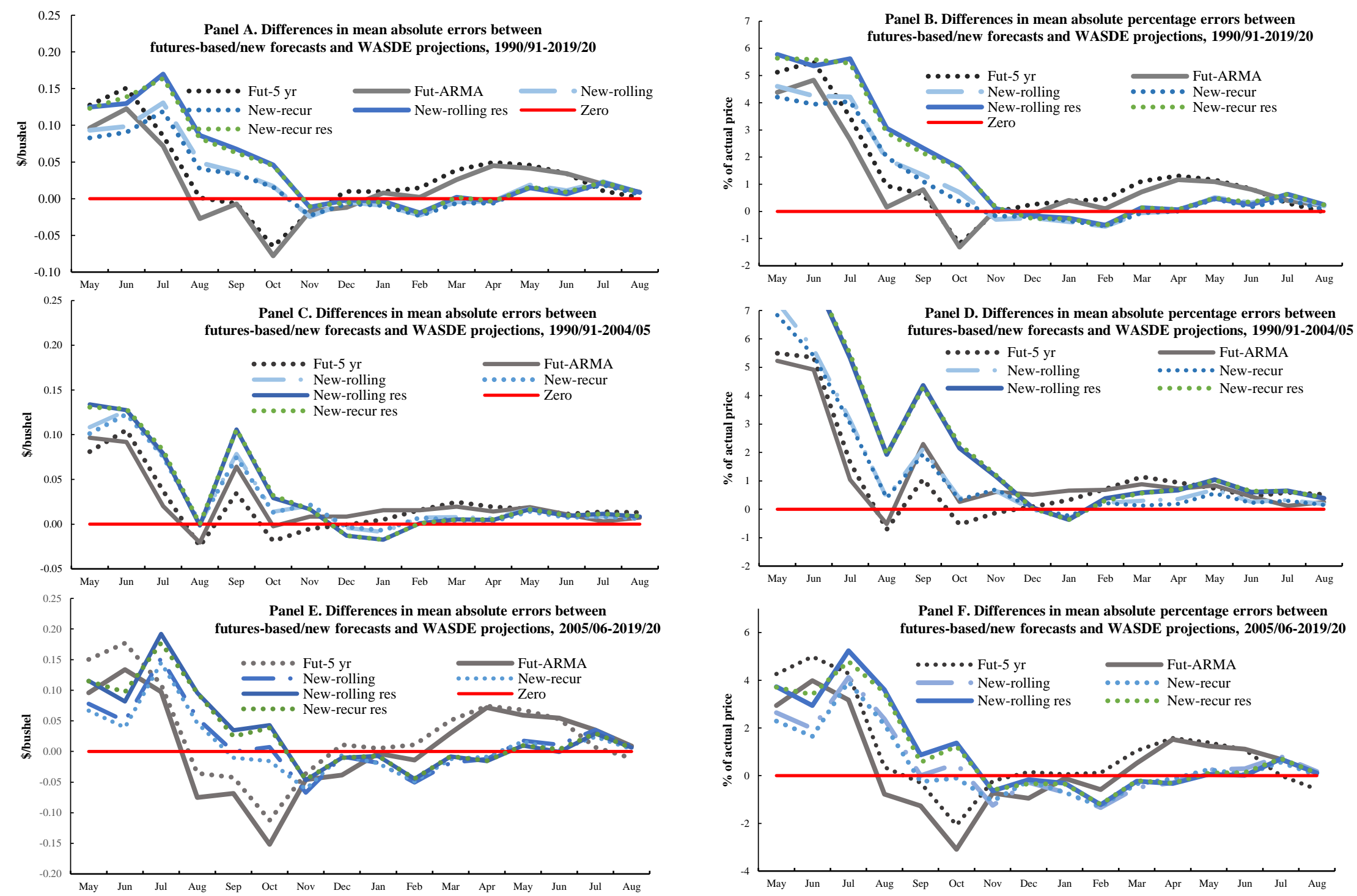

Figure 4-2. Differences in MAEs (\$/bushel) and MAPEs (\%) between futures-based/new forecasts and WASDE projections

Notes: A positive (negative) difference suggests that the WASDE projections have a lower (higher) MAE/MAPE, and hence are more (less) accurate than the competing forecaster. "Fut-5yr" and "Fut-ARMA" represent the Hoffman futures-based forecasts with 5-year moving average basis and ARMA basis, respectively. "New-rolling" and "New-rolling res" are the proposed forecasts based on rolling-window estimations with and without parameter restrictions, respectively. "New-recur" and "New-recur res" are the proposed forecasts based on recursive estimations without and with parameter restrictions, respectively. 

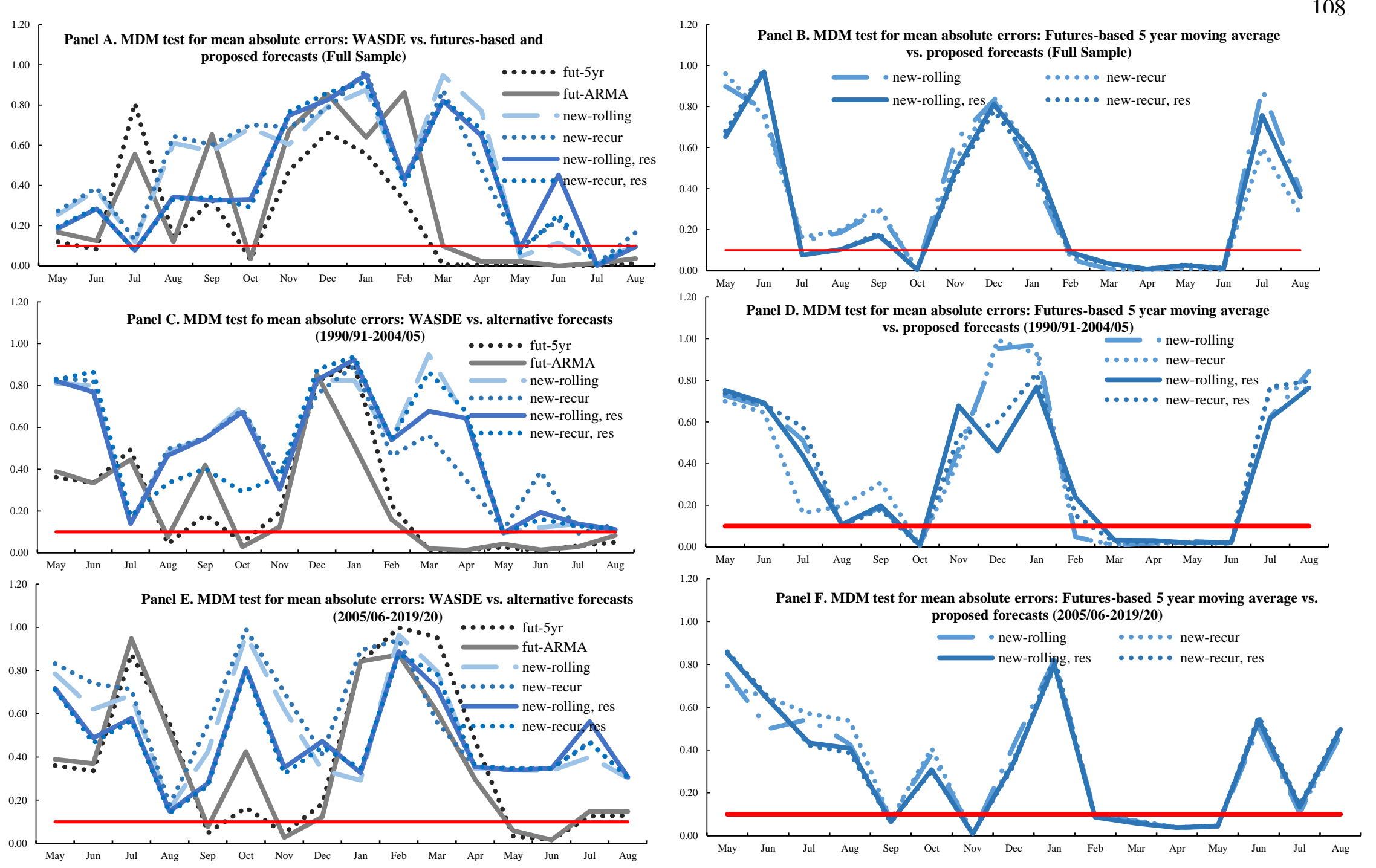

Figure 4-3. P-values of MDM test throughout the forecast cycle (red line represents $10 \%$ significance level)

Notes: "Fut-5yr" and "Fut-ARMA" represent the Hoffman futures-based forecasts with 5-year moving average basis and ARMA basis, respectively. "Newrolling" and "New-rolling res" are the proposed forecasts based on rolling-window estimations with and without parameter restrictions, respectively. "Newrecur" and "New-recur res" are the proposed forecasts based on recursive estimations without and with parameter restrictions, respectively. 

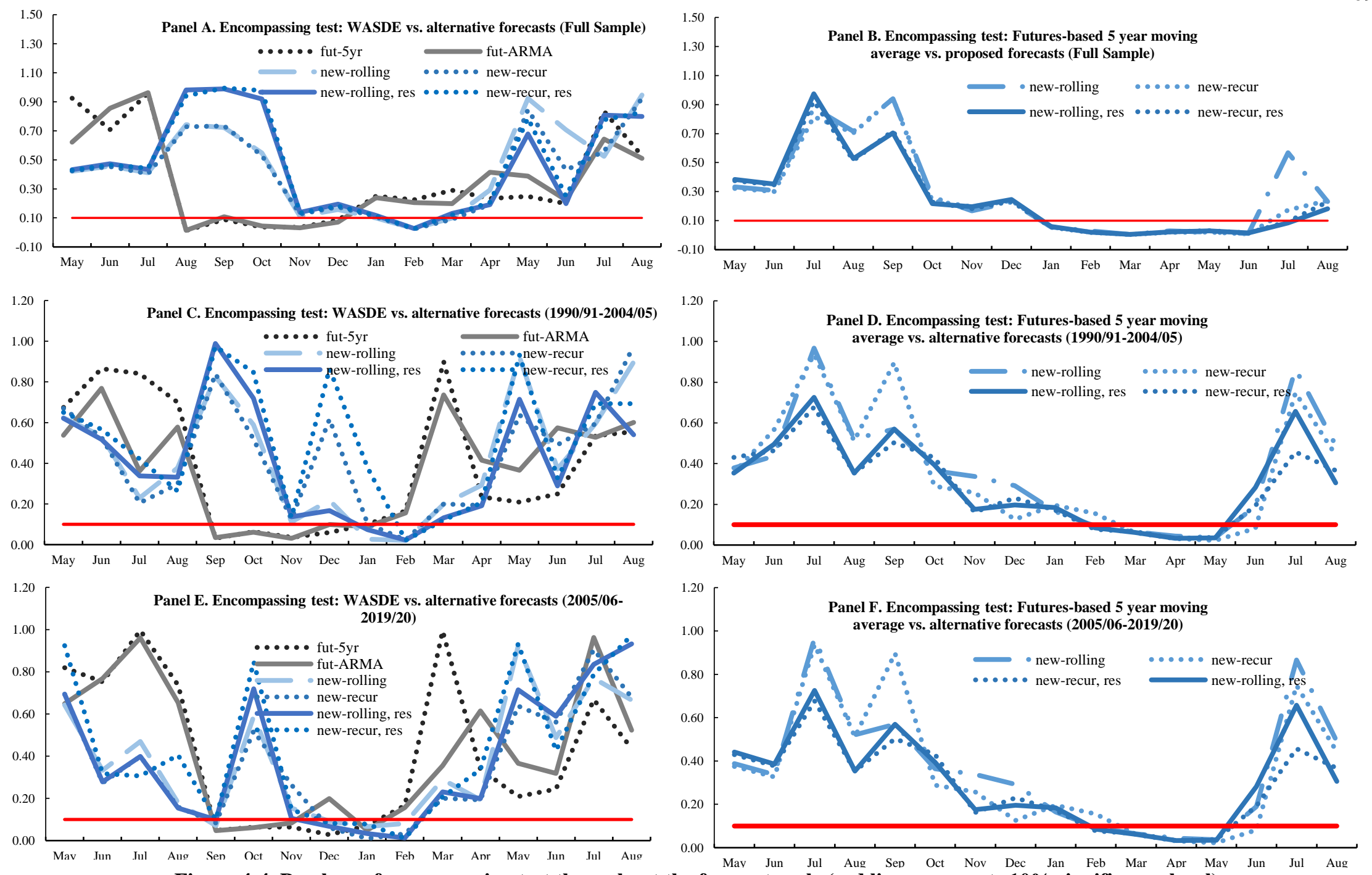

Figure 4-4. P-values of encompassing test throughout the forecast cycle (red line represents $10 \%$ significance level)

Notes: "Fut-5yr" and "Fut-ARMA" represent the Hoffman futures-based forecasts with 5-year moving average basis and ARMA basis, respectively. "Newrolling" and "New-rolling res" are the proposed forecasts based on rolling-window estimations with and without parameter restrictions, respectively. "Newrecur" and "New-recur res" are the proposed forecasts based on recursive estimations without and with parameter restrictions, respectively. 


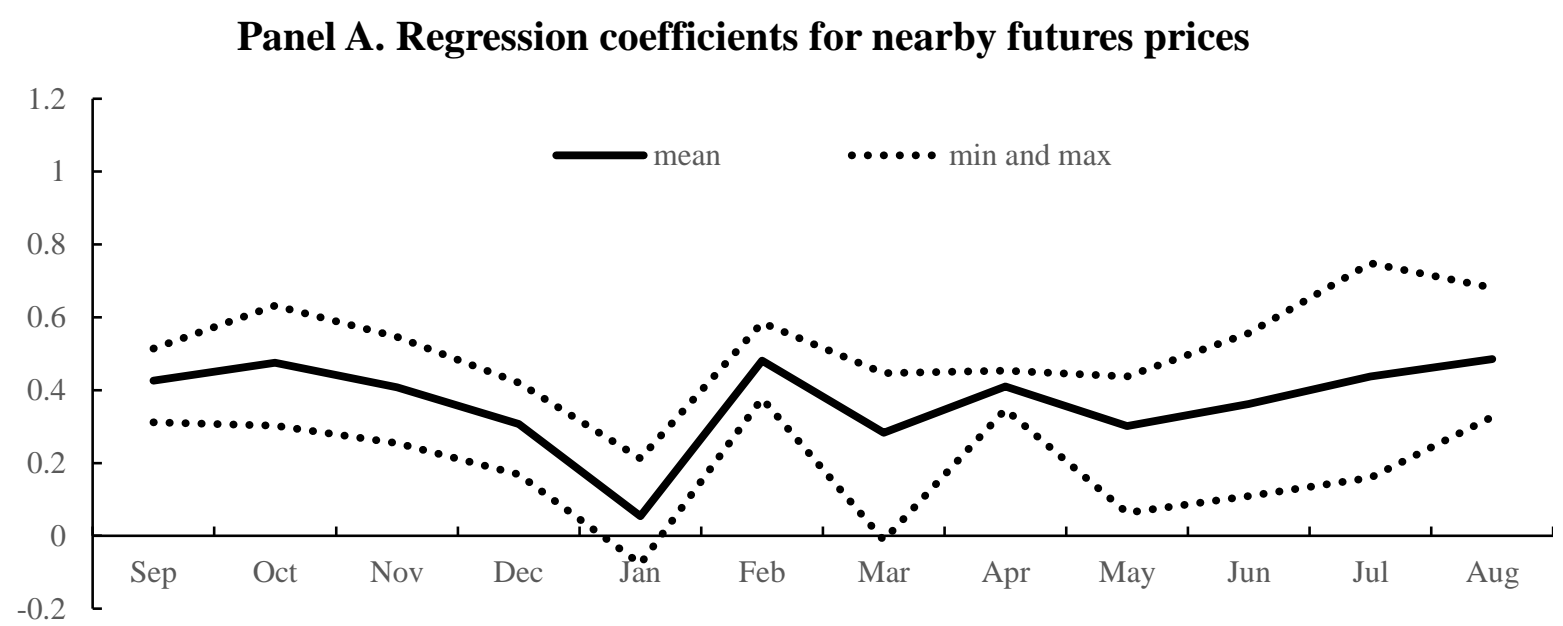

Panel B. Regression coefficients for previous period cash prices

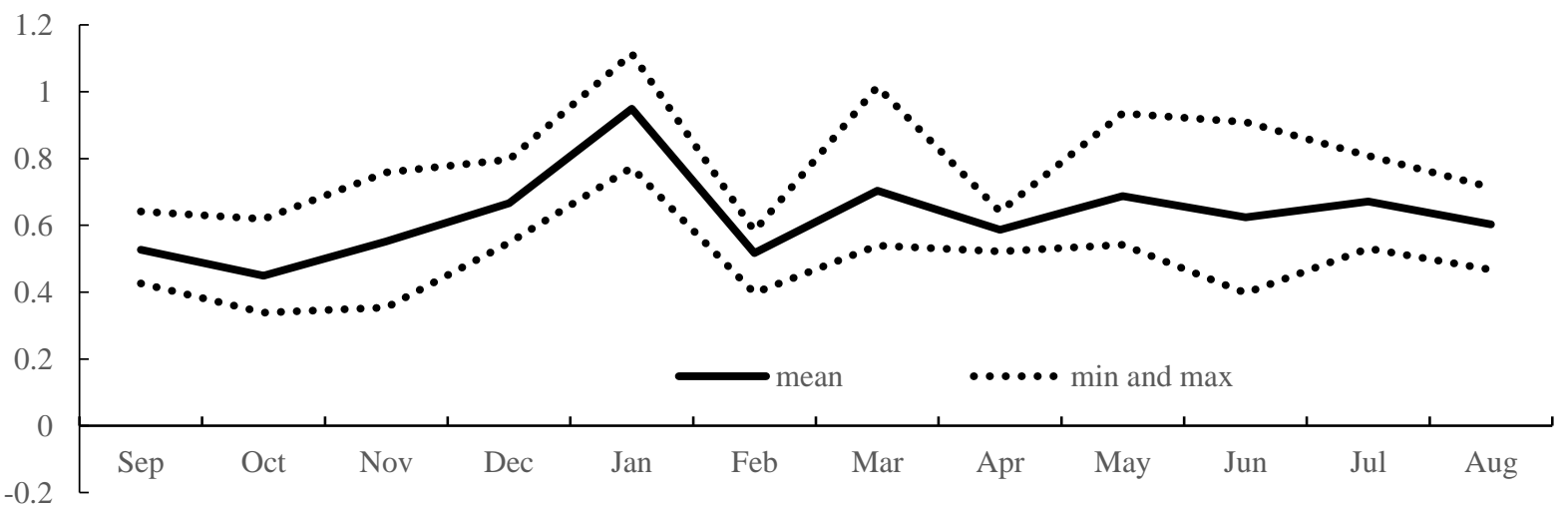

Figure 4-5. Regression coefficients for nearby futures prices and previous period cash prices in equation (4-1) based on 15-year rolling window analysis 


\section{Chapter 5. Concluding Remarks}

The goal of this dissertation is to analyze energy and agricultural commodity prices in the U.S. Chapter 2 compares the forecasting performances of various individual and composite forecasting models in predicting Henry Hub natural gas prices. Chapter 3 investigates how natural gas prices react to inventory surprises contained in Energy Information Administration's weekly inventory report, and Chapter 4 explores an alternative futures-based procedure to forecast the season-average farm price (SAFP) for U.S. corn.

In Chapter 2, we find that overall, futures-based forecasts give a more accurate prediction of natural gas prices at short term (1- and 3-month ahead horizons), while the STEO forecast generated by Energy Information Administration performs well at longer forecasting horizons (6month and 12-month ahead horizons). Additionally, the relative forecast performances of the time series models improved significantly when natural gas prices experienced less volatility during the time period of January 2009 to December 2020. The Hotelling forecasts appear to perform well at the 1- and 3-month ahead horizons. Furthermore, our findings support the additional benefits of combining forecasts for deriving more accurate price forecasts in the natural gas market. In particular, simple average forecasts perform consistently well against STEO forecasts.

Chapter 3 shows natural gas prices react differently to positive versus negative storage surprises. Negative surprises (more-than-expected) have larger impacts compared to positive (lessthan-expected) surprises during withdrawal season and full sample, which confirms the asymmetric response of prices to negative and positive news in the natural gas market. We also find the impact of EIA's report on natural gas prices is more prominent in low inventory regimes 
for withdrawal seasons and the full sample. Further, the announcement effects are on average larger during the injection season compared to the withdrawal season. The results of time-varying analyses indicate that while the EIA inventory report is still influential in natural gas futures markets, the impacts are generally decreasing over the sample period studied.

Finally, Chapter 4 indicates that the proposed method based on futures prices and previous period cash prices performs similarly or demonstrates an improvement in forecast accuracy compared to the Hoffman model in almost all months except for July and October, or the 15- and 11-months ahead forecasts. Compared to the WASDE projections, the proposed method performs similarly or better in November through April during the marketing year. Additionally, the relative forecast performances of the proposed procedure improved significantly during the period that corn prices experienced more volatility. The no-change forecast appears to be useful or perform well only at the beginning of the forecast cycle.

This dissertation provides several implications for investors, policymakers, and researchers. First, the results highlight the importance of a dynamic forecasting approach as different forecasting models perform heterogeneously as the underlying market conditions change and that composite forecasts may provide superior performance compared to individual forecasts. Second, Chapter 2 suggests that from the practitioner's perspective, futures-based forecasts, or simple nochange forecasts may be used for short-term prediction of U.S. natural gas prices, while at longer horizons, STEO forecasts generated by EIA should be used due to their superior performances. Additionally, using composite forecasts may prove to be preferable at longer forecasting horizons. Thirdly, Chapter 3 shows that the EIA natural gas inventory report still provides valuable information for market participants. However, the impacts of this public report on natural gas 
prices declined during the later time period of this research (2012 to 2020). Lastly, Chapter 4 suggests that at the beginning of the forecast cycle (from May to July), the WASDE forecast generated by USDA is clearly the forecast to follow. At the end of the growing season and in the entire harvest season, the Hoffman futures-based forecast appears to perform slightly better than the competing forecasts. The proposed SAFP forecast is the best forecast to follow in the first half of the post-harvest season, namely January to April.

Future research may wish to expand on these issues and use higher-frequency data and largescale models. For instance, machine learning forecasting methods such as Long Short-Term Memory (LSTM) and Neural Network algorithm have become increasingly popular in the industry due to the availability of data and computing resources. Would forecasts based on these data-driven models outperform the forecasting models evaluated in the present study, most of which are based on supply-and-demand balances and economic theories? Moreover, we show that the natural gas futures market's reaction to EIA inventory reports has declined over some specific time periods. Future research could evaluate the importance of EIA inventory reports relative to alternative information inventory reports. In addition, it may be informative to analyze how the improvement in natural gas infrastructure, as well as the rise of renewable energy, changes the impact of inventory surprises. 


\section{References}

Adjemian, M., Garcia, P., Irwin, S.H., Smith, A., 2013. Non-convergence in domestic commodity futures markets: causes, consequences, and remedies. USDA-ERS Econ. Inf. Bull.

Adjemian, M.K., 2012. Quantifying the WASDE announcement effect. Am. J. Agric. Econ. 94, $238-256$.

Adjemian, M.K., Bruno, V.G., Robe, M.A., 2016. Forward-Looking USDA Price Forecasts.

Alquist, R., Kilian, L., 2010. What do we learn from the price of crude oil futures? J. Appl. Econom. 25, 539-573.

Alturki, S., Kurov, A., 2020. Market Inefficiencies Surrounding Energy Announcements. Available SSRN 3747330.

Arisoy, I., Ozturk, I., 2014. Estimating industrial and residential electricity demand in Turkey: A time varying parameter approach. Energy 66, 959-964.

Arnade, C., Hoffman, L., 2015. The impact of price variability on cash/futures market relationships: implications for market efficiency and price discovery. J. Agric. Appl. Econ. 47, 539-559.

Arora, V., 2014. Estimates of the price elasticities of natural gas supply and demand in the United States.

Arora, V., Lieskovsky, J., 2014. Natural gas and US economic activity. Energy J. 35.

Atewamba, C., Nkuiya, B., 2017. Testing the assumptions and predictions of the hotelling model. Environ. Resour. Econ. 66, 169-203.

Ball, R., 2009. The global financial crisis and the efficient market hypothesis: what have we learned? J. Appl. Corp. Financ. 21, 8-16.

Barberis, N. and Thaler, R. H. (2003). A survey of behavioral finance. In: G. M. Constantinides, M. Harris and R. M. Stulz (eds), Handbook of the Economics of Finance, Volume 1B, Financial Markets and Asset Pricing. Amsterdam: North Holland, 1053-1123.

Bates, J.M., Granger, C.W.J., 1969. The combination of forecasts. J. Oper. Res. Soc. 20, 451-468.

Baumeister, C., Kilian, L., 2015. Forecasting the real price of oil in a changing world: a forecast combination approach. J. Bus. Econ. Stat. 33, 338-351.

Baumeister, C., Kilian, L., 2012. Real-time forecasts of the real price of oil. J. Bus. Econ. Stat. 30, 326-336.

Baumeister, C., Kilian, L., Lee, T.K., 2014. Are there gains from pooling real-time oil price 
forecasts? Energy Econ. 46, S33-S43.

Bernard, J.-T., Khalaf, L., Kichian, M., Yelou, C., 2018. Oil price forecasts for the long term: expert outlooks, models, or both? Macroecon. Dyn. 22, 581-599.

Bjursell, J., Gentle, J.E., Wang, G.H.K., 2015. Inventory announcements, jump dynamics, volatility and trading volume in US energy futures markets. Energy Econ. 48, 336-349.

Black, F., 1976. Studies of stock market volatility changes. 1976 Proc. Am. Stat. Assoc. bisiness Econ. Stat. Sect.

Brennan, M.J., Schwartz, E.S., 1985. Evaluating natural resource investments. J. Bus. 135-157.

Campbell, J.Y., Hentschel, L., 1992. No news is good news: An asymmetric model of changing volatility in stock returns. J. financ. econ. 31, 281-318.

Carnero, M.A., Pérez, A., 2019. Leverage effect in energy futures revisited. Energy Econ. 82, 237252.

Chavas, J.-P., Pope, R.D., Kao, R.S., 1983. An analysis of the role of futures prices, cash prices and government programs in acreage response. West. J. Agric. Econ. 27-33.

Chebbi, T., 2019. The inventory change surprise's role in energy price behaviour. Int. J. Glob. Energy Issues 42, 1-20.

Chinn, M.D., Coibion, O., 2014. The predictive content of commodity futures. J. Futur. Mark. 34, 607-636.

Chinn, M.D., LeBlanc, M., Coibion, O., 2005. The predictive content of energy futures: an update on petroleum, natural gas, heating oil and gasoline. National Bureau of Economic Research Cambridge, Mass., USA.

Chiou-Wei, S.-Z., Linn, S.C., Zhu, Z., 2014. The response of US natural gas futures and spot prices to storage change surprises: Fundamental information and the effect of escalating physical gas production. J. Int. Money Financ. 42, 156-173.

Chiou-Wei, S.Z., Linn, S.C., Zhu, Z., 2007. Fundamental news and the behavior of the commodity prices: Price discovery and jumps in US natural gas futures and spot prices. Financ. Manag. Assoc. Int.

Chkili, W., Hammoudeh, S., Nguyen, D.K., 2014. Volatility forecasting and risk management for commodity markets in the presence of asymmetry and long memory. Energy Econ. 41, 1-18.

Christie, A.A., 1982. The stochastic behavior of common stock variances: Value, leverage and interest rate effects. J. financ. econ. 10, 407-432.

Claeskens, G., Magnus, J.R., Vasnev, A.L., Wang, W., 2016. The forecast combination puzzle: A 
simple theoretical explanation. Int. J. Forecast. 32, 754-762.

Claassen, R., and A. Effland. 2014. Agricultural Act of 2014: Highlights and Implications. Economic Research Service, U.S. Department of Agriculture, available at https://www.ers.usda.gov/agricultural-act-of-2014-highlights-and-implications/, accessed on $12 / 15 / 2018$.

Clemen, R.T., 1989. Combining forecasts: A review and annotated bibliography. Int. J. Forecast. $5,559-583$.

Clements, A., Doolan, M.B., 2020. Combining multivariate volatility forecasts using weighted losses. J. Forecast. 39, 628-641.

Colino, E. V, Irwin, S.H., 2010. Outlook vs. futures: Three decades of evidence in hog and cattle markets. Am. J. Agric. Econ. 92, 1-15.

Colino, E. V, Irwin, S.H., Garcia, P., 2008. How Much Can Outlook Forecasts be Improved? An Application to the US Hog Market.

Colino, E. V, Irwin, S.H., Garcia, P., Etienne, X., 2012. Composite and outlook forecast accuracy. J. Agric. Resour. Econ. 228-246.

Cootner, P.H., 1960. Returns to speculators: Telser versus Keynes. J. Polit. Econ. 68, 396-404.

Crane, D.B., Crotty, J.R., 1967. A two-stage forecasting model: Exponential smoothing and multiple regression. Manage. Sci. 13, B-501.

Damodaran, A., 1993. A simple measure of price adjustment coefficients. J. Finance 48, 387-400.

Durbin, J., Koopman, S.J., 2001. An efficient and simple simulation smoother for state space time series analysis. Society for Computational Economics.

Efimova, O., \& Serletis, A. (2014). Energy markets volatility modelling using GARCH. Energy Economics, 43, 264-273.

Energy Information Administration, D. of E., 2018. EIA [WWW Document]. URL http://www.eia.doe.gov/emeu/steo/pub /document/partb.html

Energy Information Administration, 2020. EIA [U.S. Natural Gas Gross Withdrawals (Million Cubic Feet) (eia.gov)]. URL https://www.eia.gov/dnav/ng/hist/n9010us2a.htm

Energy Information Administration, 2020. URL https://www.eia.gov/energyexplained/us-energyfacts/

Ederington, L.H., Lin, F., Linn, S.C., Yang, L.Z., 2019. EIA storage announcements, analyst storage forecasts, and energy prices. Energy J. 40. 
Erdogdu, E., 2010. Natural gas demand in Turkey. Appl. Energy 87, 211-219.

Ergen, I., \& Rizvanoghlu, I. (2016). Asymmetric impacts of fundamentals on the natural gas futures volatility: An augmented GARCH approach. Energy Economics, 56, 64-74.

ERS. 2018. Corn \& Other Feedgrains. Economic Research Service, U.S. Department of Agriculture, available at https://www.ers.usda.gov/topics/crops/corn-and-other-feedgrains/, accessed on 12/15/2018.

Etienne, X.L., Irwin, S.H., Garcia, P., 2015. Price explosiveness, speculation, and grain futures prices. Am. J. Agric. Econ. 97, 65-87.

Etienne, X.L., Irwin, S.H., Garcia, P., 2014. Bubbles in food commodity markets: Four decades of evidence. J. Int. Money Financ. 42, 129-155.

Fama, E., 1991. Efficient Capital Markets: II. $\square$ e Journal of Finance, 46 (5), 1575.

Fama, E.F., 1965. The behavior of stock-market prices. J. Bus. 38, 34-105.

Fan, Y., Zhang, Y.-J., Tsai, H.-T., Wei, Y.-M., 2008. Estimating 'Value at Risk'of crude oil price and its spillover effect using the GED-GARCH approach. Energy Econ. 30, 3156-3171.

Fernandez, V., 2006. Forecasting crude oil and natural gas spot prices by classification methods.

Feunou, B., Lopez Aliouchkin, R., Tédongap, R., Xi, L., 2017. Variance premium, downside risk and expected stock returns. Bank of Canada.

French, K.R., Schwert, G.W., Stambaugh, R.F., 1987. Expected stock returns and volatility. J. financ. econ. 19, 3-29.

Gamson, N., 2008. Personal Communication. U.S. Department of Energy, Energy Information Association, Short Term Analysis and Forecasting, Energy Fuel Price, June (2008)

Garbade, K.D., and W.L. Silber. 1983. "Price Movements and Price Discovery in Futures and Cash Markets." The Review of Economics and Statistics 65 (2):289-297.

Garcia, P., Irwin, S.H., Leuthold, R.M., Yang, L., 1997. The value of public information in commodity futures markets. J. Econ. Behav. Organ. 32, 559-570.

Garcia, P., Irwin, S.H., Smith, A., 2015. Futures market failure? Am. J. Agric. Econ. 97, 40-64.

Gay, G.D., Simkins, B.J., Turac, M., 2009. Analyst forecasts and price discovery in futures markets: The case of natural gas storage. J. Futur. Mark. Futur. Options, Other Deriv. Prod. $29,451-477$.

Genre, V., Kenny, G., Meyler, A., Timmermann, A., 2013. Combining expert forecasts: Can anything beat the simple average? Int. J. Forecast. 29, 108-121. 
Gouel, C., Legrand, N., 2017. Estimating the competitive storage model with trending commodity prices. J. Appl. Econom. 32, 744-763.

Gramlich, E.M., 2004. Oil shocks and monetary policy. Annual economic luncheon, Federal Reserve Bank of Kansas City, Kansas City, MO.

Granger, C.W.J., 1989. Invited review combining forecasts-twenty years later. J. Forecast. 8, $167-173$.

Granger, C.W.J., Ramanathan, R., 1984. Improved methods of combining forecasts. J. Forecast. 3, 197-204.

Gu, C., Kurov, A., 2018. What drives informed trading before public releases? Evidence from natural gas inventory announcements. J. Futur. Mark. 38, 1079-1096.

Guerra, E.A., Bobenrieth, E.S., Bobenrieth, J.R.A., Cafiero, C., 2015. Empirical commodity storage model: the challenge of matching data and theory.

Gunter, S.I., Aksu, C., 1989. N-step combinations of forecasts. J. Forecast. 8, 253-267.

Halova, M.W., Kurov, A., Kucher, O., 2014. Noisy inventory announcements and energy prices. J. Futur. Mark. 34, 911-933.

Hansen, B.E., 2000. Sample splitting and threshold estimation. Econometrica 68, 575-603.

Harvey, D., Leybourne, S., Newbold, P., 1997. Testing the equality of prediction mean squared errors. Int. J. Forecast. 13, 281-291.

Harvey, D.I., Leybourne, S.J., Newbold, P., 1998. Tests for forecast encompassing. J. Bus. Econ. Stat. 16, 254-259.

Hatemi-J, A., Al Shayeb, A., Roca, E., 2017. The effect of oil prices on stock prices: fresh evidence from asymmetric causality tests. Appl. Econ. 49, 1584-1592.

Herbert, J.H., 1993. The relation of monthly spot to futures prices for natural gas. Energy 18, 1119-1124.

Hoffman, L.A. 2005. Forecasting the Counter-Cyclical Payment Rate for U.S. Corn: An Application of the Futures Price Forecasting Model. Economic Research Service Electronic Outlook Report No. FDS-05a-01, U.S. Department of Agriculture, available at https://www.ers.usda.gov/publications/pub-details/?pubid=36456, accessed on 12/15/2018.

Hoffman, L.A., Etienne, X.L., Irwin, S.H., Colino, E. V, Toasa, J.I., 2015. Forecast performance of WASDE price projections for US corn. Agric. Econ. 46, 157-171.

Hoffman, L.A., Irwin, S.H., Toasa, J., 2007. Forecast performance of futures price models for corn, soybeans, and wheat. 
Hotelling, H., 1931. The economics of exhaustible resources. J. Polit. Econ. 39, 137-175.

Huang, K.-M., Etienne, X., 2021. Do natural hazards in the Gulf Coast still matter for state-level natural gas prices in the US? Evidence after the shale gas boom. Energy Econ. 98, 105267.

Hulshof, D., Van Der Maat, J.-P., Mulder, M., 2016. Market fundamentals, competition and natural-gas prices. Energy Policy 94, 480-491.

Irwin, S.H. 2018. "Trilogy for Troubleshooting Convergence: Manipulation, Structural Imbalance, and Storage Rates.” Journal of Commodity Markets forthcoming.

Irwin, S., Good, D., 2015. Long-Term Corn, Soybeans, and Wheat Price Forecasts and the Farm Bill Program Choice. farmdoc Dly. 5.

Irwin, S.H., Garcia, P., Good, D.L., Kunda, E.L., 2011. Spreads and non-convergence in Chicago board of trade corn, soybean, and wheat futures: are index funds to blame? Appl. Econ. Perspect. Policy 33, 116-142.

Isengildina-Massa, O., Irwin, S.H., Good, D.L., 2010. Quantile Regression Estimates of Confidence Intervals for WASDE Price Forecasts. J. Agric. Resour. Econ. 545-567.

Jin, J., Kim, J., 2015. Forecasting natural gas prices using wavelets, time series, and artificial neural networks. PLoS One 10, e0142064.

Joutz, F., 2009. Estimating regional short-run and long-run price elasticities of residential natural gas demand in the US. Available SSRN 1444927.

Just, R.E., Rausser, G.C., 1981. Commodity price forecasting with large-scale econometric models and the futures market. Am. J. Agric. Econ. 63, 197-208.

Kalman, R.E., 1960. A new approach to linear filtering and prediction problems.

Kao, C.-W., Wan, J.-Y., 2009. Information transmission and market interactions across the Atlantic - an empirical study on the natural gas market. Energy Econ. 31, 152-161.

Karali, B., Thurman, W.N., 2009. Announcement effects and the theory of storage: an empirical study of lumber futures. Agric. Econ. 40, 421-436.

Keynes, J. M. (1930). Treatise on money: Pure theory of money Vol. I.

Kilian, L., Vega, C., 2011. Do energy prices respond to US macroeconomic news? A test of the hypothesis of predetermined energy prices. Rev. Econ. Stat. 93, 660-671.

Koutmos, G., 1998. Asymmetries in the conditional mean and the conditional variance: Evidence from nine stock markets. J. Econ. Bus. 50, 277-290.

Kristoufek, L., 2014. Leverage effect in energy futures. Energy Econ. 45, 1-9. 
L'Hégaret, G., Siliverstovs, B., Neumann, A., von Hirschhausen, C., 2003. International Market Integration for Gas? A Cointegration Analysis of Gas Prices in Europe, North America and Japan. Citeseer.

Lin, B., Wesseh Jr, P.K., Appiah, M.O., 2014. Oil price fluctuation, volatility spillover and the Ghanaian equity market: Implication for portfolio management and hedging effectiveness. Energy Econ. 42, 172-182.

Lin, C.-Y.C., Wagner, G., 2007. Steady-state growth in a Hotelling model of resource extraction. J. Environ. Econ. Manage. 54, 68-83.

Linn, S.C., Zhu, Z., 2004. Natural gas prices and the gas storage report: Public news and volatility in energy futures markets. J. Futur. Mark. Futur. Options, Other Deriv. Prod. 24, 283-313.

Malkiel, B.G., and E.F. Fama. 1970. "Efficient Capital Markets: A Review of Theory and Empirical Work." The Journal of Finance 25 (2):383-417.

Malkiel, B.G., 2003. The efficient market hypothesis and its critics. J. Econ. Perspect. 17, 59-82.

Manescu, C., Van Robays, I., 2014. Forecasting the Brent oil price: addressing time-variation in forecast performance.

Mason, C.F., Roberts, G., 2018. Price elasticity of supply and productivity: an analysis of natural gas wells in Wyoming. Energy J. 39.

Mattos-Silveira, J., 2016. Diamino fluoreto de prata - uma nova proposta para o tratamento não operatório de lesões proximais em molares decíduos: estudo clínico randomizado TT - Silver diamine fluoride - a new proposal for the non-operative treatment for approximal caries lesions. https://doi.org/10.11606/T.23.2016.TDE-08082016-104859

McCallum, A.H., Wu, T., 2005. Do oil futures prices help predict future oil prices? FRBSF Econ. Lett.

McPhail, L.L., Du, X., Muhammad, A., 2012. Disentangling corn price volatility: The role of global demand, speculation, and energy. J. Agric. Appl. Econ. 44, 401-410.

Miao, H., Ramchander, S., Wang, T., Yang, J., 2018. The impact of crude oil inventory announcements on prices: Evidence from derivatives markets. J. Futur. Mark. 38, 38-65.

Mirakyan, A., Meyer-Renschhausen, M., Koch, A., 2017. Composite forecasting approach, application for next-day electricity price forecasting. Energy Econ. 66, 228-237.

Mirmirani, S., Li, H.C., 2004. A comparison of VAR and neural networks with genetic algorithm in forecasting price of oil, in: Applications of Artificial Intelligence in Finance and Economics. Emerald Group Publishing Limited.

Mishra, V., Smyth, R., 2016. Are natural gas spot and futures prices predictable? Econ. Model. 54, 
$178-186$.

NASS. 2018. Agricultural Prices (November 2018 Issue). National Agricultural Statistics Service, U.S. Department of Agriculture, available at https://downloads.usda.library.cornell.edu/usdaesmis/files/c821gj76b/st74cv012/dn39x484s/agpr1118.pdf, accessed on 12/15/2018.

Nelson, D.B., 1991. Conditional heteroskedasticity in asset returns: A new approach. Econom. J. Econom. Soc. 347-370.

Newbold, P., Harvey, D.I., 2002. Forecast combination and encompassing. A companion to Econ. Forecast. 1, 620.

Newell, R.G., Prest, B.C., Vissing, A.B., 2019. Trophy hunting versus manufacturing energy: The price responsiveness of shale gas. J. Assoc. Environ. Resour. Econ. 6, 391-431.

Nick, S., Thoenes, S., 2014. What drives natural gas prices?-A structural VAR approach. Energy Econ. 45, 517-527.

Nomikos, N., Andriosopoulos, K., 2012. Modelling energy spot prices: Empirical evidence from NYMEX. Energy Econ. 34, 1153-1169.

Nowotarski, J., Raviv, E., Trück, S., Weron, R., 2014. An empirical comparison of alternative schemes for combining electricity spot price forecasts. Energy Econ. 46, 395-412.

Pak, A., 2018. Predicting crude oil prices: Replication of the empirical results in "What do we learn from the price of crude oil?" J. Appl. Econom. 33, 160-163.

Poncela, P., Rodríguez, J., Sánchez-Mangas, R., Senra, E., 2011. Forecast combination through dimension reduction techniques. Int. J. Forecast. 27, 224-237.

Prokopczuk, M., Simen, C.W., Wichmann, R., 2021. The natural gas announcement day puzzle. Energy J. 42.

Reboredo, J.C., 2011. How do crude oil prices co-move?: A copula approach. Energy Econ. 33, 948-955.

Rogel-Salazar, J., Sapsford, N., 2014. Seasonal effects in natural gas prices and the impact of the economic recession. Wilmott 2014, 74-81.

Rousse, O., Sévi, B., 2019. Informed trading in the WTI oil futures market. Energy J. 40.

Rubaszek, M., Uddin, G.S., 2020. The role of underground storage in the dynamics of the US natural gas market: A threshold model analysis. Energy Econ. 87, 104713.

Sanders, D.R., Manfredo, M.R., 2005. Forecast encompassing as the necessary condition to reject futures market efficiency: Fluid milk futures. Am. J. Agric. Econ. 87, 610-620. 
Sanders, D.R., Manfredo, M.R., Boris, K., 2009. Evaluating information in multiple horizon forecasts: The DOE's energy price forecasts. Energy Econ. 31, 189-196.

Schwert, G.W., 2003. Anomalies and market efficiency. Handb. Econ. Financ. 1, 939-974.

Schwert, G.W., 1990. Stock volatility and the crash of'87. Rev. Financ. Stud. 3, 77-102.

Shiller, R.J., 2015. Irrational exuberance. Princeton university press.

Smith, A.D., Ubilava, D., 2019. The Signal and the Noise of Short-Term Climate Forecasts: Evidence from Grain Futures Markets.

Smith, J., Wallis, K.F., 2009. A simple explanation of the forecast combination puzzle. Oxf. Bull. Econ. Stat. 71, 331-355.

Stock, J.H., Watson, M.W., 2004. Combination forecasts of output growth in a seven-country data set. J. Forecast. 23, 405-430.

Summer, D.A., Mueller, R.A.E., 1989. Are harvest forecasts news? USDA announcements and futures market reactions. Am. J. Agric. Econ. 71, 1-8.

Symeonidis, L., Prokopczuk, M., Brooks, C., Lazar, E., 2012. Futures basis, inventory and commodity price volatility: An empirical analysis. Econ. Model. 29, 2651-2663.

Szeto, K.Y., Fong, L.Y., 2000. How adaptive agents in stock market perform in the presence of random news: A genetic algorithm approach, in: International Conference on Intelligent Data Engineering and Automated Learning. Springer, pp. 505-510.

Telser, L.G., 1958. Futures trading and the storage of cotton and wheat. J. Polit. Econ. 66, 233255.

Tomek, W.G., 1997. Commodity futures prices as forecasts. Appl. Econ. Perspect. Policy 19, 2344.

Trolle, A.B., Schwartz, E.S., 2010. Variance risk premia in energy commodities. J. Deriv. 17, 1532.

Van Goor, H., Scholtens, B., 2014. Modeling natural gas price volatility: The case of the UK gas market. Energy 72, 126-134.

Wang, K., Fu, W., Chen, T., Zhang, B., Xiong, D., Fang, P., 2020. A compound framework for wind speed forecasting based on comprehensive feature selection, quantile regression incorporated into convolutional simplified long short-term memory network and residual error correction. Energy Convers. Manag. 222, 113234.

Weiss, C.E., Raviv, E., Roetzer, G., 2018. Forecast Combinations in R using the ForecastComb Package. R J. 10. 
Wiggins, S., Etienne, X.L., 2017. Turbulent times: Uncovering the origins of US natural gas price fluctuations since deregulation. Energy Econ. 64, 196-205.

Wong-Parodi, G., Dale, L., Lekov, A., 2006. Comparing price forecast accuracy of natural gas models and futures markets. Energy Policy 34, 4115-4122.

Working, E.J., 1927. What do statistical “demand curves” show? Q. J. Econ. 41, 212-235.

Yang, D., Dong, Z., 2018. Operational photovoltaics power forecasting using seasonal time series ensemble. Sol. Energy 166, 529-541.

Ying, J., Chen, Y., Dorfman, J.H., 2019. Flexible Tests for USDA Report Announcement Effects in Futures Markets. Am. J. Agric. Econ. 101, 1228-1246.

Zhang, Y.-J., Fan, Y., Tsai, H.-T., Wei, Y.-M., 2008. Spillover effect of US dollar exchange rate on oil prices. J. Policy Model. 30, 973-991.

Zulauf, C., Schnitkey, G., 2014. ARC-CO and PLC Payment Indicator for 2014 Crop Year: December 2014 WASDE US Yield and Price. farmdoc Dly. 4.

Zulauf, C.R., Irwin, S.H., Ropp, J.E., Sberna, A.J., 1999. A reappraisal of the forecasting performance of corn and soybean new crop futures. J. Futur. Mark. 19, 603-618. 